\title{
ROQUEFORT
}

\section{Containment Data Report}

\author{
Ted Stubbs \\ Ray Heinle
}

\section{December 1994}

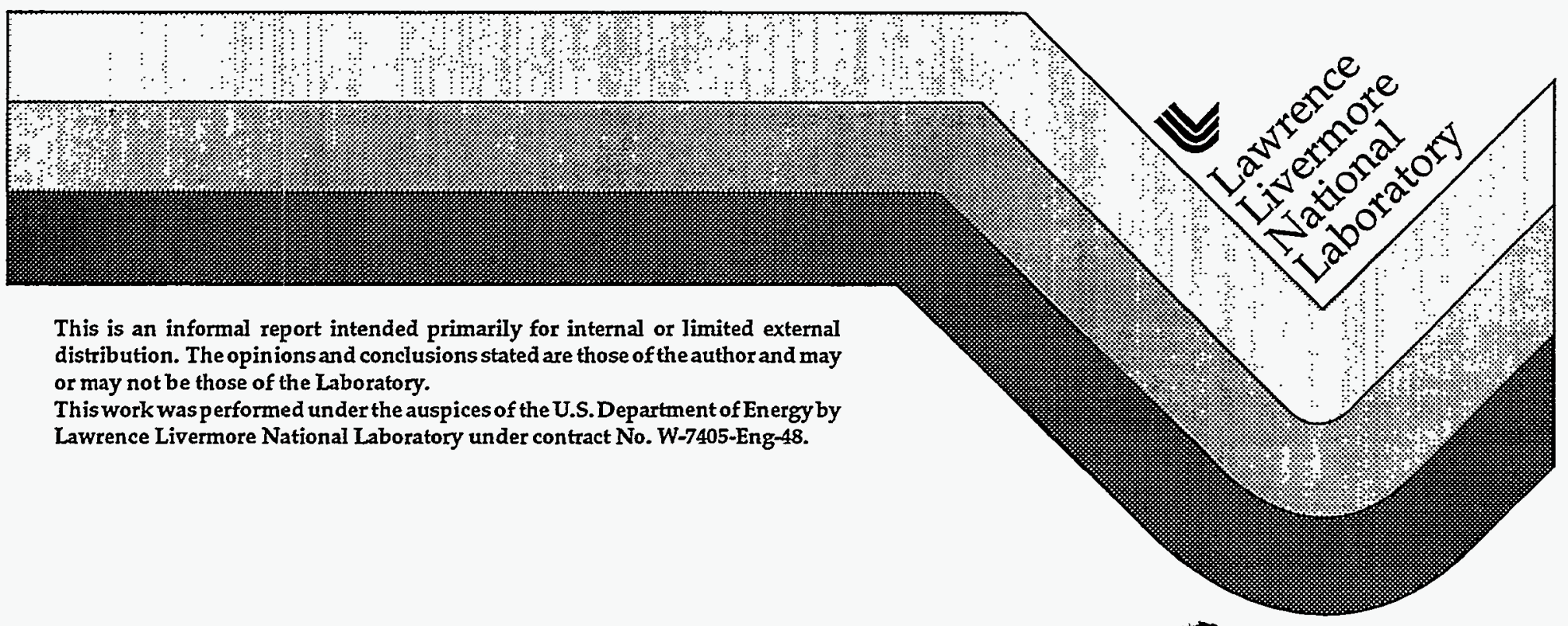

This is an informal report intended primarily for internal or limited external distribution. The opinions and conclusions stated are those of the author and may or may not be those of the Laboratory.

This work was performed under the auspices of the U.S. Department of Energy by Lawrence Livermore National Laboratory under contract No. W-7405-Eng-48.

\section{MASTER}

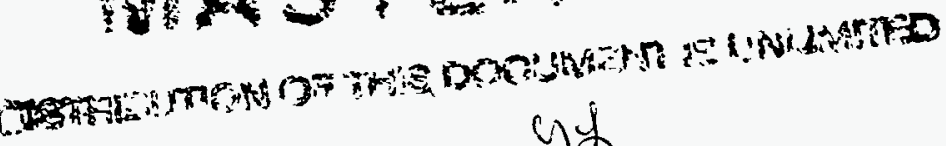

gif 


\section{DISCLAIMER}

This document was prepared as an account of work sponsored by an agency of the United States Government. Neither the United States Government nor the University of California nor any of their employees, makes any warranty, express or implied, or assumes any legal liability or responsibility for the accuracy, completeness, or usefulness of any information, apparatus, product, or process disclosed, or represents that its use would not infringe privately owned rights. Reference herein to any specific commercial product, process, or service by trade name, trademark, manufacturer, or otherwise, does not necessarily constitute or imply its endorsement, recommendation, or favoring by the United States Government or the University of California. The views and opinions of authors expressed herein do not necessarily state or reflect those of the United States Government or the University of California, and shall not be used for advertising or product endorsement purposes.

This report has been reproduced directly from the best available copy.

Available to DOE and DOE contractors from the Office of Scientific and Technical Information

P.O. Box 62, Oak Ridge, TN 37831

Prices available from (615) 576-8401, FIS 626-8401

Available to the public from the

National Technical Information Service

U.S. Department of Commerce 5285 Port Royal Rd. Springfield, VA 22161 


\section{DISCLAIMER}

Portions of this document may be illegible in electronic image products. Images are produced from the best available original document. 


\begin{tabular}{lll} 
Classification Guide & Topic Number & \multicolumn{1}{c}{ Subject } \\
\cline { 2 - 3 } COK-88-024 & 1.5 .6 & Event announcement \\
NV-89-18 & & Event announcement \\
TCG-WT-1 & 1113 & Contractor identification \\
TCG-WT-1 & 1121 & Personnel identification \\
TCG-WT-1 & 1210 & Geology \\
TVG-WT-1 & 1260 & Crater (map) \\
TCG-WT-1 & 1413 & Statement concerning venting \\
TCG-WT-1 & 1452 & Event announcement \\
TCG-WT-1 & 1831 & Depth of burial \\
TCG-WT-1 & 1843 & Stemming material, amount,etc \\
TCG-WT-1 & 1925 & Diagnostic canister dimensions \\
TCG-WT-1 & 3542.3 & Ground motion \\
TCG-WT-1 & 4810 & Radiation measurement \\
TCG-WT-1 & 4820 & Acceleration, pressure, \\
& & temperature measurement
\end{tabular}


ROQUEFORT Instrumentation Summary

\begin{tabular}{|c|c|c|c|}
\hline Instrumentation & $\begin{array}{l}\text { Fielded on } \\
\text { this Event }\end{array}$ & $\begin{array}{c}\text { Data } \\
\text { Return } \\
\end{array}$ & $\begin{array}{l}\text { Present in } \\
\text { this Report }\end{array}$ \\
\hline Plug Emplacement & yes & yes & yes \\
\hline Radiation & yes & yes & yes \\
\hline Pressure & & & \\
\hline Stemming & yes & yes & yes \\
\hline Challenge & yes & yes & yes \\
\hline Cavity & no & - & - \\
\hline Atmospheric & yes & yes & yes \\
\hline Motion & & & \\
\hline Free Field & no & - & - \\
\hline Surface & yes & yes & yes \\
\hline Plug & yes & yes & yes \\
\hline Stemming & yes & yes & yes \\
\hline Surface Casing & no & - & - \\
\hline Emplacement Pipe & no & - & 二 \\
\hline Hydrovield (a) & yes & yes & no \\
\hline Collapse (b) & yes & yes & yes \\
\hline Stress & yes & yes & yes \\
\hline Strain (c) & yes & yes & yes \\
\hline Other Measurements & no & - & \\
\hline
\end{tabular}

(a) CORRTEX or SLIFER in emplacement hole.

(b) EXCOR or CLIPER in emplacement hole.

(c) Emplacement pipe and instrumentation pendant.

\section{Event Personnel}

Containment Physics

$\begin{array}{ll}\text { B. Hudson } & \text { LLNL } \\ \text { V. Wheeler } & \text { LLNL } \\ \text { J. Kalinowski } & \text { EG\&G/AVO } \\ \text { T. Stubbs } & \text { EG\&G/AVO }\end{array}$

Instrumentation
C. Cordill
LLNL
R. MCnairy
C. Simkins
LLNL
T. Williams
EG\&G/AVO
L. Farthing
EG\&G/NVO
EG\&G/NVO 


\section{Contents}

1. Event Description

1.1 Site

1.2 Instrumentation.

2. Emplacement

2.1 Pipe and instrumentation pendant strain $\quad . \quad \ldots \quad$. $\quad . \quad 8$

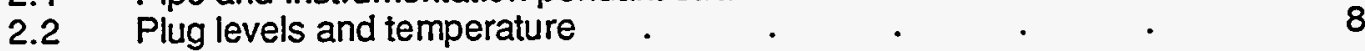

3. Stemming Performance

3.1 Radiation and Pressure . . . . . . . . . $\quad . \quad 13$

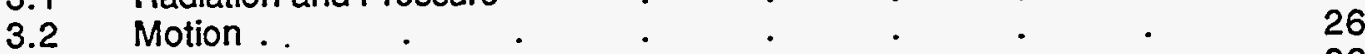

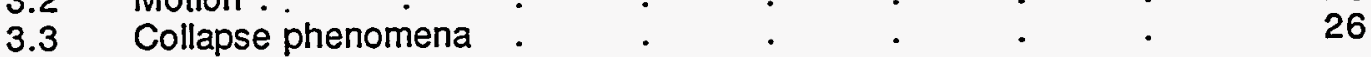

4. Other Measurements

4.1 Surface motion ..

4.2 Geophone history during and after detonation. . $\quad . \quad$. 53

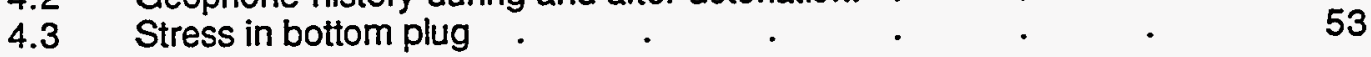

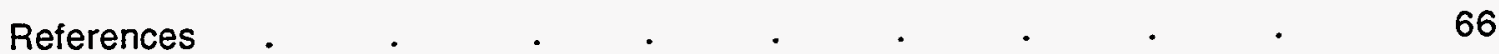




\section{Event Description}

\subsection{Site}

The ROQUEFORT event was detonated in hole U4as of the Nevada Test Site as indicated in Fig. 1.1. The device had a depth-of-burial of $415 \mathrm{~m}$ in the tunnel beds tuff, immediately below a $12 \mathrm{~m}$ thick layer of light ash (Grouse-Canyon Airfall) of Area 4 . The working point was about $180 \mathrm{~m}$ above the standing water level (SWL), as shown in Figures 1.2 and 1.3.(1). Stemming of the $2.44 \mathrm{~m}$ diameter emplacement hole followed the plan shown in Fig. 1.4. A log of the stemming operations was maintained by Holmes \& Narver( 2 ).

Detonation time was 21:35 PST on October 16, 1985 and about 1 hours, 37 minutes later collapse reached the surface, leaving a crater with mean radius of $66.9 \mathrm{~m}$ and maximum depth of $8.9 \mathrm{~m}$.

No radiation arrivals were detected in the emplacement hole and the ROQUEFORT containment was considered successful.

\subsection{Instrumentation}

Figure 1.5 is a schematic layout of the instrumentation designed to monitor the emplacement procedures and stemming performance of the ROQUEFORT event.

The usual final engineering report was not issued for this event, but details of the instrumentation are given in Reference 4.

Three of the five stemming plugs (the first, fourth and fifth) were composed of coarse gypsum aggregate in a gypsum cement slurry. Each of the three gypsum filled aggregate (GFA) plugs was monitored during emplacement with arrays of conductivity probes and thermistors. The remaining two plugs were soft, coal tar aggregate (CT/A) gas seal membranes having a thickness of about $3 \mathrm{~m}$ sandwiched between $3 \mathrm{~m}$ thick layers of fines. A $2 m$ thick CT/A membrane was poured on the top of the two uppermost GFA plugs. 
Gas pressure challenging the bottom plug was monitored through two short sections (about $50 \mathrm{~m}$ ) of gas-sample hose that penetrated the plug. One of the hose sections serviced two sensor stations, one within and near the bottom of the plug with the second on the top of the hose, about $35 \mathrm{~m}$ above the plug. The third challenge pressure station was fielded about $8 \mathrm{~m}$ below the second station and had its own hose section penetrating the plug. Although shown in Figure 1.5, Station 32 (containing crack gauges and a pressure sensor) was not recorded.

Two CLIPER/CORRTEX sensors were emplaced, as indicated in Figure 1.5, to measure the hydrodynamic yield of the device and to monitor cavity collapse and chimney formation. Results of the yield measurements are reported elsewhere ${ }^{(3)}$.

In the emplacement hole, vertical motion was monitored at each of the seven pressureradiation stations in the coarse stemming and at two separate motion stations in each of the top GFA plugs. See Figure 1.5. Additionally, four motion stations were fielded in the ground surface and one in the recording trailer. The surface array stations were approximately equally spaced on a line extending from the emplacement hole for a distance of $630 \mathrm{~m}$ in a direction $44^{\circ}$ west of north.

A Genisco reel-type displacement gauge was mounted between an anchor in the ground suface about $75 \mathrm{~m}$ from the emplacement hole and the gas samping hose. It had an initial extension of $10 \mathrm{ft}$ with a full system range of greater than $85 \mathrm{ft}$.

Stress was monitored at two elevations in the bottom GFA plug as indicated in Figure 1.5. 


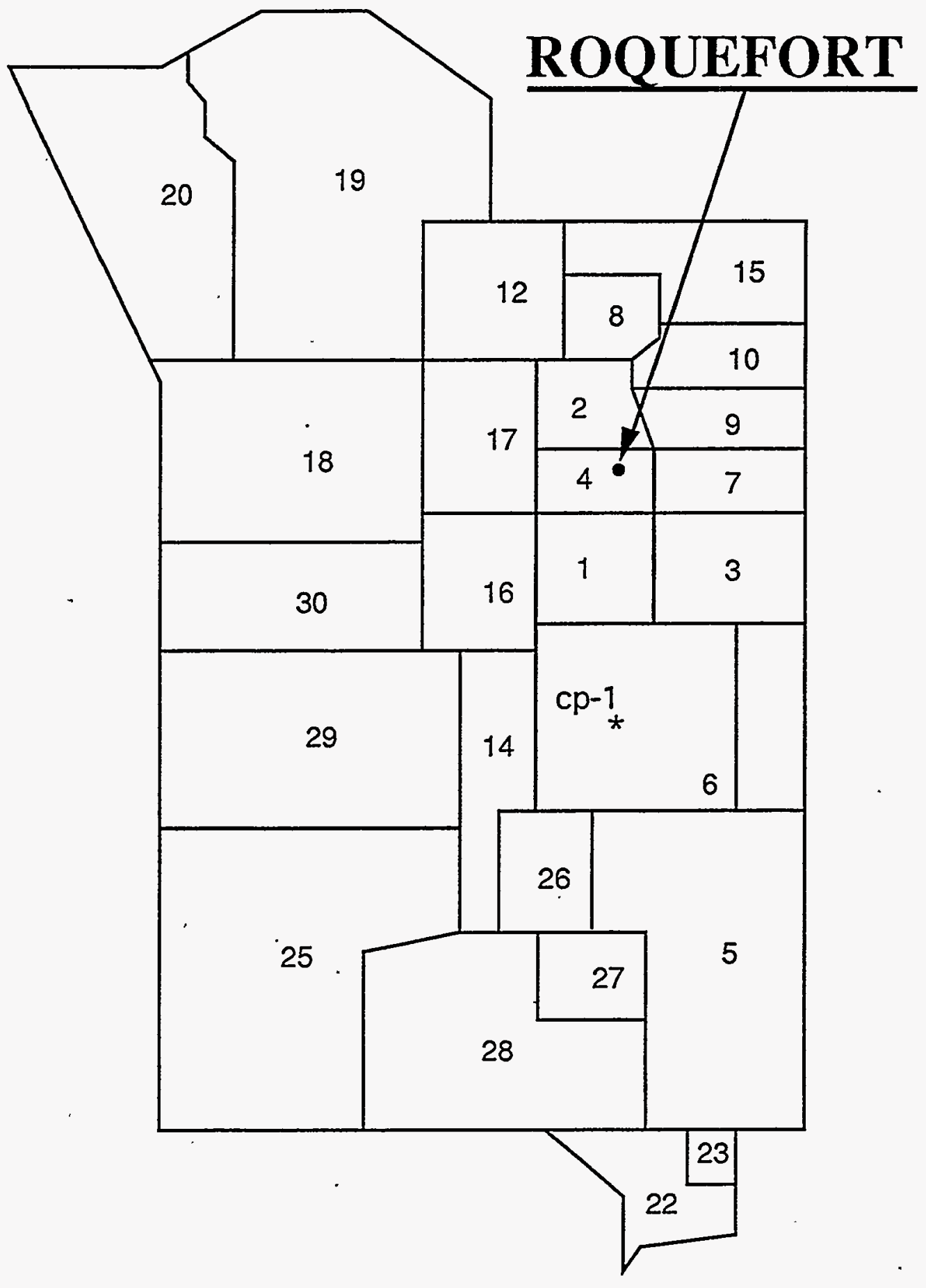

Figure 1.1 Map of the Nevada Test Site indicating the location of hole U4as. 


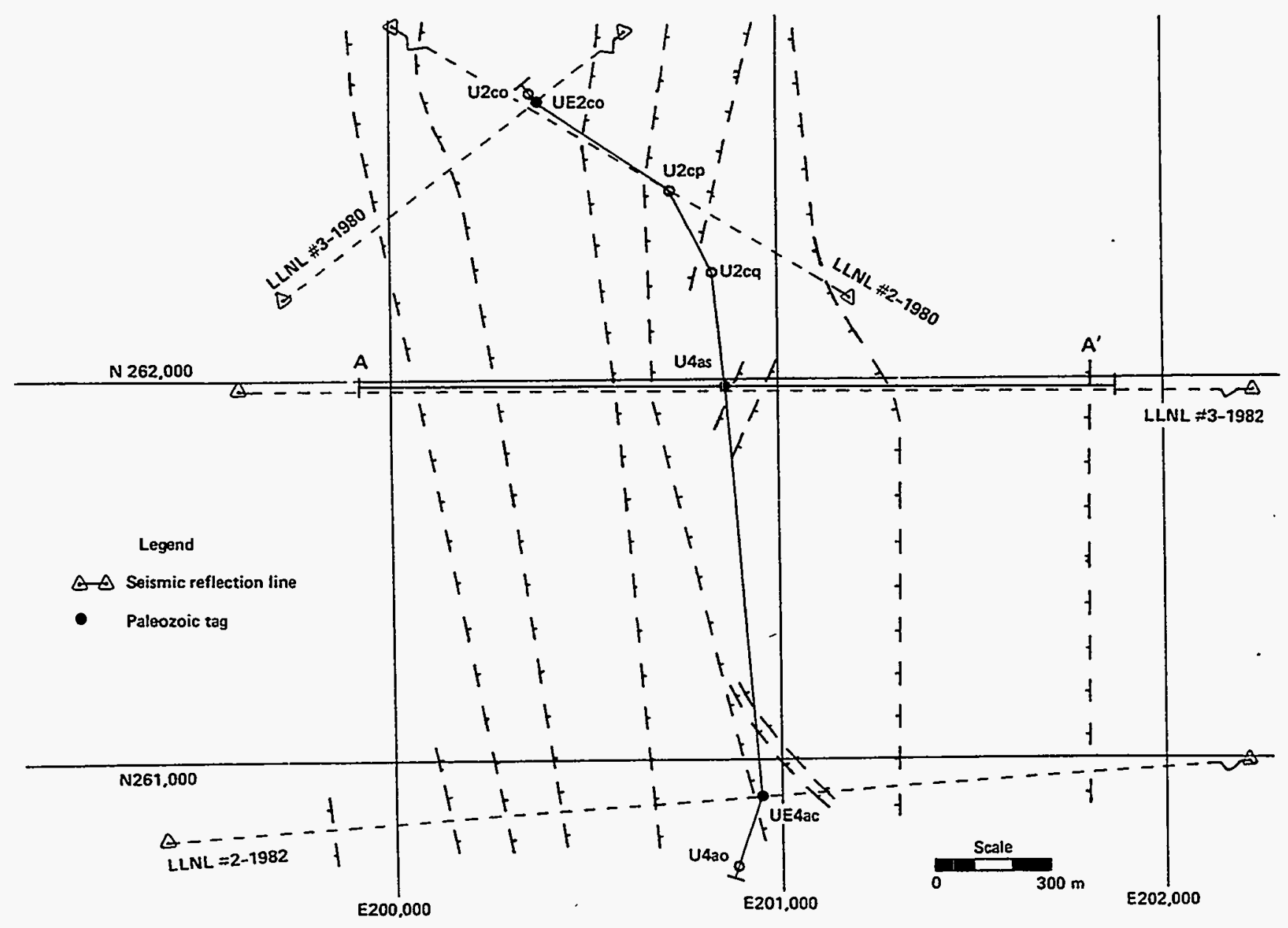

Figure 1.2 Surface geological map of the U4as site. 
A

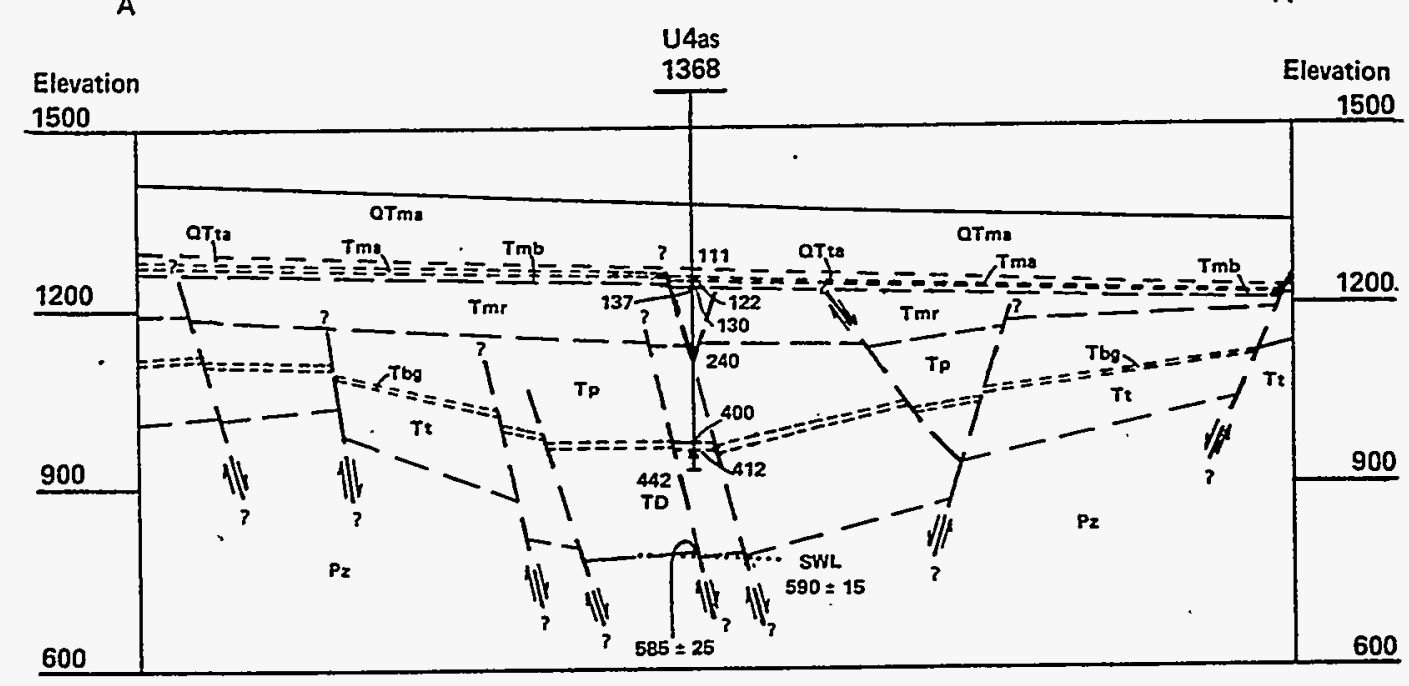

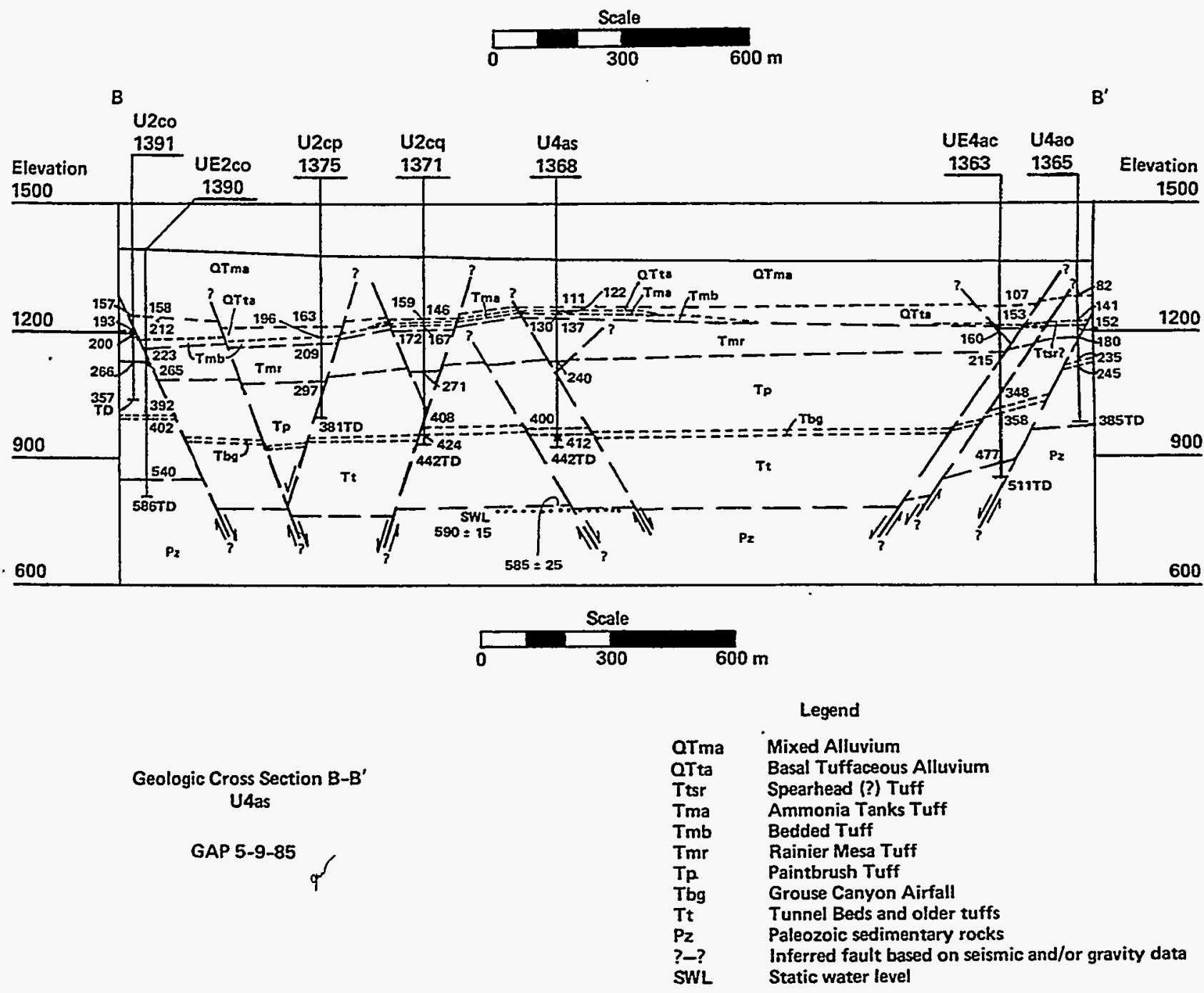

Figure 1.3 Geologic cross sections through hole U4as. 


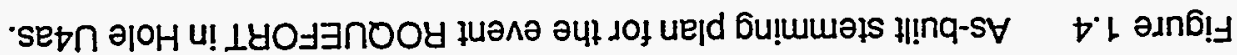

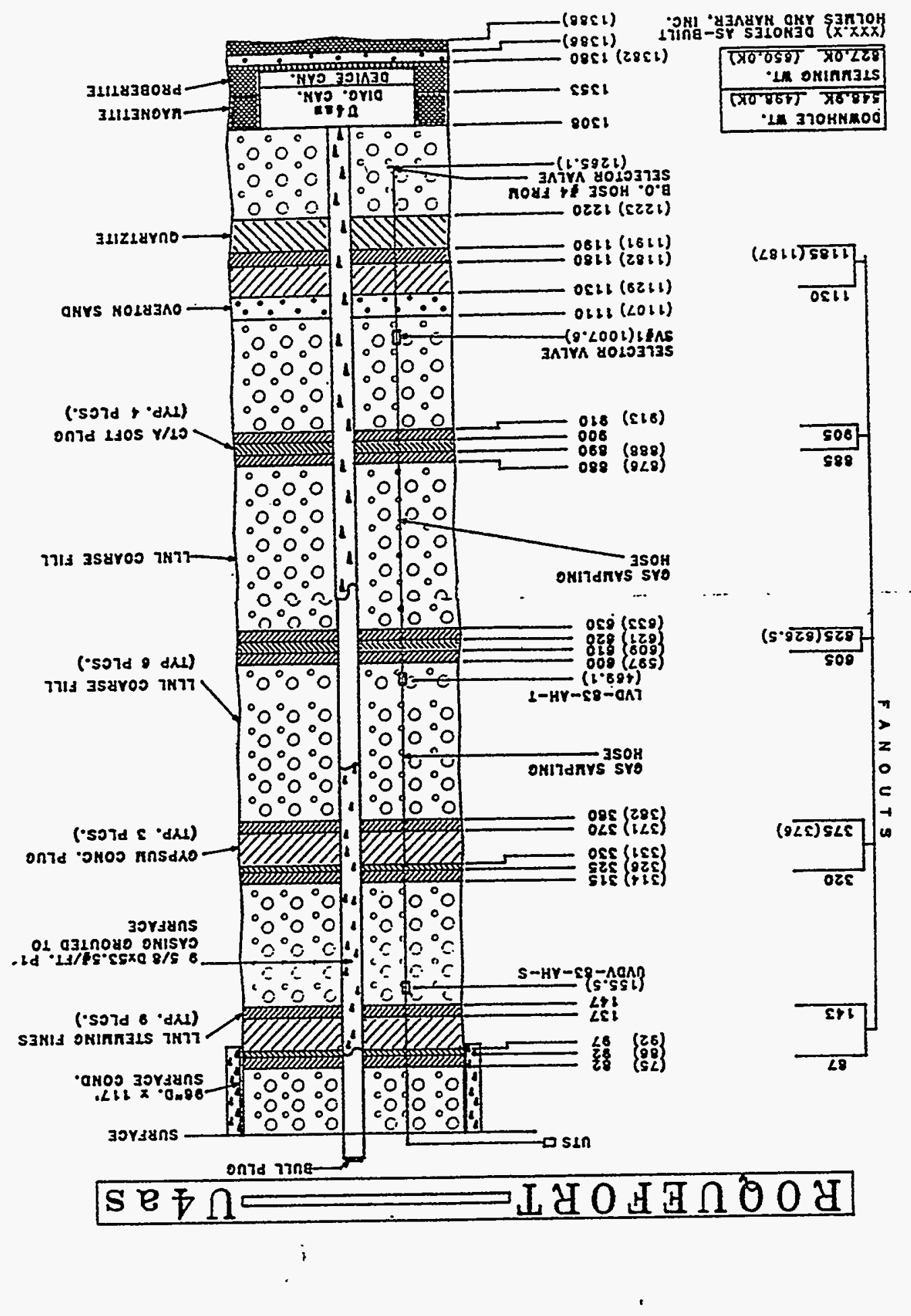




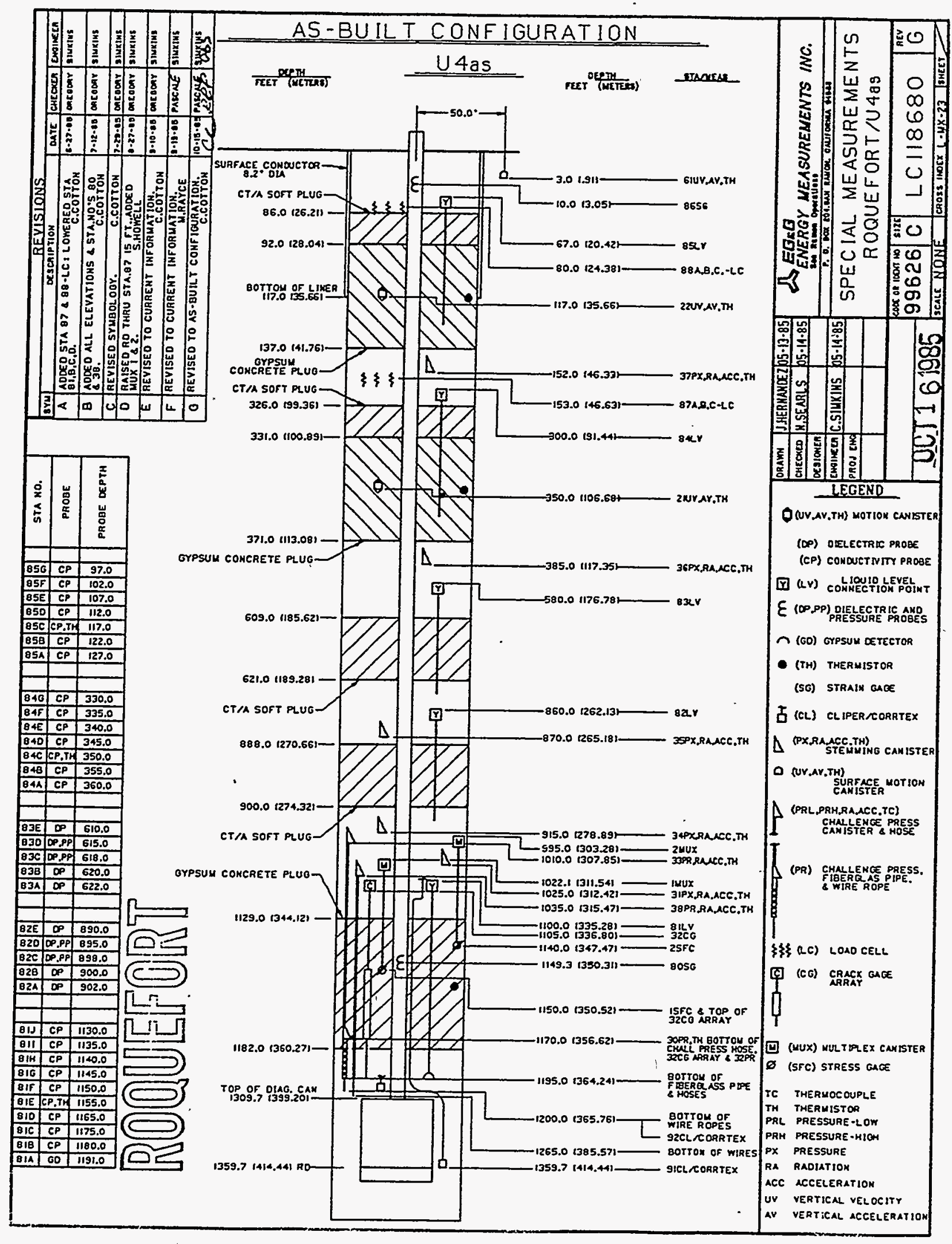

Figure 1.5 As-built containment instrumentation plan for the ROQUEFORT event. 


\section{Emplacement}

\subsection{Pipe and instrumentation pendant strain}

Figure 2.1 is the strain history measured on the emplacement pipe during stemming of the ROQUEFORT experiment. The emplacement pipe was instrumented with a strain gage station on the final pipe section just below the load collar (Station 86) and another station on the emplacement pipe just above the diagnostics canister (Station 80).

Load on the instrumentation pendant was monitored at elevations on either side of the top SGC plug (Stations 87 and 88). The data returned from these positions are also shown in Figure 2.1 .

\subsection{Plug levels and temperature}

The emplacement of each of the three gypsum concrete plugs was monitored with an array of conductivity probes and thermistors. The locations of the probes are tabulated in Figure 1.7. The upper and lower boundary positions of the plugs were determined by tag lines. Figures 2.2 through 2.4 contain plots of the arrival times of the GFA slurry as a function of depth (as determined from the conductivity probes and tag lines) and GFA temperature histories. A temperature sensor was located at the approximate mean depth of each concrete plug. These data indicate that all plugs were emplaced as planned. 

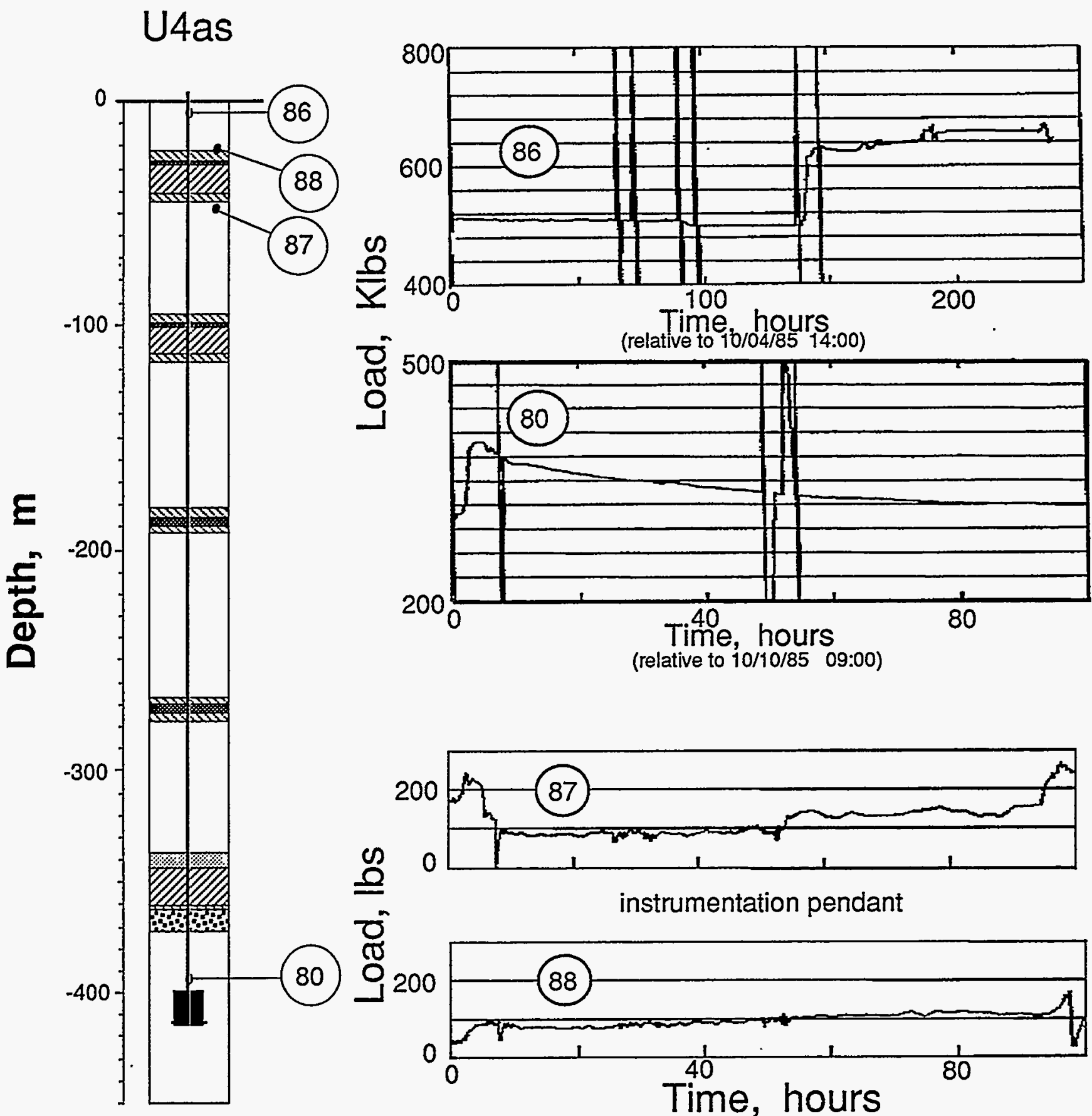

80

${ }_{0} 200$

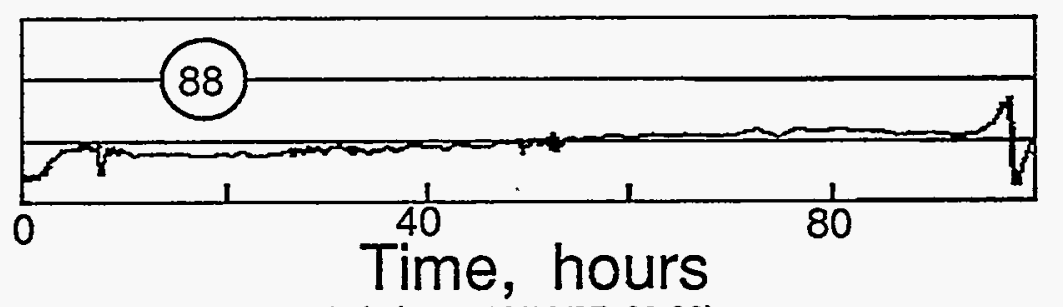

(relative to 10/10/85 09:00)

Figures 2.1 The upper pair of plots show the strain history of the emplacement pipe during the stemming at Stations 86 (near the top of the pipe), and 80 (above the diagnostics canister near the bottom of the pipe). The lower two plots show the load history measured on the instrumentation pendant (Stations 87 and 88). 

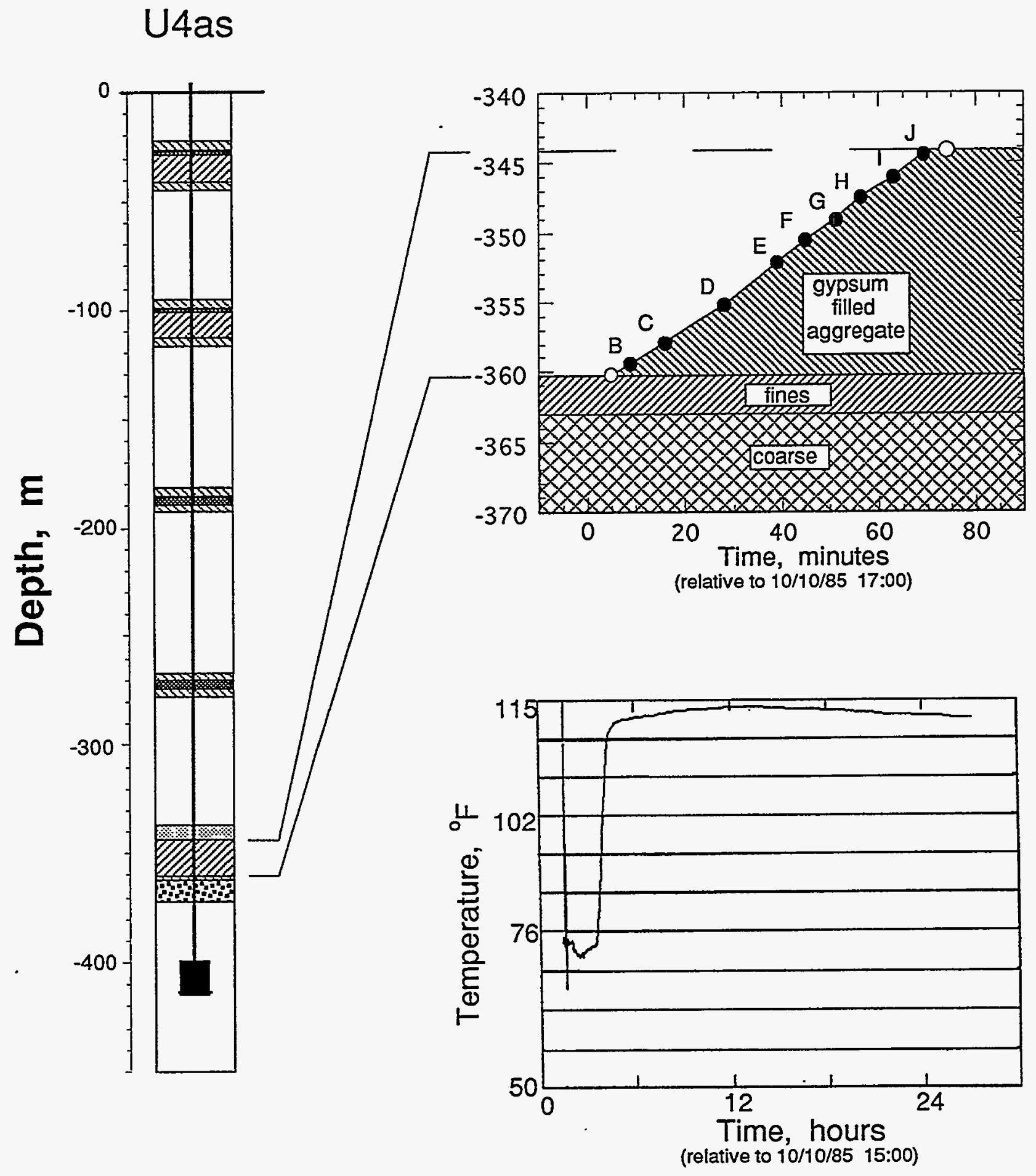

Figure 2.2. Emplacement diagnostics data at GFA plug 1 at a depth of $344 \mathrm{~m}$. The upper and lower boundaries of the plug were determined with a tag line. Solid symbols indicate the elevation of the probes; the open symbols are at the tag depths. The temperature sensor was located at probe "E". 


\section{U4as}
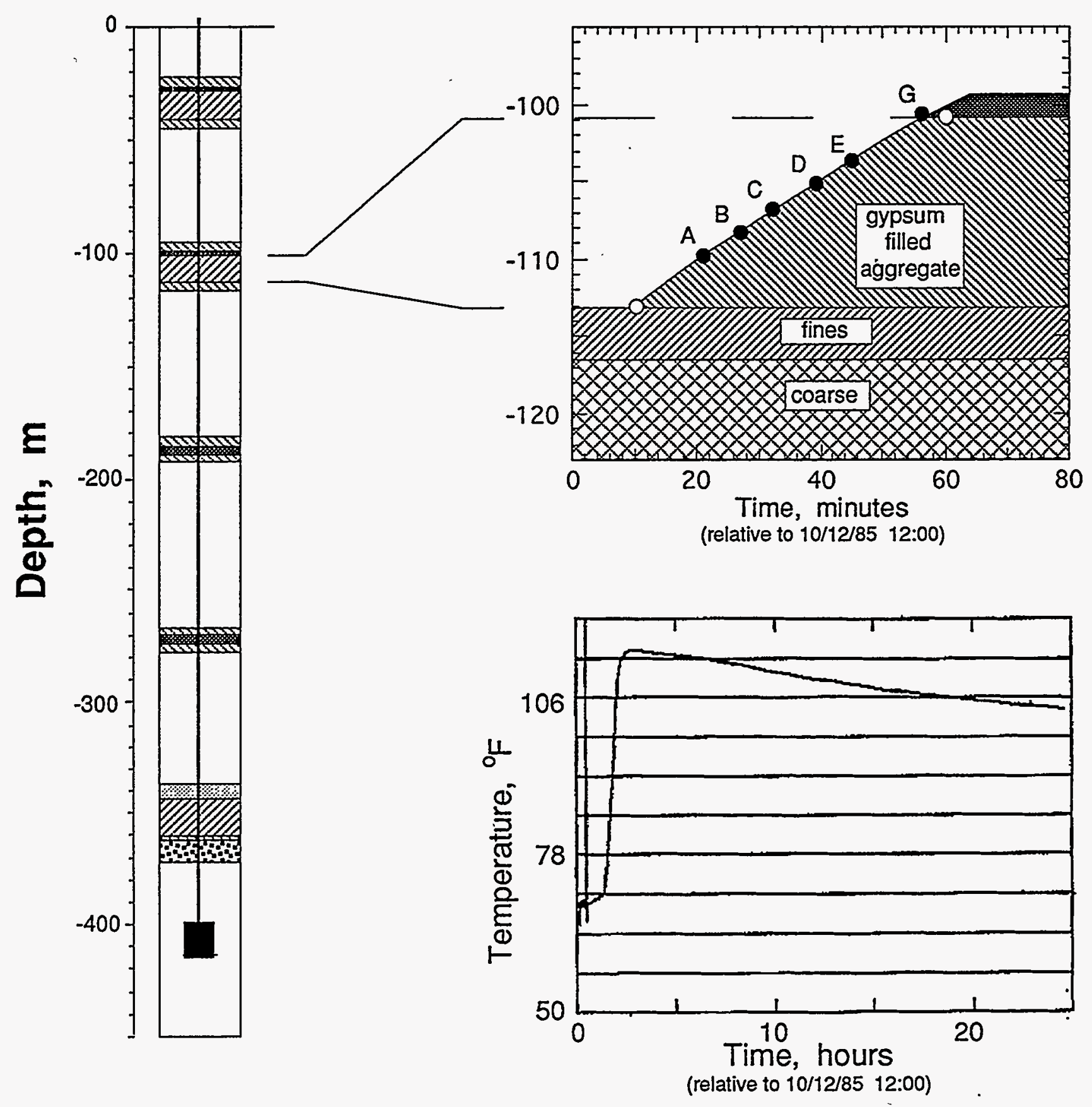

Figure 2.3. Emplacement diagnostics data at GFA plug 4 at a depth of $100 \mathrm{~m}$. The upper and lower boundaries of the plug were determined with a tag line. Solid symbols indicate the elevation of the probes; the open symbols are at the tag depths. The temperature sensor was located at probe " $\mathrm{C}$ ". 


\section{U4as}
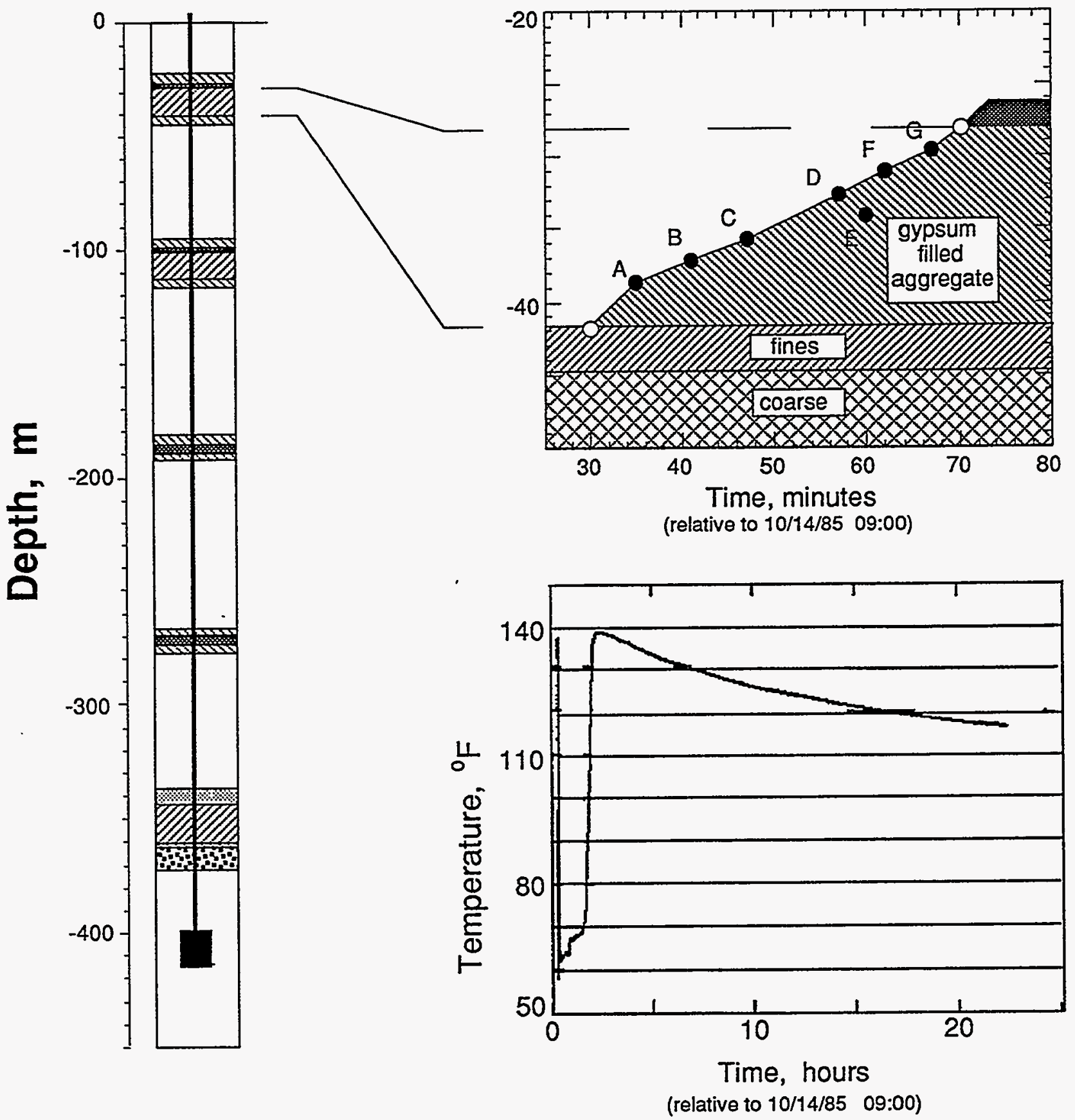

Figure 2.4. Emplacement diagnostics data at ĠFA plug 5 at a depth of $28 \mathrm{~m}$. The upper and lower boundaries of the plug were determined with a tag line. Solid symbols indicate the elevation of the probes; the open symbols are at the tag depths. The temperature sensor was located at probe " $\mathrm{C}$ ". 


\section{Stemming Performance}

\subsection{Radiation and Pressure}

As seen in Figure 1.7, the region below each GFA plug was monitored by pressure and radiation stations as were the regions between the deepest GFA plug and around the deepest CT/A plug. The signals were transmitted to the recording trailer in analog form and recorded on magnetic tape for later processing.

Emplacement hole pressure and radiation histories, from a few seconds before detonation until recording termination, are displayed in Figures 3.1 through 3.10. Cavity collapse reached the ground surface at about 1 hour, 37 minutes at which time all down-hole pressure and radiation instrumentation was lost.

Pressure and radiation challenging the deepest GFA plug are shown in Figures 3.1 -3.4. Station 31 (in the GFA plug and on a section of gas-sample hose) was lost at detonation time and the resulting pressure record is shown in Figure 3.1 for completeness (radiation was not monitored at this station). Pressure and radiation are separately shown in Figures 3.2 and 3.3 to linear scales while Figure 3.4 is a composite of both stations shown to logarithmic scales. This latter representation allows the earlier portion of the records to be shown to greater definition. Further, these data suggest a pressure decay history following $P \approx P_{0} \star 10(-0.8 T)$ after about 5 minutes.

Figures 3.5 - 3.9 show the measured pressure and radiation histories from a few seconds before detonation until cavity collapse terminated the records. The only station showing neither radiation nor pressure change was 37 (below the top plug, Figure 3.9). A small pulse of radiation was observed at Station 36 (Figure 3.8), but not at Station 37, indicating that radiation was contained below plug 4 . Figure 3.10 is a composite of pressure and radiation measured at all of the stemming stations with the exception of Station 37. Again, for ease of presentation, a logarithmic scale is used. Station 33 is included as a measure of the pressure below the deepest plug and to compare the radiation wave form with that of Station 31. Except for a scale factor, the radiation wave forms from Stations 31 and 33 are nearly identical between 200 and 2000 seconds. Further, the major radiation arrival appears to be riding on the pressure wave as it travels up the emplacement hole. A minor radiation arrival is evident at the stemming stations below 36 and both major and minor arrivals are plotted in Figure 3.11. 
Note that the radiation detector electronics requires that the detector be shut down immediately after the EMP for a time of about 100 seconds, followed by a short recovery period. Thus there may be earlier, undetected arrivals.

Since no pressure changes other than those attributable to ground motion were seen above Station 35 and no radiation arrivals were seen above Station 36 , the pressure and radiation data are consistent with satisfactory containment. 


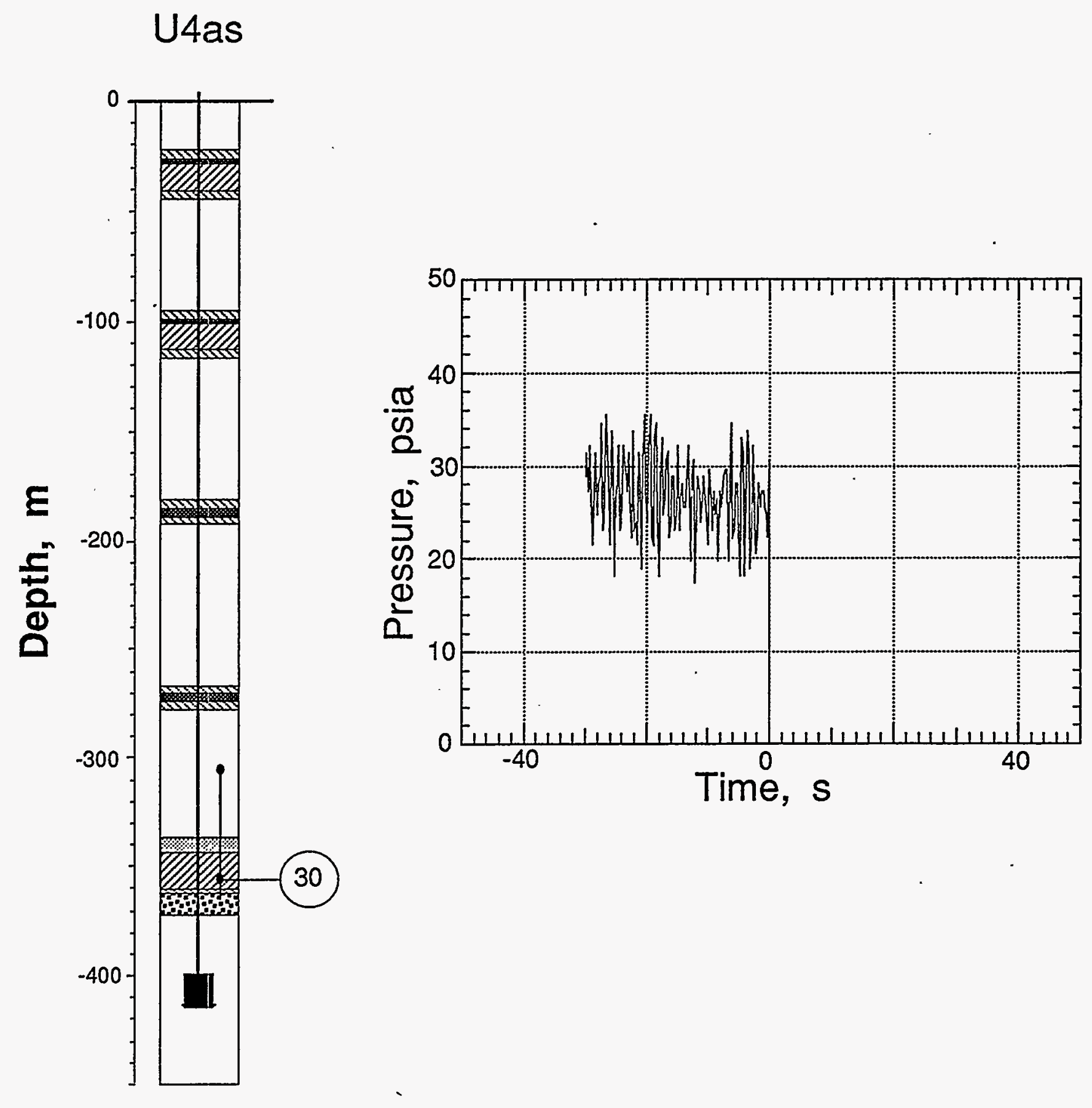

Figure 3.1 Measurement of the pressure challenging the deepest GFA plug. Sensor station (Station 30) was in the plug, connected to a section of gas-sample hose penetrating to a sand layer below the plug. Signals from this station were terminated at zero time. 

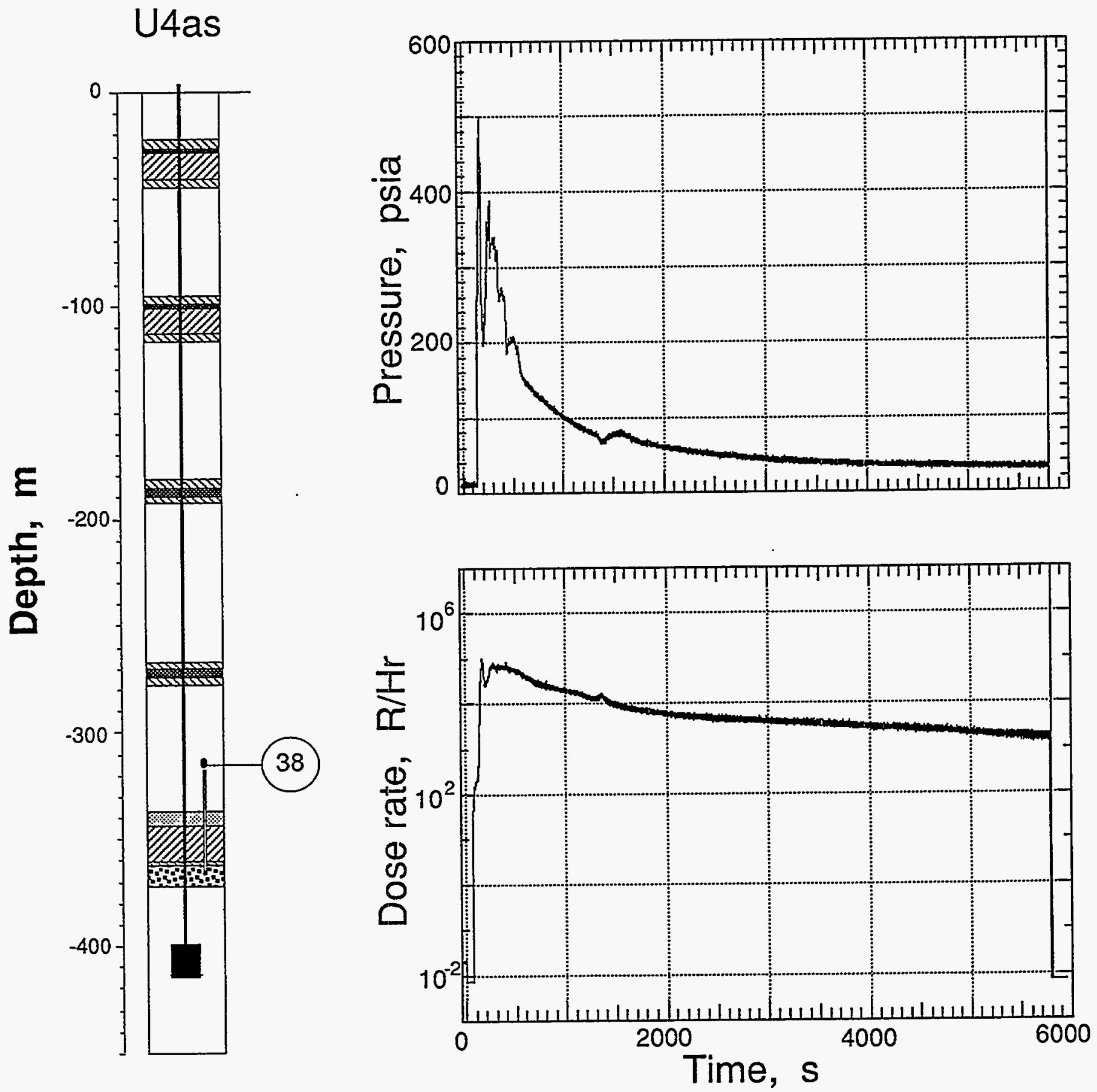

Figure 3.2 Measurement of pressure and radiation challenging the deepest GFA plug. Sensor station (Station 33, at a depth of $307.9 \mathrm{~m}$ ) was in the coarse stemming, $36 \mathrm{~m}$ above the plug, connected to a section of gas-sample hose penetrating through the plug to a sand layer below it. This was the same hose on which was mounted Station 30 . 

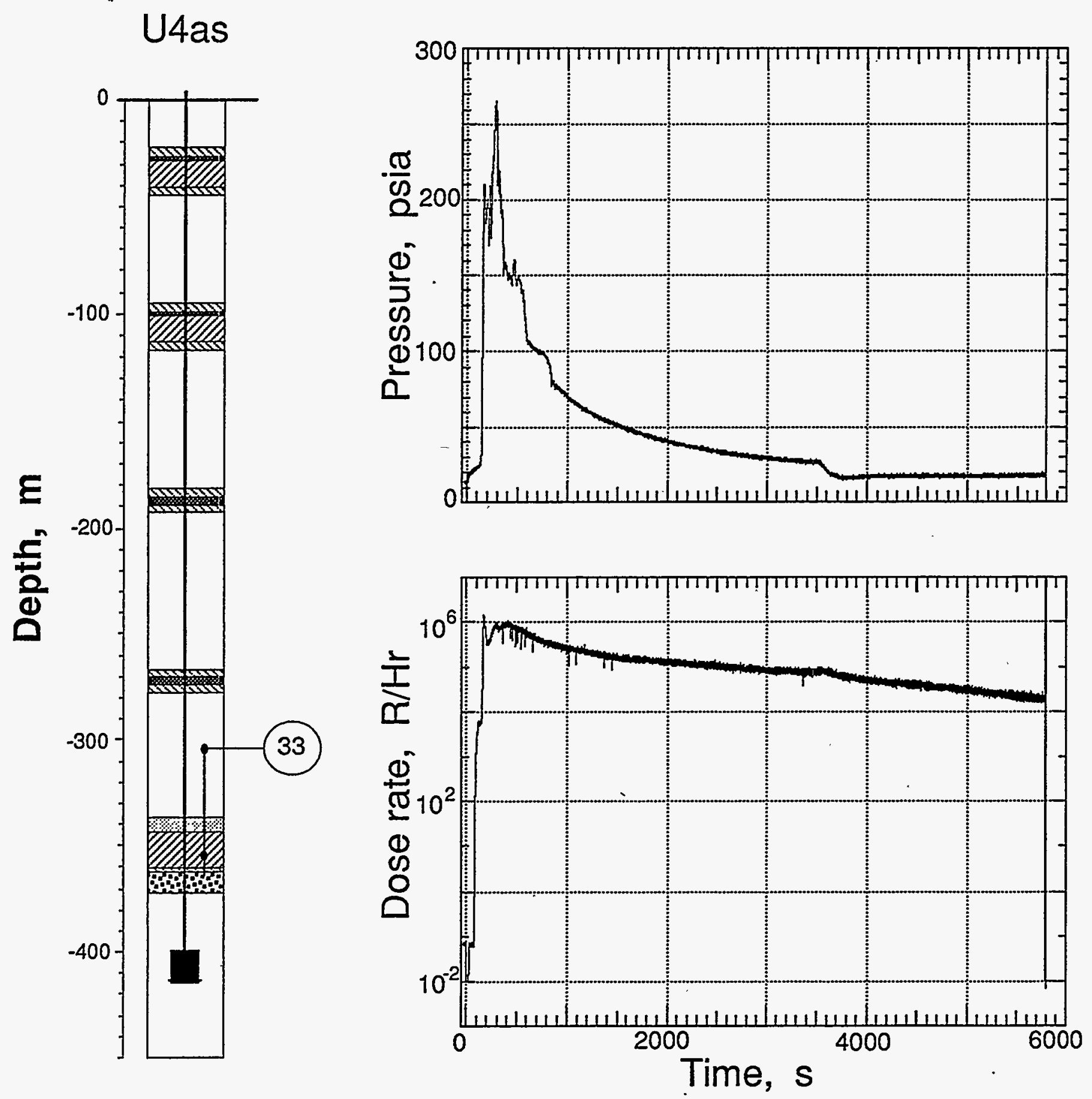

Figure 3.3 Measurement of pressure and radiation challenging the deepest GFA plug. Sensor station (Station 38 , at a depth of $315.5 \mathrm{~m}$ ) was in the coarse stemming, $29 \mathrm{~m}$ above the plug, connected to a section of gas-sample hose penetrating through the plug to a sand layer below it. 

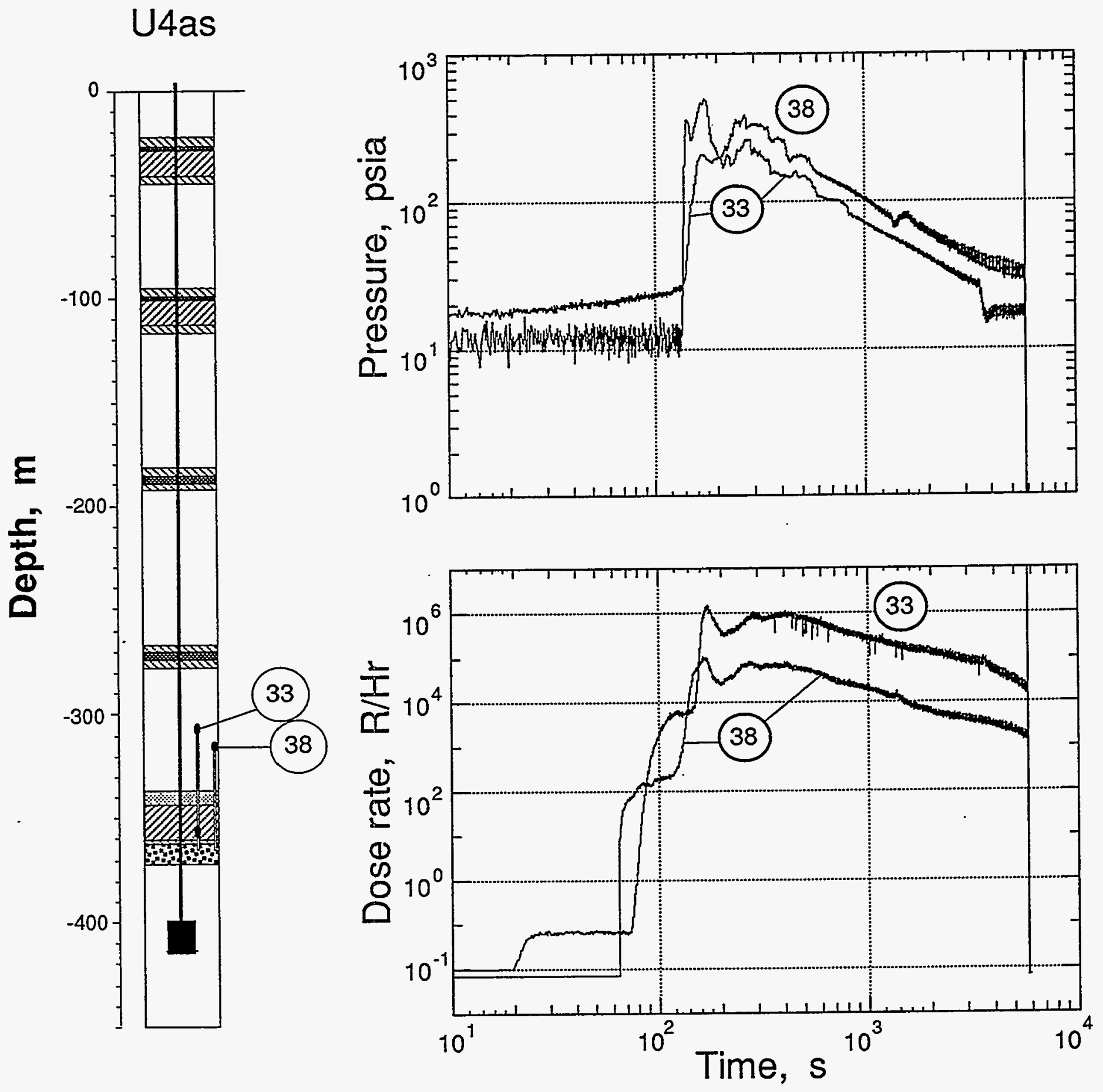

Figure 3.4 Composite of challenge pressure and radiation for the first 2000 seconds after detonation. 

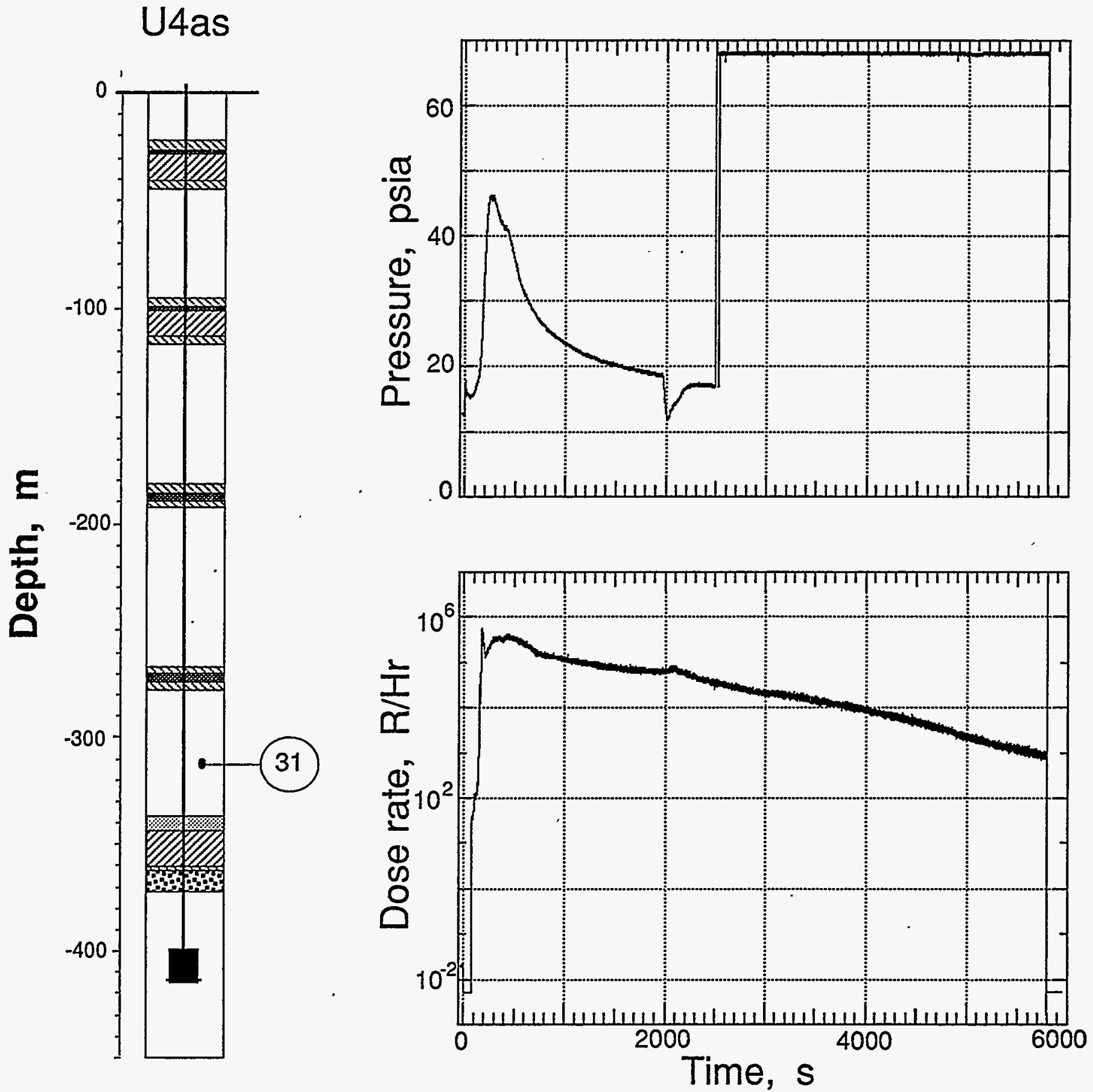

Figure 3.5 Pressure and radiation measured in the coarse stemming between the plugs 1 and 2 (Station 31 at $312.4 \mathrm{~m}$ depth). 

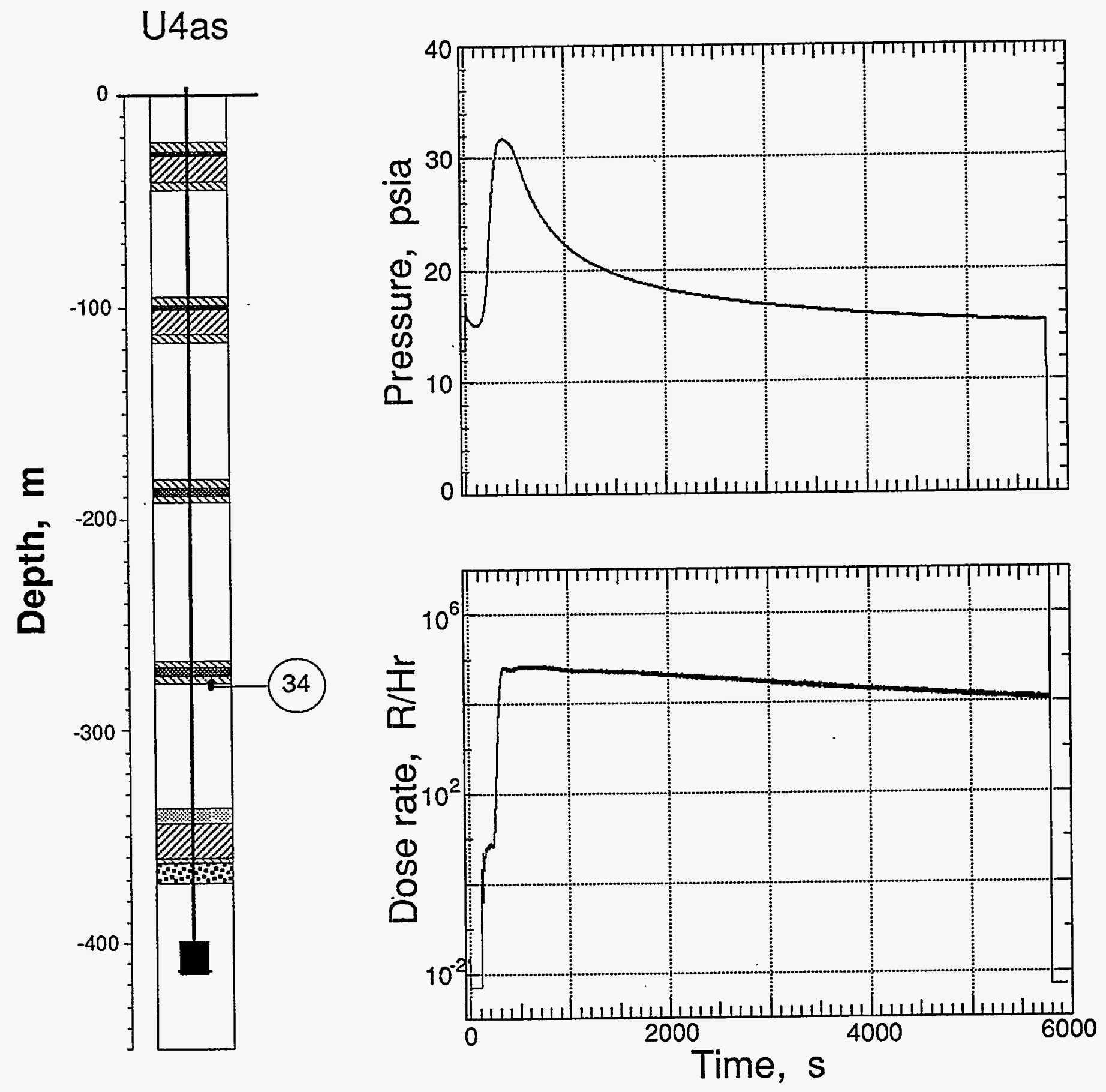

Figure 3.6 Pressure and radiation measured in the coarse stemming below the CT/A plug 2 (Station 34 at $278.9 \mathrm{~m}$ depth). 

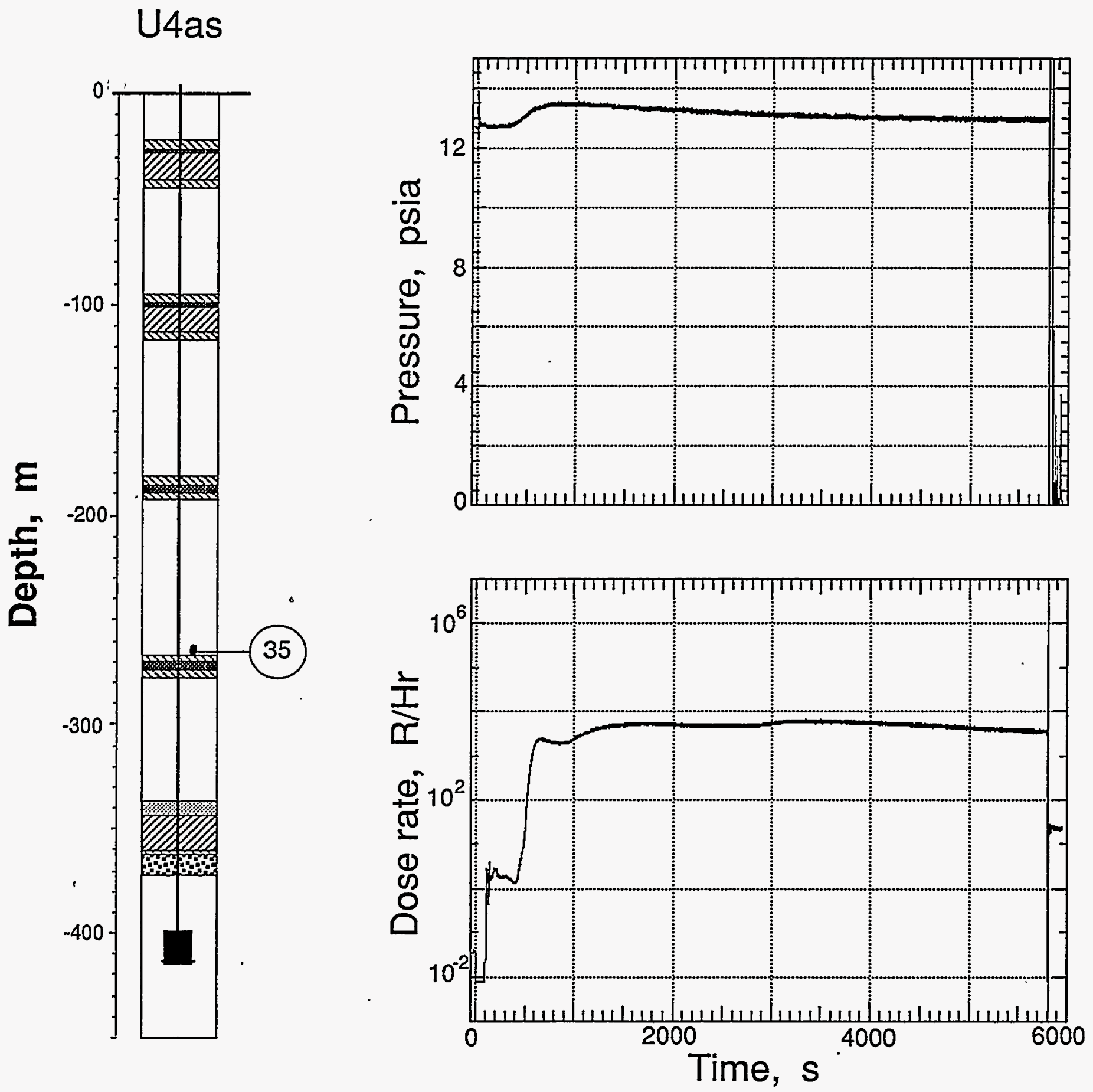

Figure 3.7 Pressure and radiation measured in the coarse stemming above the CT/A plug 2 (Station 35 at $265.2 \mathrm{~m}$ depth). 

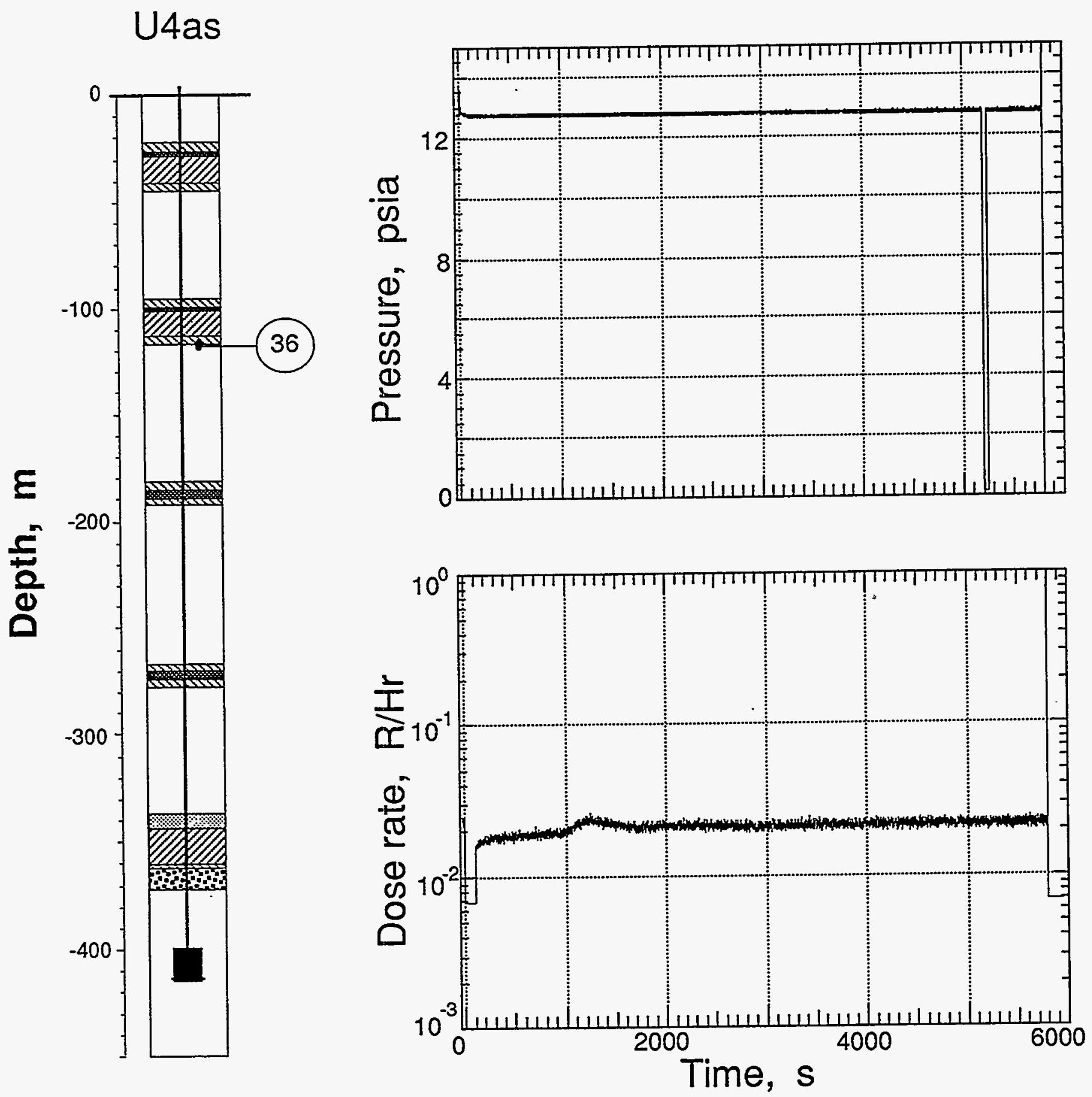

Figure 3.8 Pressure and radiation measured in the coarse stemming below the GFA plug 4 (Station 36 at $117.4 \mathrm{~m}$ depth). 

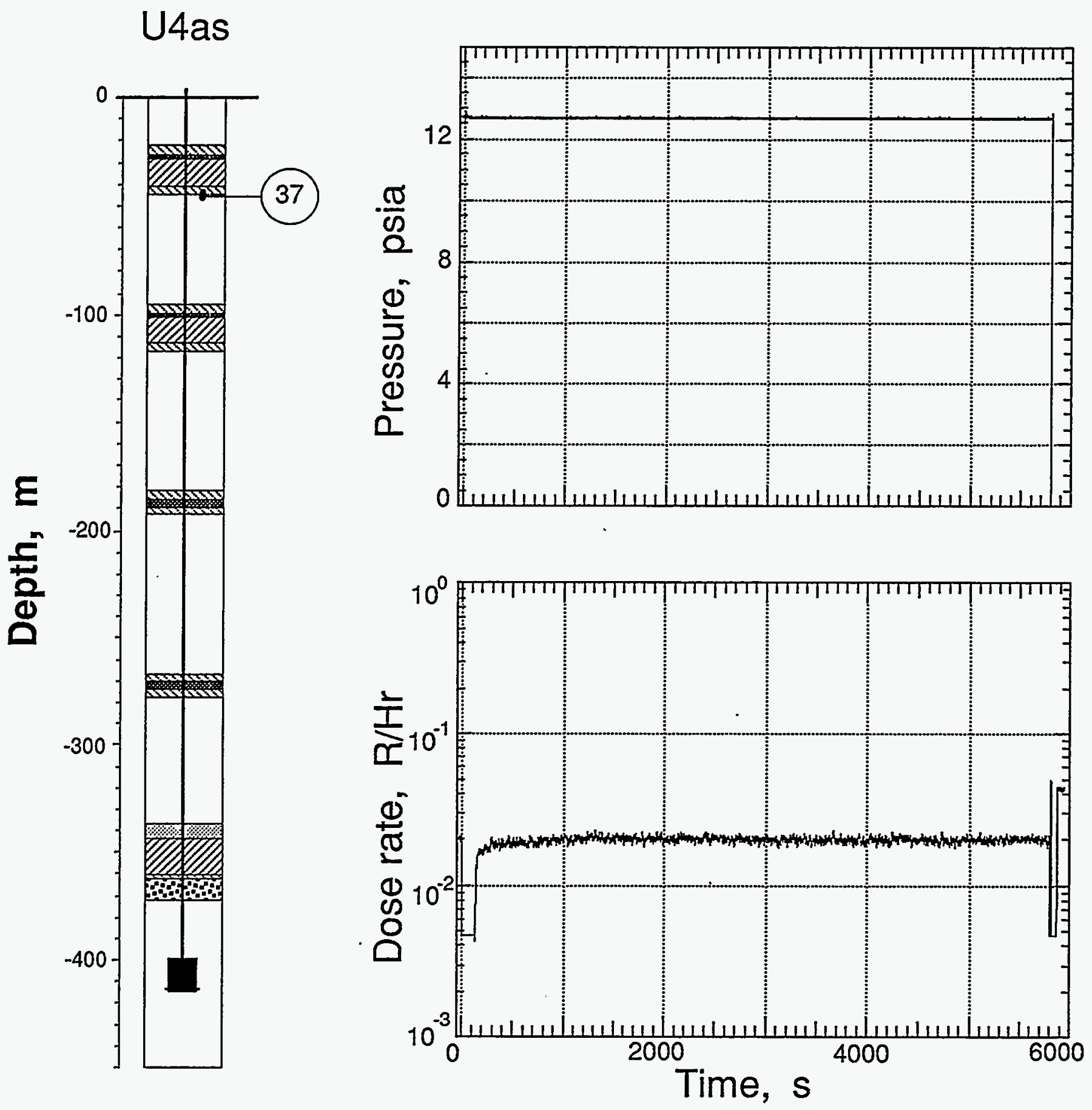

Figure 3.9 Pressure and radiation measured in the coarse stemming below the top GFA plug (Station 37 at $46.3 \mathrm{~m}$ depth). 


\section{U4as}
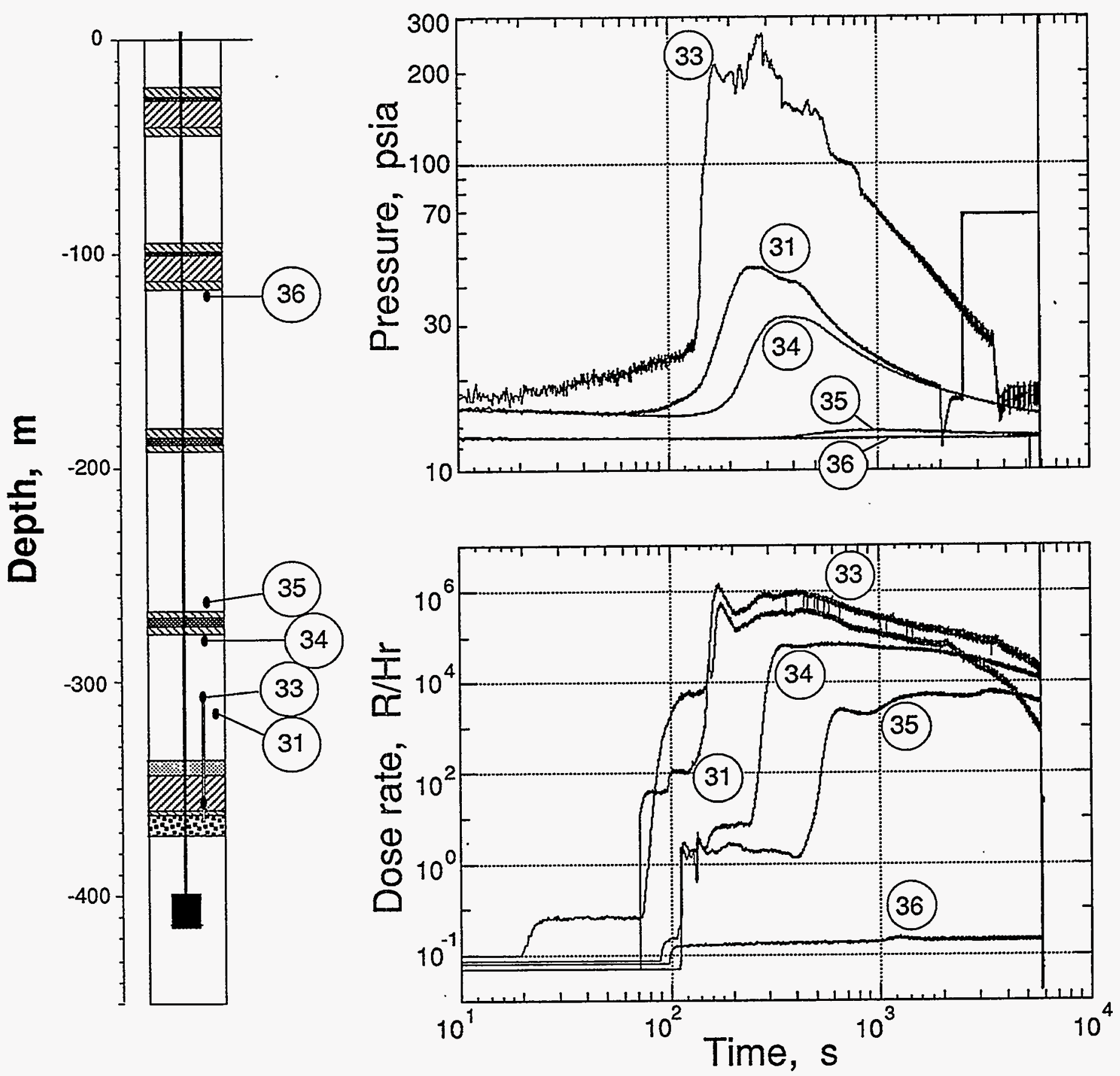

Figure 3.10 Overlay of the pressure and radiation histories from stations in the stemming. Those stations which detected either radiation or gas pressure (other than ground motion-induced) are represented. Included for comparison are the data from Station 33 which was designed to monitor the gas challenging the deepest plug. Note the logarithmic scales. 

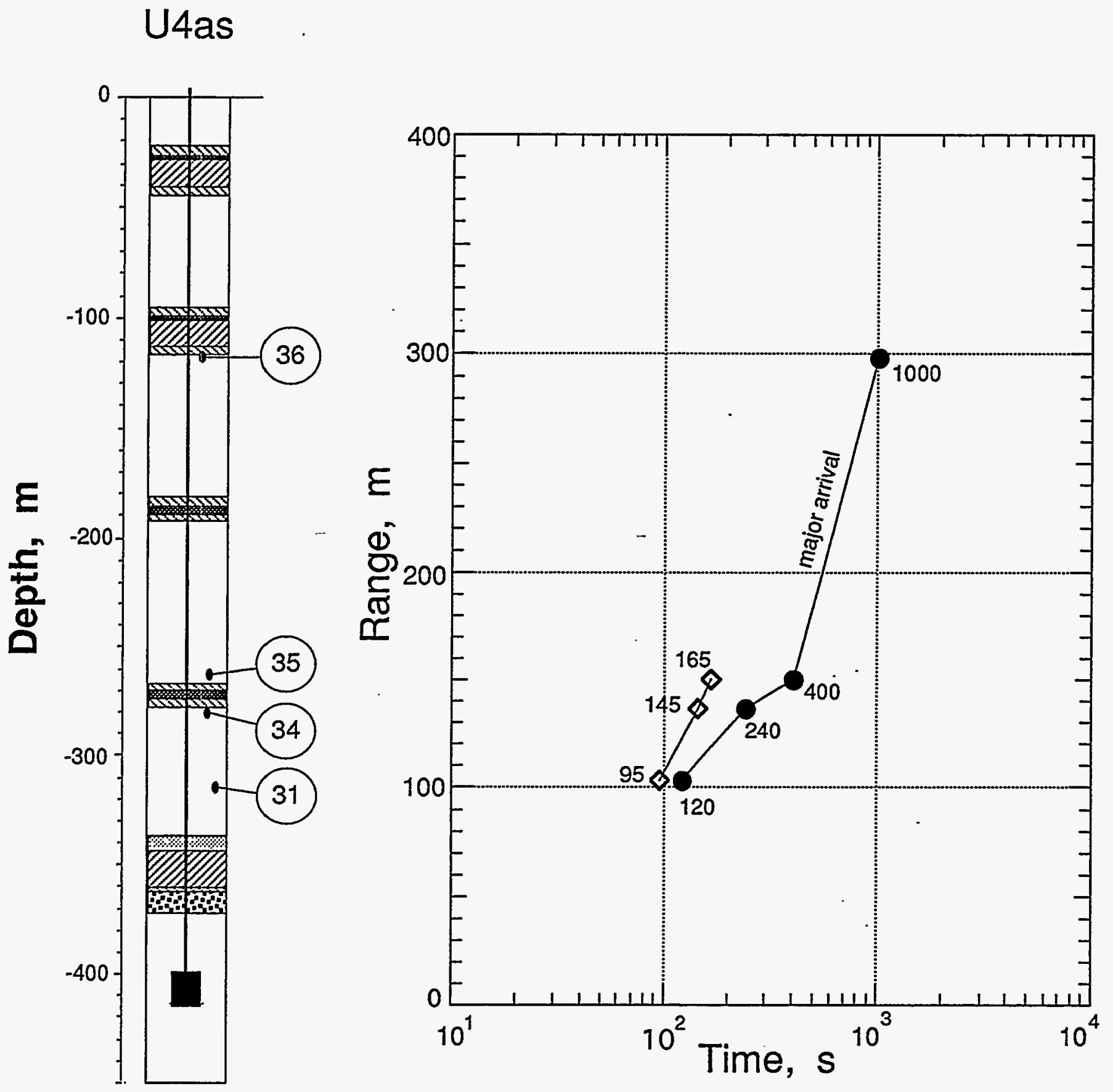

Figure 3.11 Arrival times in the coarse stemming material. 'Detectable radiation does not flow above the stemming platform (plug 4). A first, low-level arrival is indicated by the open diamonds while the major radiation arrival is indicated by the solid circles.

Arrival times (in seconds) are shown for convenience. 


\subsection{Motion}

Explosion-induced motion histories obtained from the ROQUEFORT emplacement hole are shown in Figures 3.12-3.21. The motion data are ordered by station elevation in the emplacement hole, not by station number. Station 21 was mounted in GFA plug 4, Station 22 was in the top GFA stemming plug, Station 61 was $0.91 \mathrm{~m}$ deep in the ground surface 15.24 $\mathrm{m}$ from surface ground zero (SGZ), and the rest were in the coarse stemming material of the emplacement hole. Station 61 is part of a linear surface array and, as such, is also reported in section 4.1. Note that Stations 33 and 38 were attached to short sections of gas-sample hoses $(48.8 \mathrm{~m}$ ) that penetrated the bottom plug and thus might have motions that are not representative of the stemming. Elevations of all stations are shown in Figure 5.

Arrivals and peaks of the motion are given in table 3.1 while characteristics of the motion transducers are given in tables 3.2 and 3.3.

\subsection{Collapse phenomena}

Both the CLIPER and EXCOR cables (Stations 91 and 92) performed as expected, giving the lower position of each cable end as a function of time during the cavity collapse. These data are shown in Figure 3.22 along with collapse motion signals.

The collapse motion data shown in Figures 3.23-3.31 are ordered by station elevation in the emplacement hole, not by station number. As previously noted, Stations 33 and 38 are attached to section of gas-sample hoses, thus possibly accounting for the early loss-time of Station 33 (Figure 3.25) as compared to the nearby stations mounted free in the coarse stemming (Stations 31 and 34). A uniform progression of the collapse to the ground surface terminated all data transmission from the emplacement hole below $35 \mathrm{~m}$ depth. At $15 \mathrm{~m}$ from SGZ (Station 61, Figure 3.31) the ground surface is seen to drop by about 7-8 $\mathrm{m}$. 
A Genico "fishing reel" type displacement transducer was mounted between an anchor in the ground surface about $25 \mathrm{~m}$ from the emplacement hole and the gas-sample hose. The device was installed with an initial extension of about $3 \mathrm{~m}$ and the shock produced an additional 15 to $20 \mathrm{~cm}$ of extension. Upon collapse, a final extension of about $10.4 \mathrm{~m}$ was observed (Figure 3.32) in accord with the displacement data from Station 61. Figure 3.33 . shows a composite plot of the CLIPER, EXCOR and Genico data during the 15 seconds of collapse. These data suggest that the gas-sample hose began to fall with plug 4 (at a depth of about $100 \mathrm{~m}$ ). The survey taken the day following the event shows a crater with a maximum depth of $8.9 \mathrm{~m}$ and a mean radius of $66.9 \mathrm{~m}$. 


\section{Table $3.1 \quad$ Summary of Motion}

\begin{tabular}{|c|c|c|c|c|c|c|}
\hline Gauge & $\begin{array}{c}\text { Slant Range } \\
(\mathrm{m})\end{array}$ & $\begin{array}{l}\text { Arrival Time } \\
(\mathrm{ms})\end{array}$ & $\begin{array}{l}\text { Acceleration } \\
\text { Peak (g) }\end{array}$ & $\begin{array}{c}\text { Velocity Peak } \\
(\mathrm{m} / \mathrm{s})\end{array}$ & $\begin{array}{l}\text { Displacement } \\
\text { Peak }(\mathrm{cm})\end{array}$ & $\begin{array}{l}\text { Displacement } \\
\text { Residual }(\mathrm{cm})\end{array}$ \\
\hline $21 a v$ & 307.8 & $75^{(a)}, 157$ & 2.35 & $0.36,0.51$ & 11,14 & 11.5 \\
\hline $21 u v$ & & & - & $0.47,0.58$ & $12.5,15$ & 4.3 \\
\hline $22 a v$ & 378.8 & $93^{(a)}, 201$ & 1.55 & $03 ., 0.70$ & 13.5 & 4.5 \\
\hline 22uv & & & - & $0.37,0.86$ & 16.0 & 4.0 \\
\hline $31 a v$ & 102.0 & 26 & 10,23 & 13.1 & 178 & 150 \\
\hline $33 a v$ & 106.6 & 50 & $8.3,25.2$ & 11.2 & 130 & o(b) \\
\hline $34 a v$ & 135.6 & $34^{(a)}, 64$ & $0.6,2.2$ & 0.8 & 9.8 & 8 \\
\hline $35 a v$ & 149.3 & $42^{(a)}, 71$ & $4.9,7.1$ & $0.68,1.80$ & 19 & 30 \\
\hline $36 a v$ & 297.1 & $59(a), 75$ & $0.85,2.8$ & 0.35 & $8.5,10$ & -1 \\
\hline $37 a v$ & 368.1 & 96 & 1.35 & 0.61 & 11.6 & 12.5 \\
\hline $38 a v$ & 99.0 & 30 & $10.2,29$ & 13.6 & 198 & 187 \\
\hline $61 a v$ & 413.8 & 235 & $3.5,7.3^{(c)}$ & 0.64 & 12.7 & 3 \\
\hline 61uv & & & - & 0.70 & 37 & 5.5 \\
\hline
\end{tabular}

(a) Early arrival, possibly from the emplacement pipe.

(b) Very difficult to estimate.

(c) Slap-down peak. 
Table $3.2 \quad$ Accelerometer Characteristics

\begin{tabular}{|c|c|c|c|}
\hline Gauge & $\begin{array}{l}\text { Natural Frequency } \\
(\mathrm{Hz})\end{array}$ & Damping Ratio & $\begin{array}{c}\text { System Range } \\
\text { (g's) }\end{array}$ \\
\hline $21 a v$ & 250 & 0.77 & 4 \\
\hline 22av & 240 & .0 .65 & 5 \\
\hline $31 \mathrm{av}$ & (a) & (b) & 625 \\
\hline $33 a v$ & (a) & (b) & 625 \\
\hline $34 a v$ & (a) & (b) & 62.5 \\
\hline $35 a v$ & (a) & (b) & 31.25 \\
\hline $36 a v$ & (a) & (b) & 31.25 \\
\hline $37 a v$ & (a) & (b) & 62.5 \\
\hline $38 a v$ & (a) & (b) & 625 \\
\hline $61 a v$ & 600 & 0.62 & 30 \\
\hline
\end{tabular}

(a) Piezoresitive element: mounted resonance $\geq 2000 \mathrm{~Hz}$.

(b) Manufacturer's specification: damping ratio $=0.7$.

Table 3.3 Velocimeter Characteristics

\begin{tabular}{|c|c|c|c|c|c|}
\hline Gauge & $\begin{array}{c}\text { Natural } \\
\text { Frequency } \\
(\mathrm{Hz})\end{array}$ & $\begin{array}{l}\text { Time to } 0.5 \\
\text { Amplitude } \\
\text { (s) }\end{array}$ & $\begin{array}{c}\text { Calibration } \\
\text { Temperature } \\
\left({ }^{\circ} \mathrm{C}\right)\end{array}$ & $\begin{array}{c}\text { Operate } \\
\text { Temperature } \\
\left({ }^{\circ} \mathrm{C}\right)\end{array}$ & $\begin{array}{c}\text { System } \\
\text { Range } \\
(\mathrm{m} / \mathrm{s})\end{array}$ \\
\hline 21 uv & 3.486 & 9.46 & 26.47 & 29.89 & 6 \\
\hline 22uv & 3.560 & 8.42 & 26.23 & 37.64 & 6 \\
\hline 61uv & 3.561 & 8.35 & 26.28 & 13.68 & 8 \\
\hline
\end{tabular}



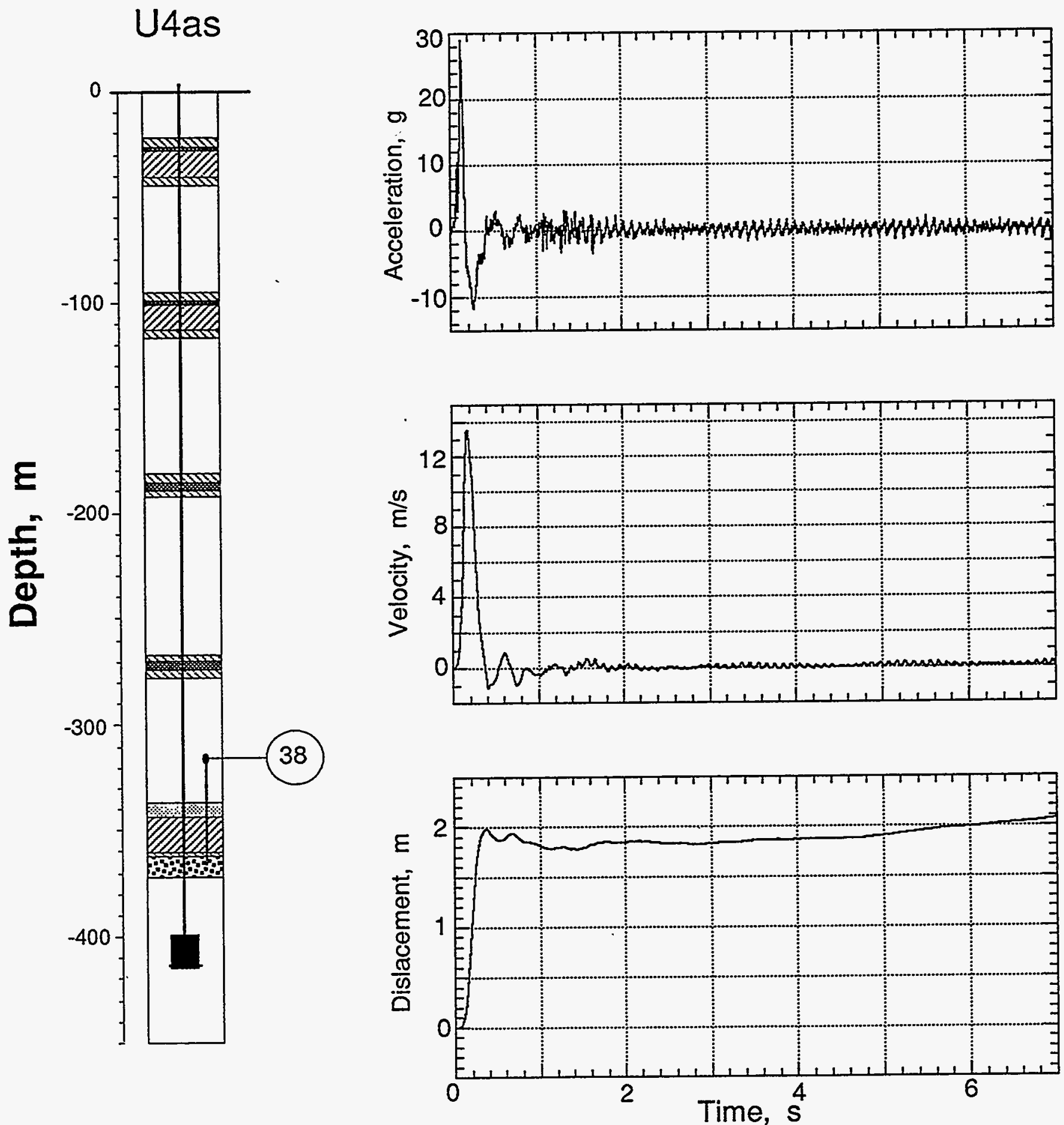

Figure 3.12 Explosion-induced vertical motion in the coarse stemming at a depth of $315.5 \mathrm{~m}$ (Station 38). This station was connected to a section of gas-sample hose penetrating the deepest plug and the motion is expected to be influenced by this element. 

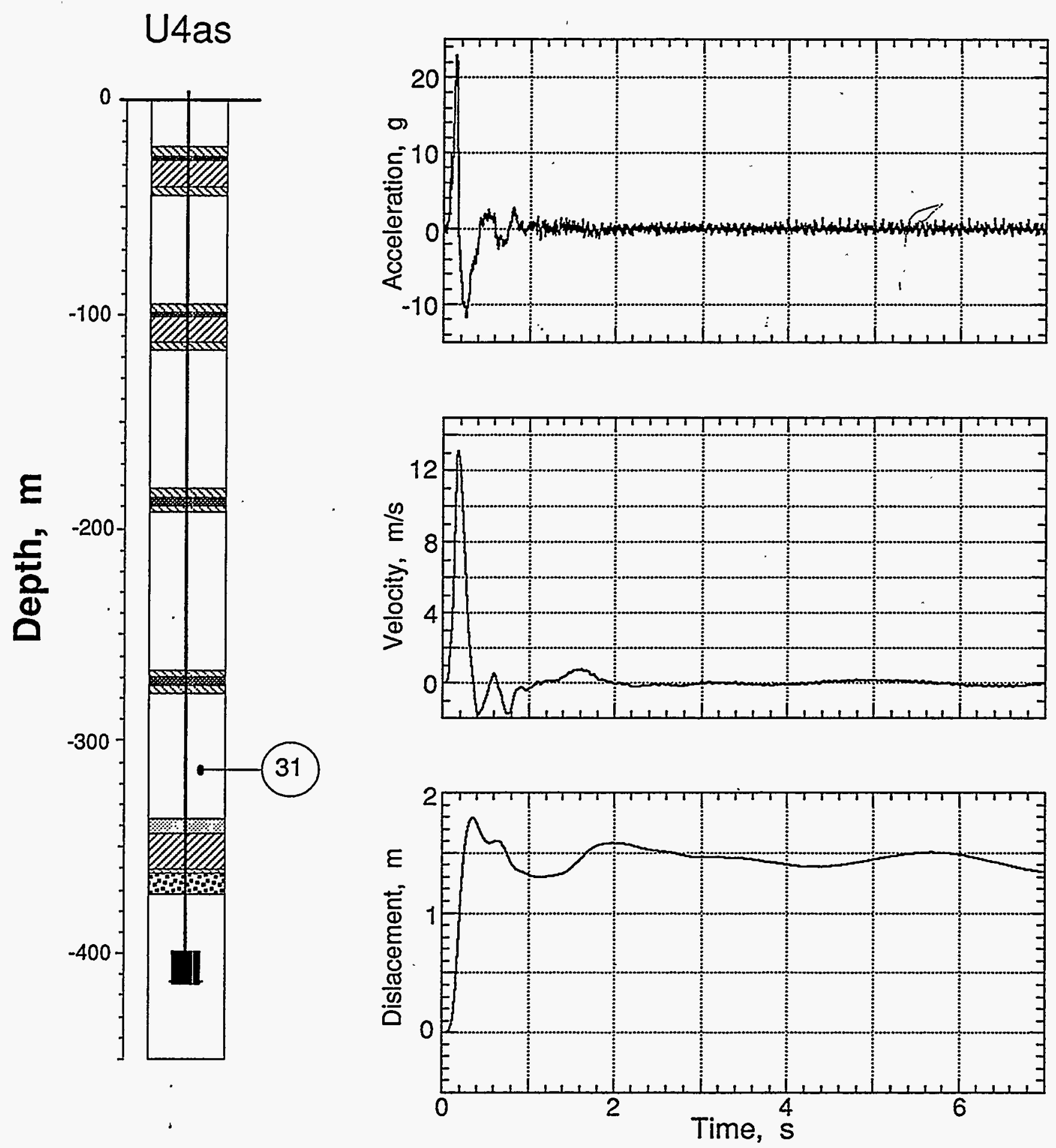

Figure 3.13 Explosion-induced vertical motion in the coarse stemming at a depth of $312.4 \mathrm{~m}$ (Station 31). 


\section{Depth, m}

8

\&

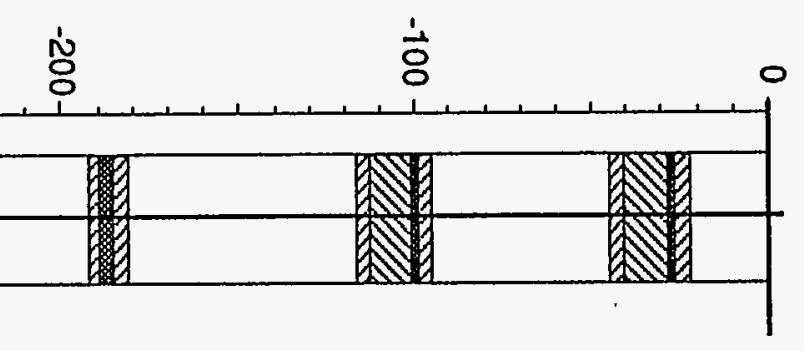

$\frac{C}{c}$

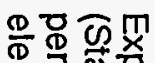

궁무음

일

ธี่

离

on

石

웅

믈 $\sum$

(5)

$\underset{N}{w}$
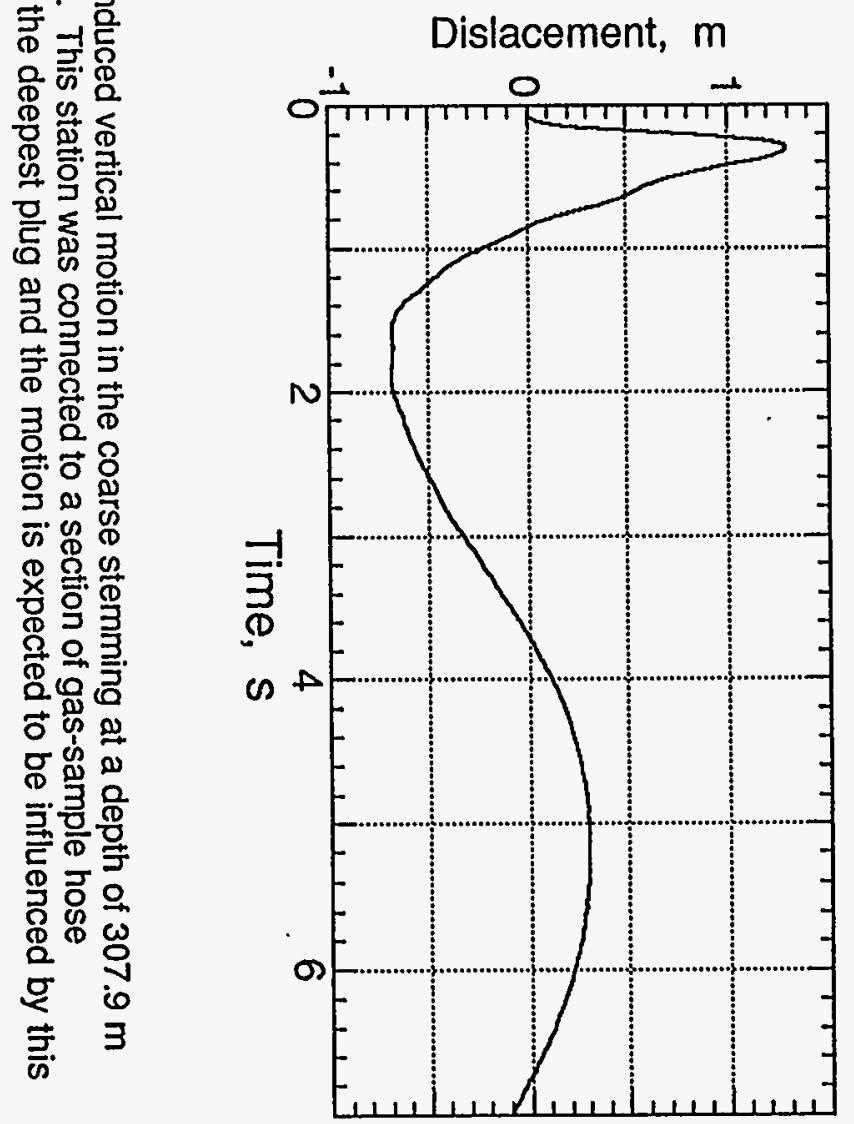

$\mathscr{\omega}$
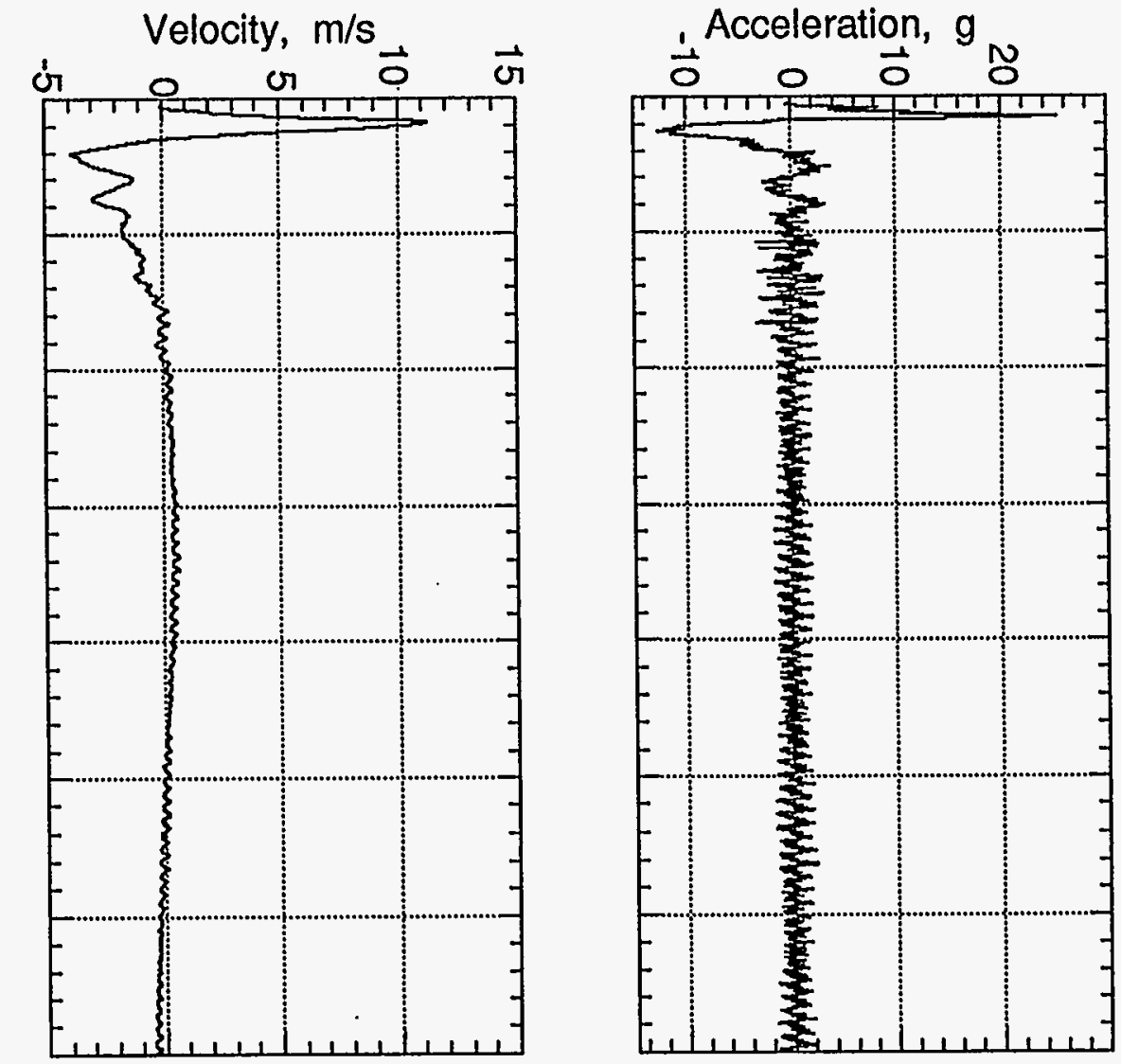

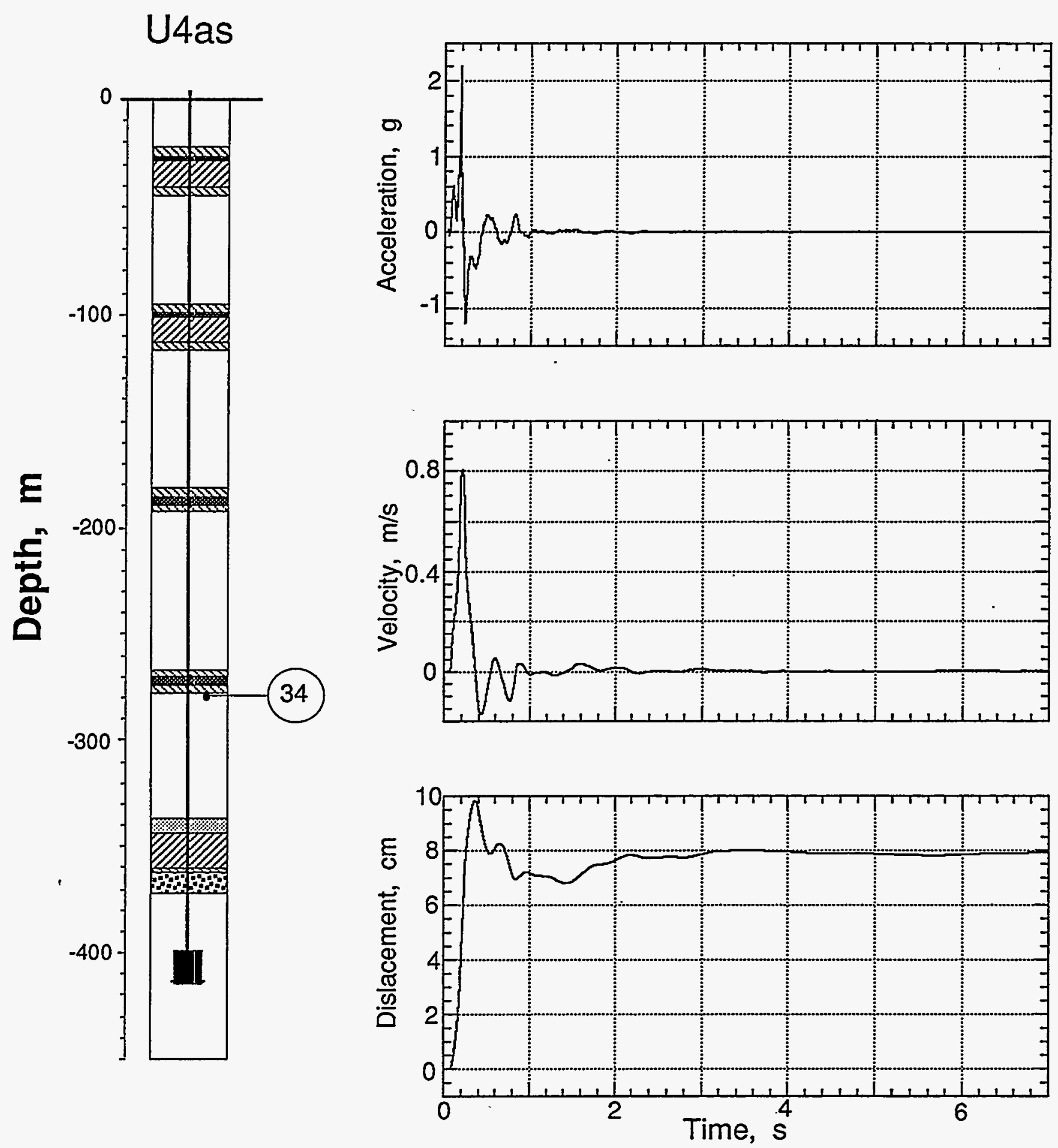

Figure 3.15 Explosion-induced vertical motion of the coarse stemming below the CT/A plug 2 (Station 34 at $278.9 \mathrm{~m}$ depth). 

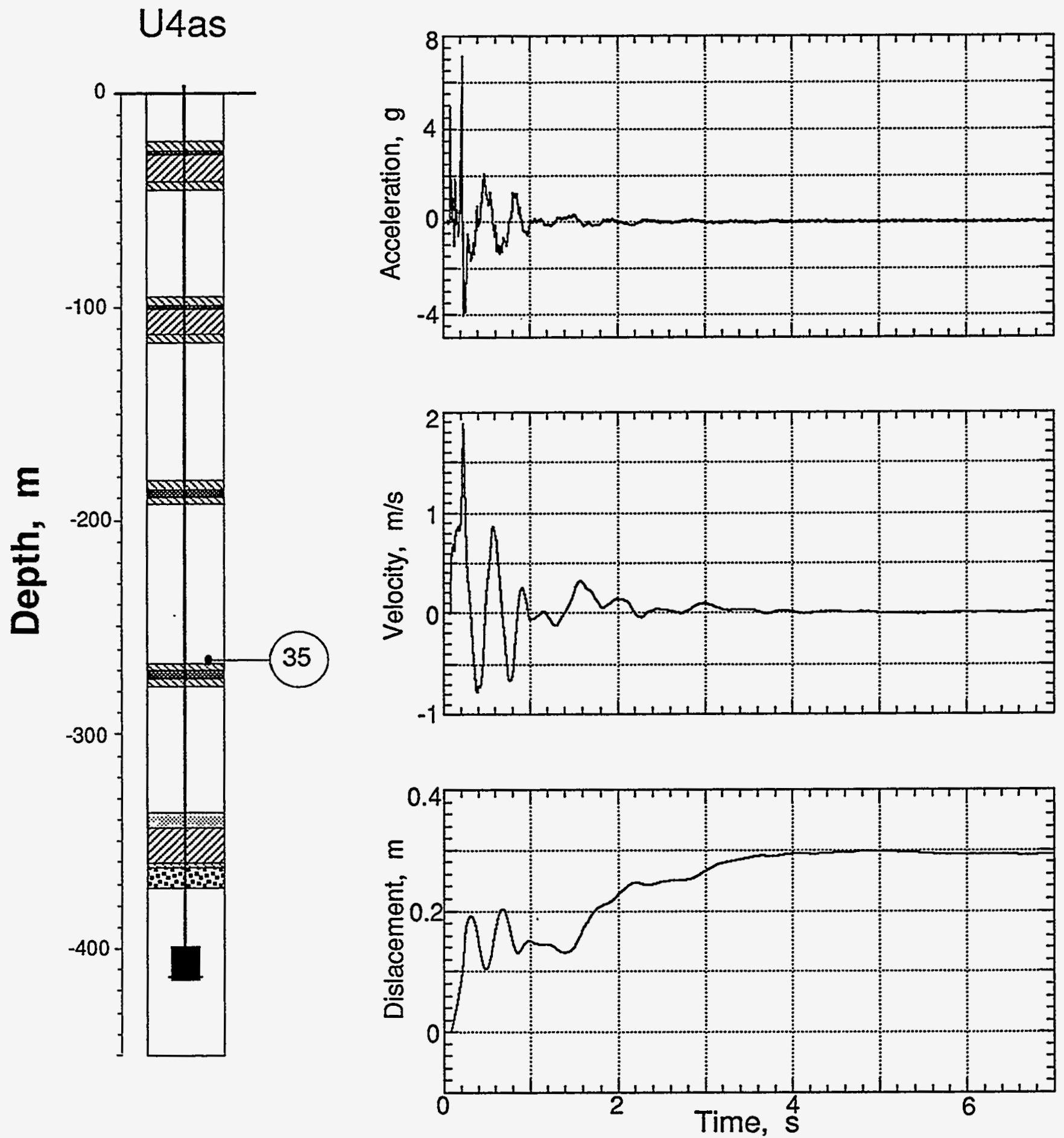

Figure 3.16 Explosion-induced vertical motion of the coarse stemming above the CT/A plug 2 (Station 35 at $265.2 \mathrm{~m}$ depth). 

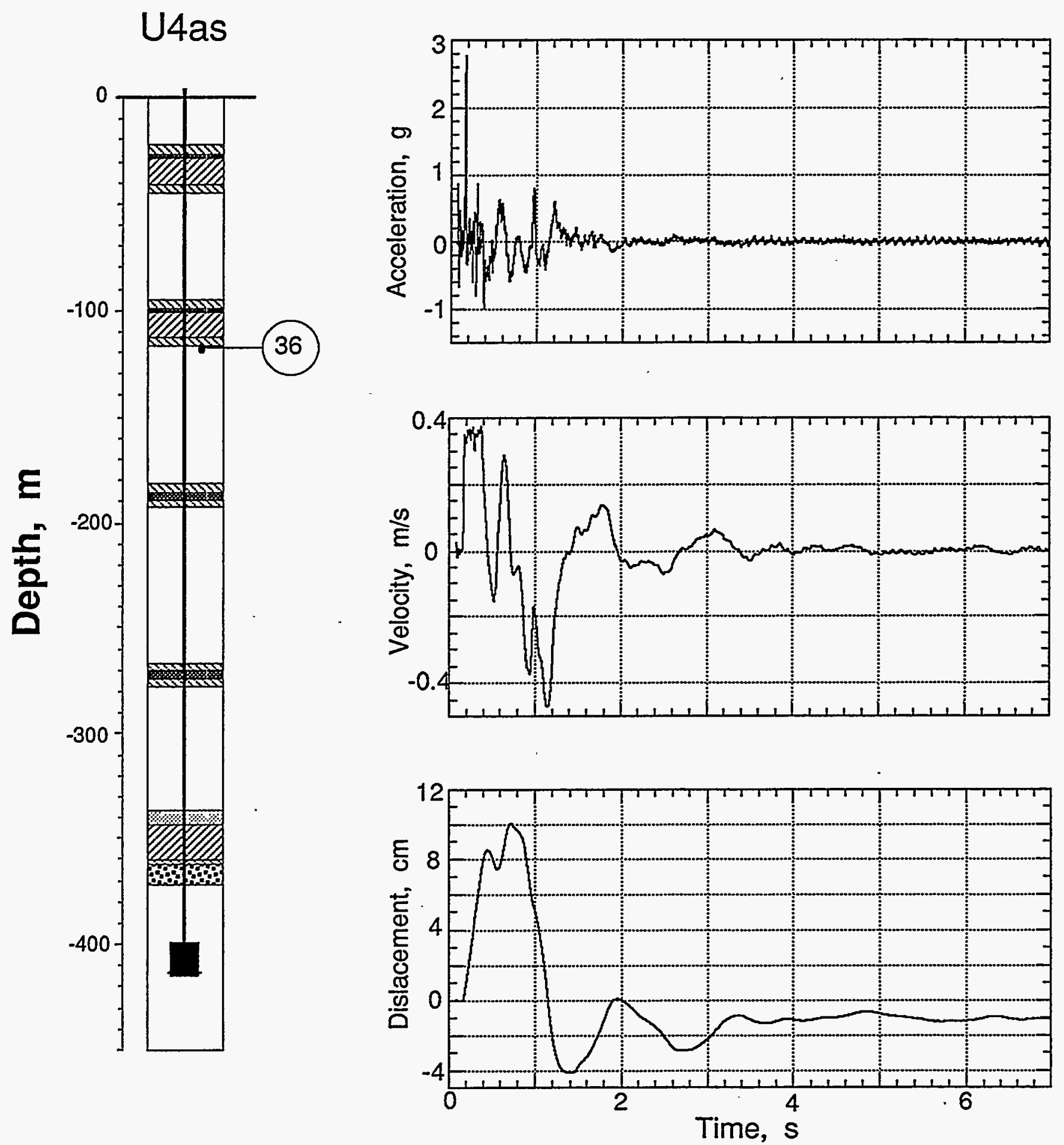

Figure 3.17 Explosion-induced vertical motion of the coarse stemming below the GFA plug 4 (Station 36 at $117.4 \mathrm{~m}$ depth). 

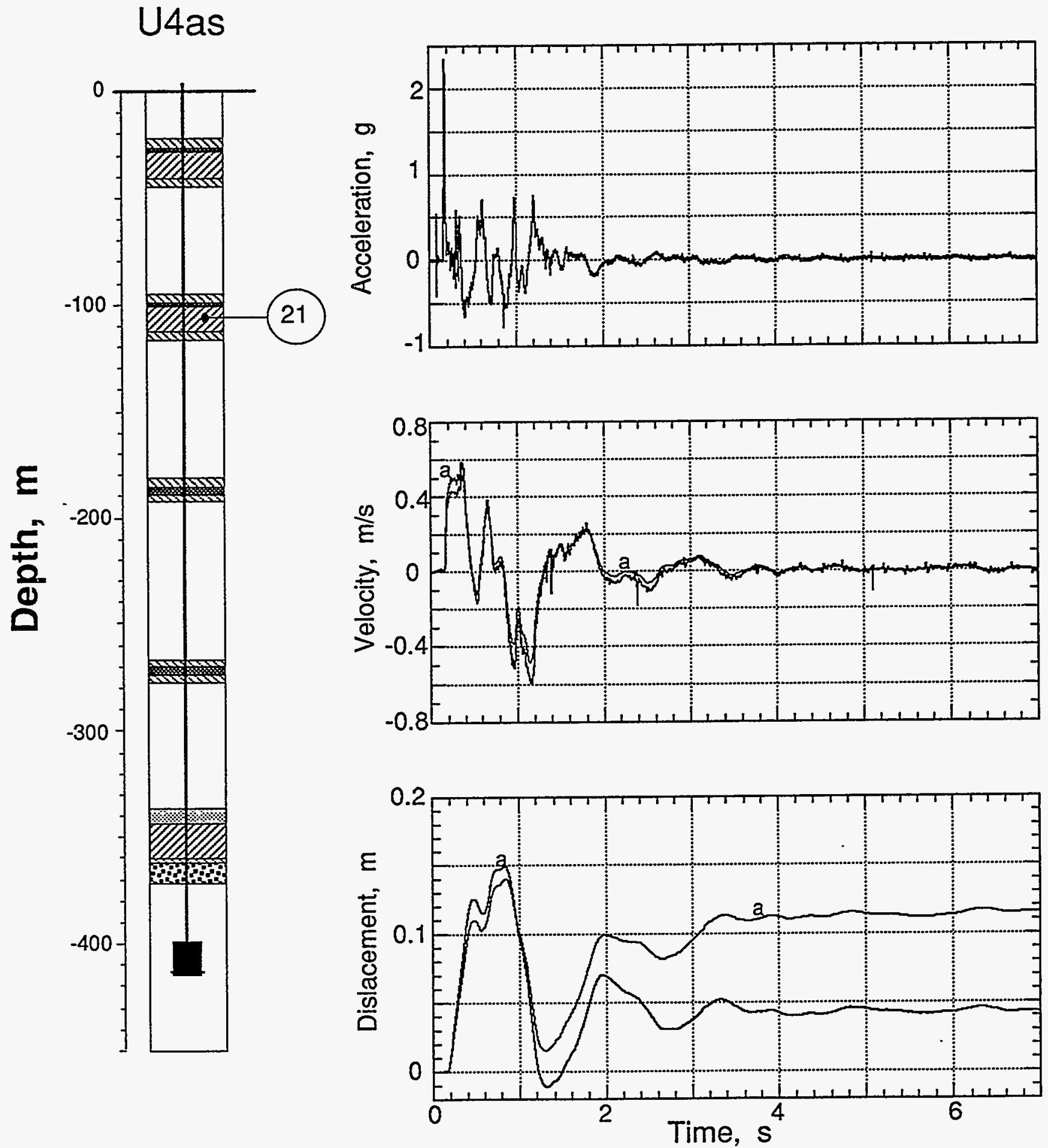

Figure 3.18 Explosion-induced vertical motion of GFA plug 4 (Station 21 at $106.7 \mathrm{~m}$ depth). Those traces annotated with "a" are derived from the acceleration history. 
Depth, m

$\frac{7}{0}$
$\stackrel{0}{0}$
$\overline{0}$
$\omega$
$\overrightarrow{0}$

ثे

ஷ்

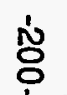

$\dot{8}$

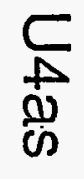

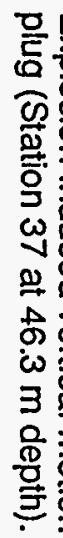

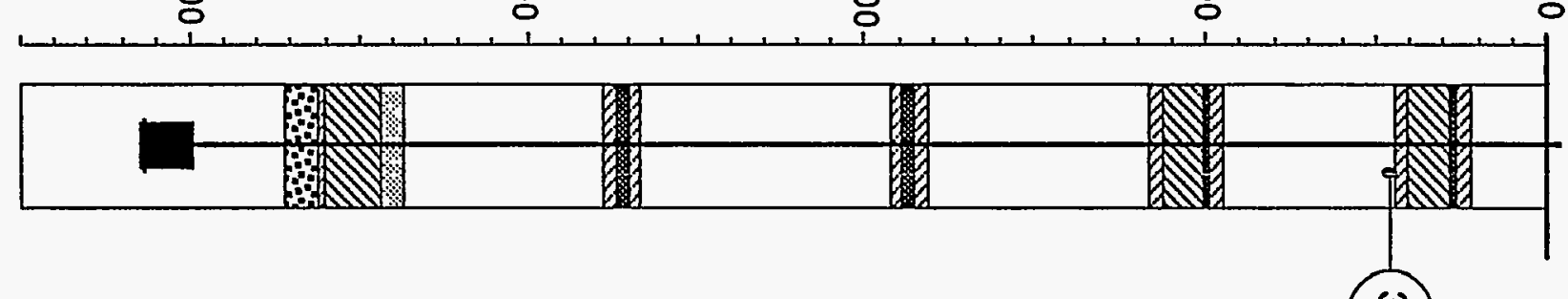

(v)
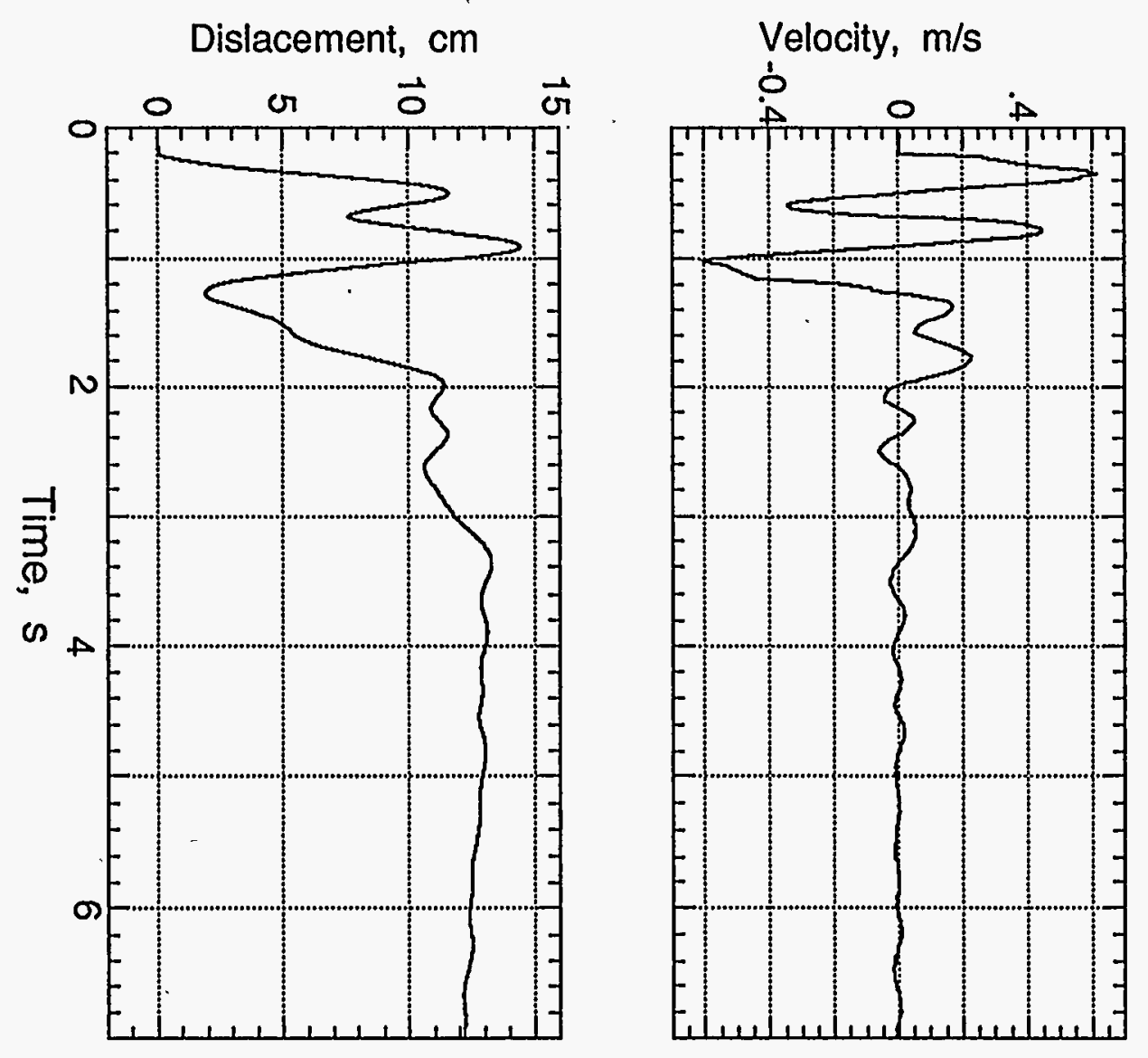

Acceleration, $g$

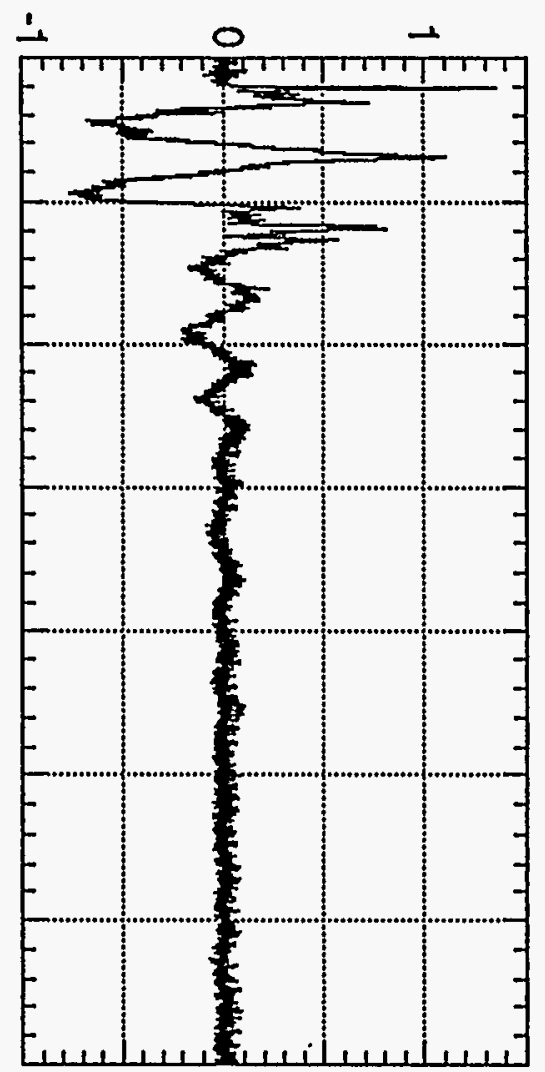



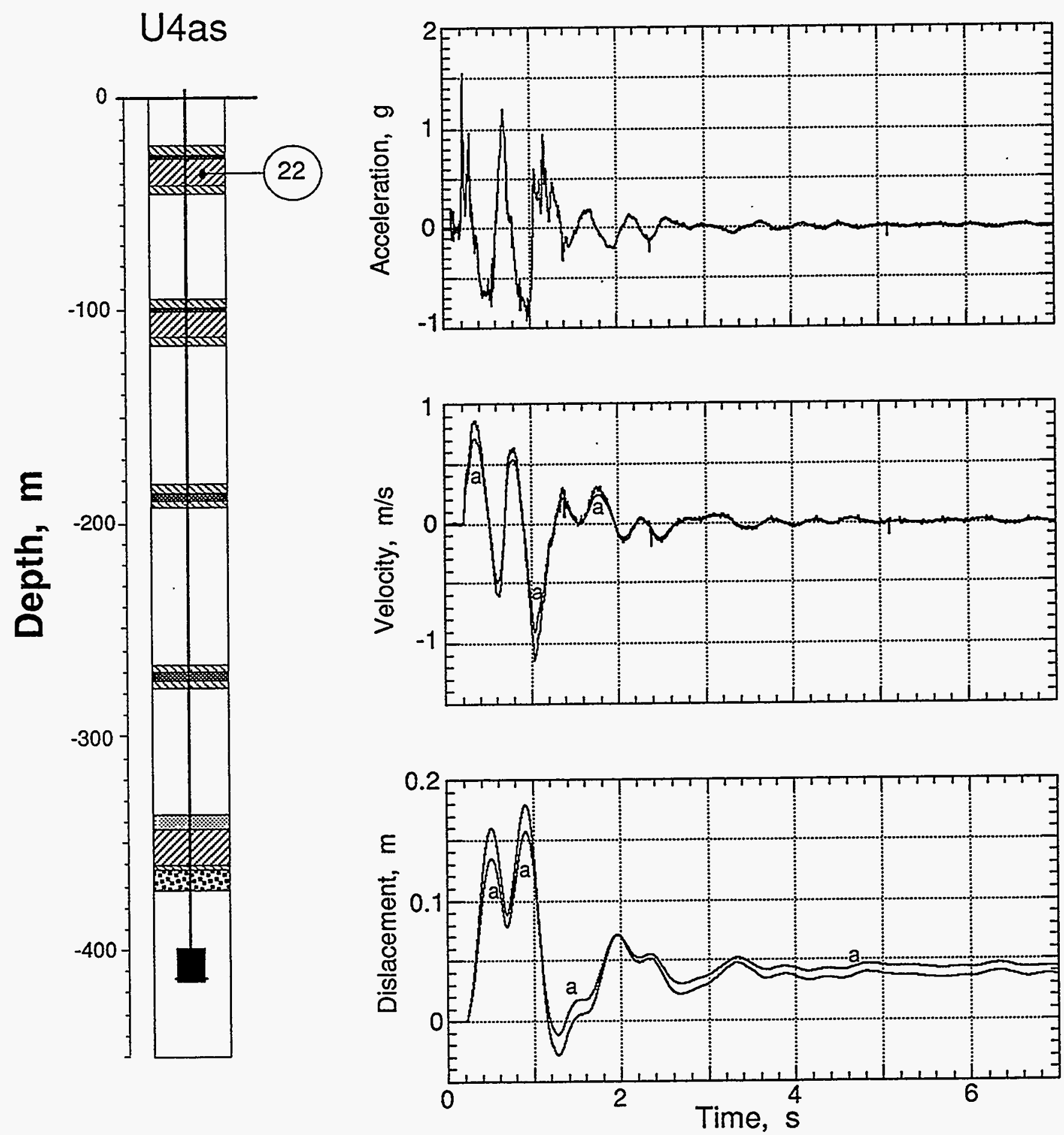

Figure 3.20 Explosion-induced vertical motion of the top GFA plug (Station 22 at $35.7 \mathrm{~m}$ depth). Those traces annotated with "a" are derived from the acceleration history. 

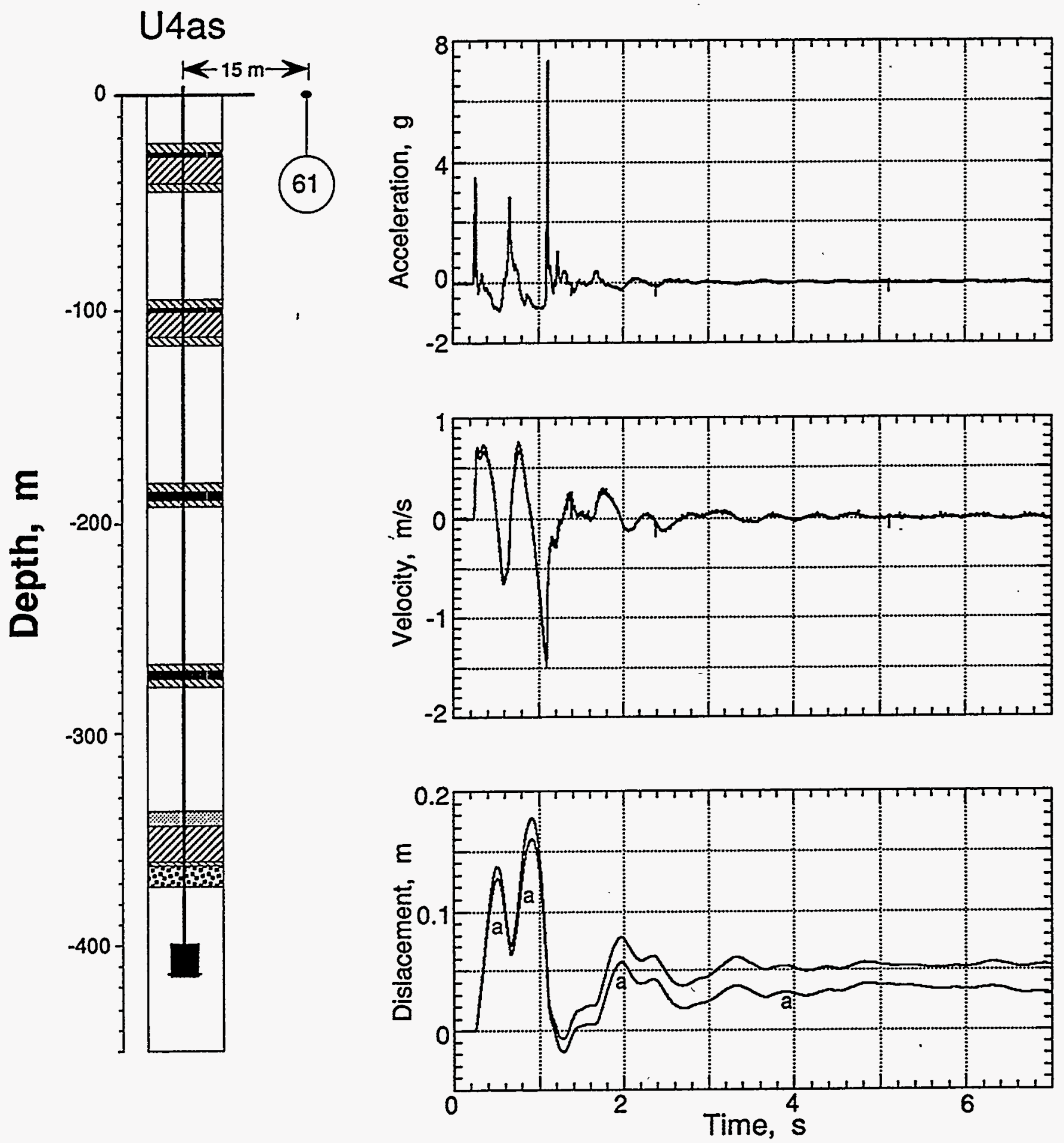

Figure 3.21 Explosion-induced vertical motion of the ground surface $15.24 \mathrm{~m}$ from Surface Ground Zero (Station 61, at a depth of $0.91 \mathrm{~m}$ ). This station is also part of the surface array and, as such, is also shown in section 4. Those traces annotated with "a" are derived from the acceleration history. 


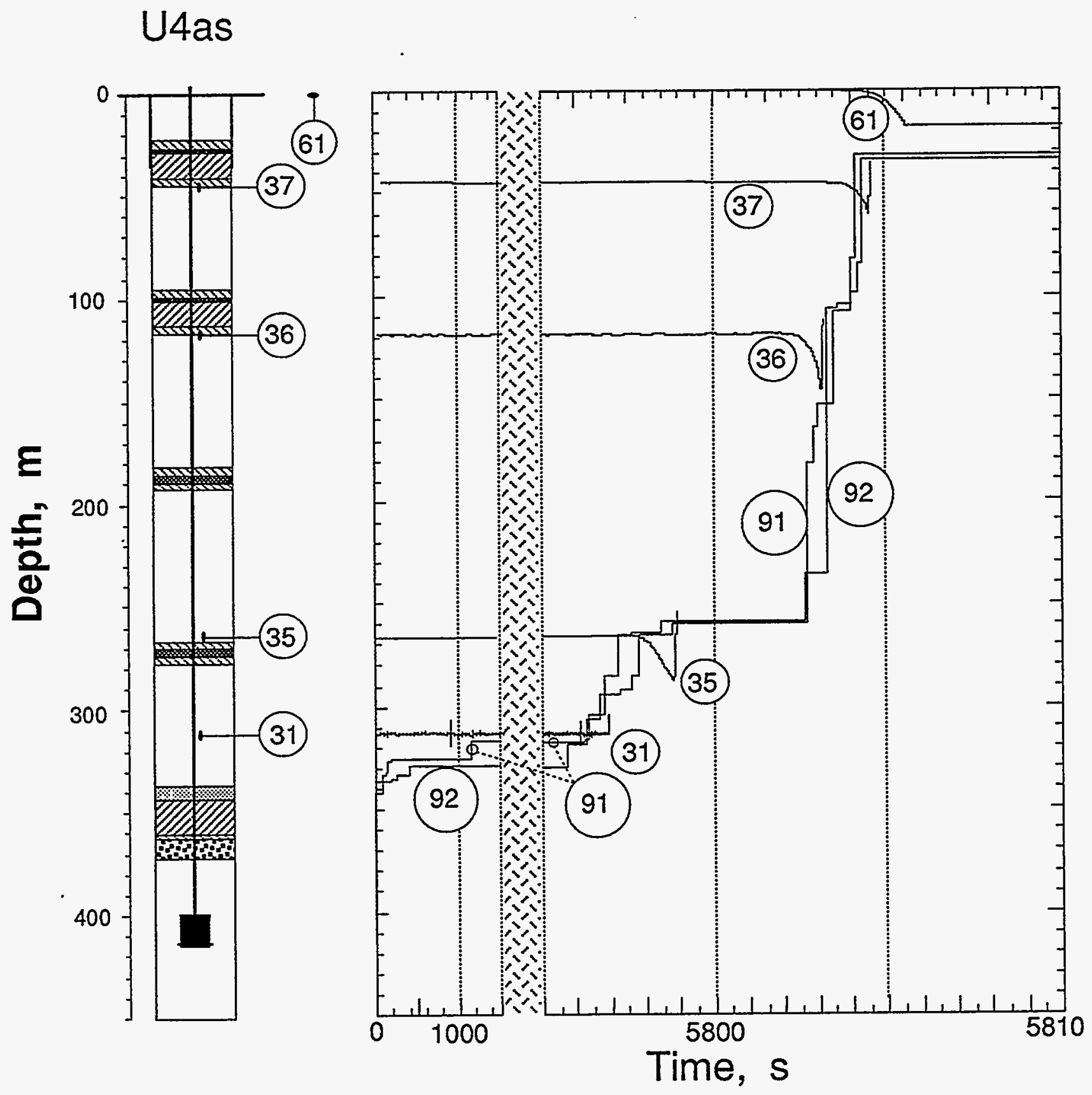

Figure 3.22 Progression of collapse in stemming column as indicated by CLIPER and EXCOR (Stations 91 and 92 ). Also shown are collapse signals obtained from stemming and surface motion stations. 

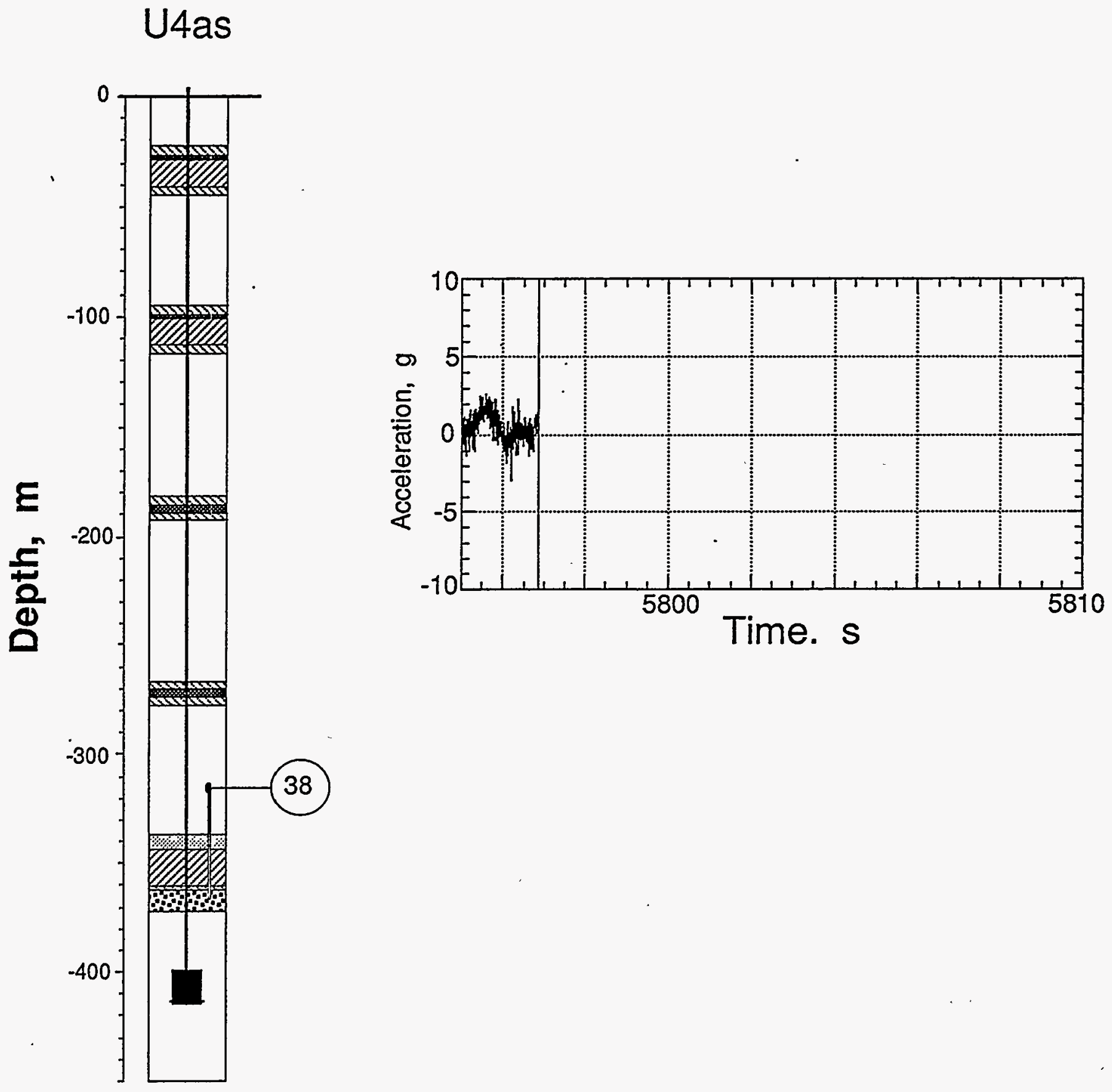

Figure 3.23 Collapse acceleration seen at Station 38 at $315.5 \mathrm{~m}$ depth. This station was connected to a section of gas-sample hose penetrating the deepest GFA plug and the motion is expected to be influenced by this element. Integrafion of these data is not meaningful and is not reported. 

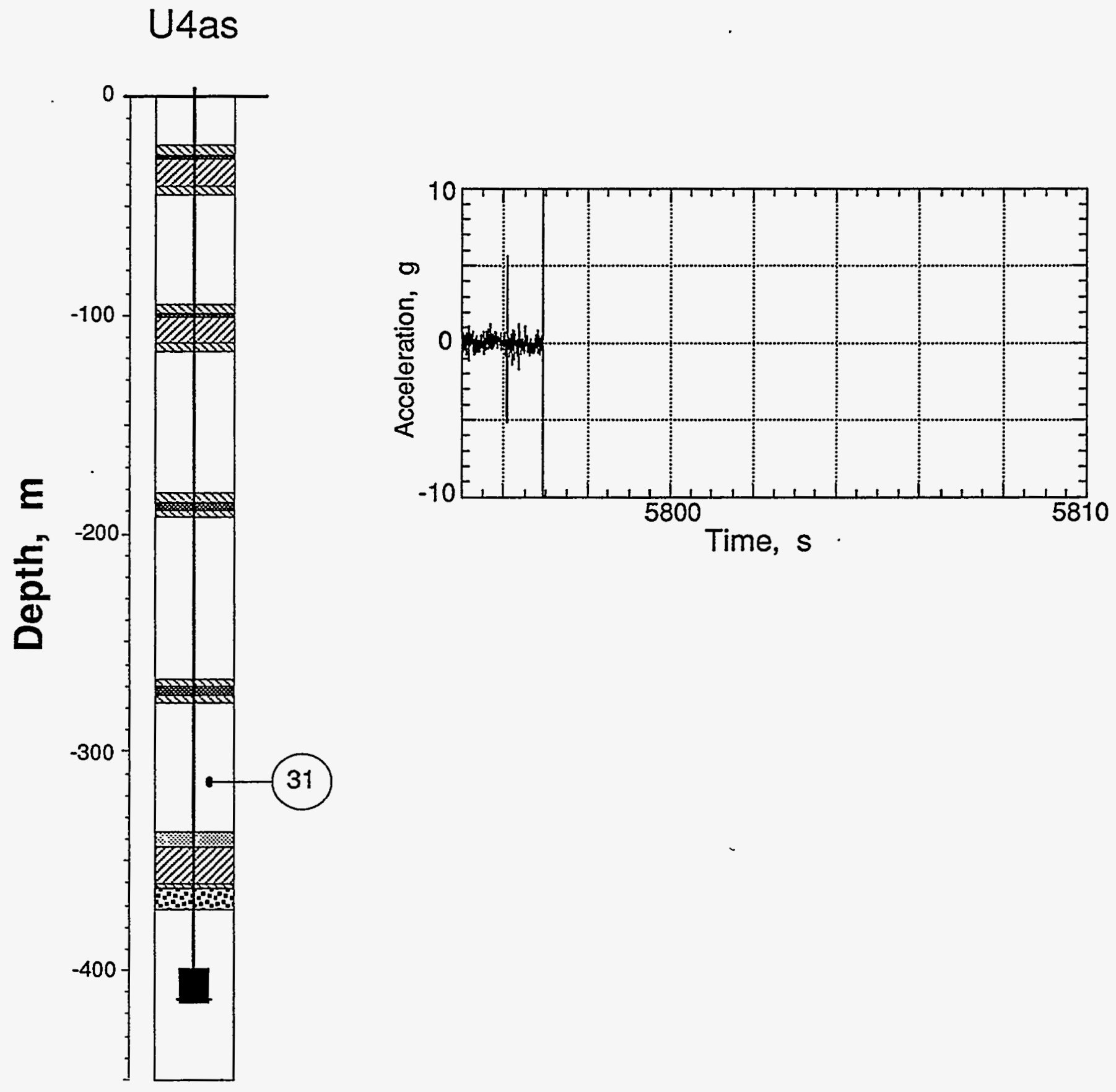

Figure 3.24 Collapse acceleration in the coarse stemming at a depth of $312.4 \mathrm{~m}$ (Station 31 ). Integration of these data is not meaningful and is not reported. 

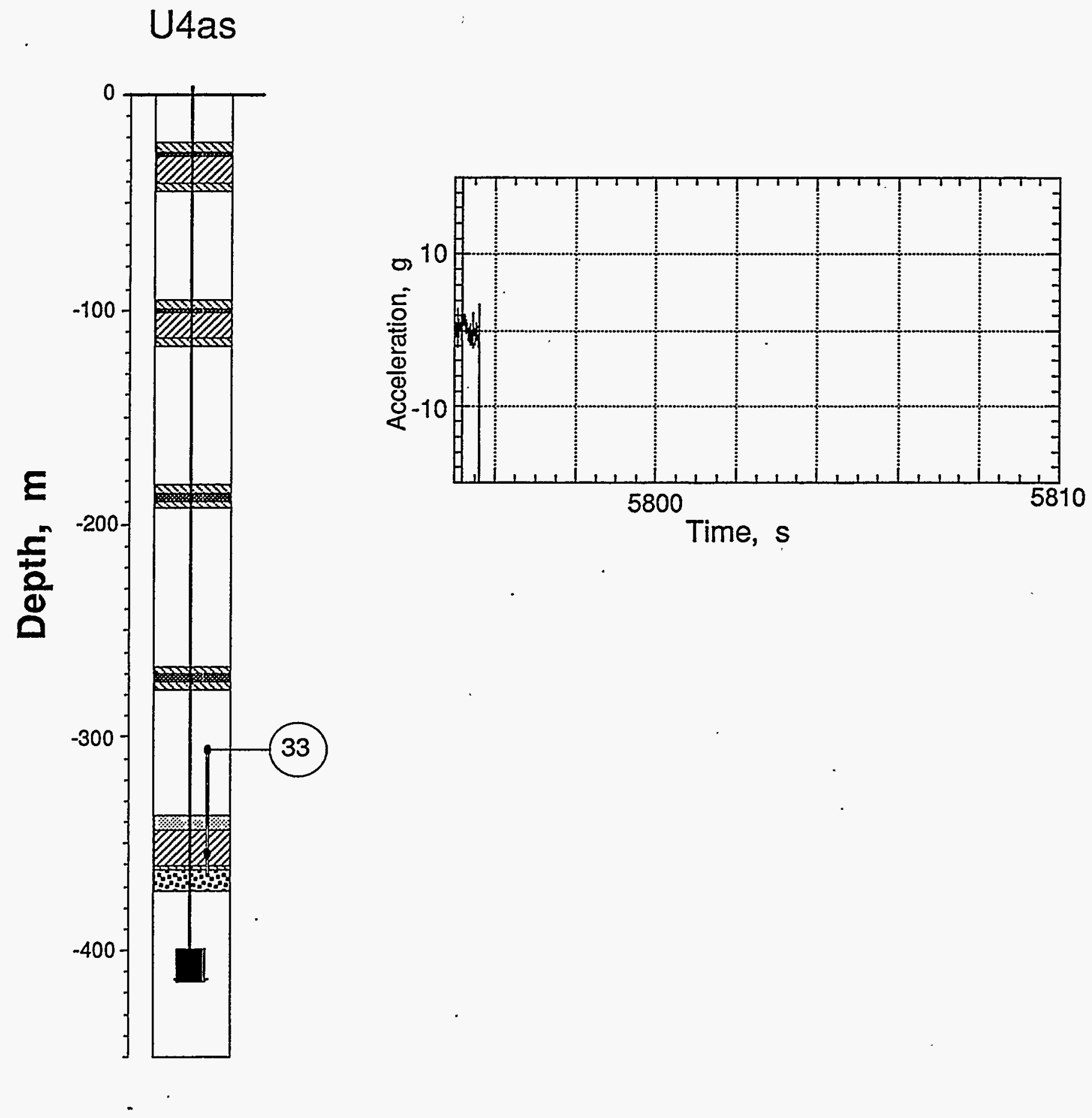

Figure 3.25 Collapse acceleration seen at Station 33 at $307.9 \mathrm{~m}$ depth. This station was connected to a section of gas-sample hose penetrating the deepest GFA plug - and the motion is expected to be influenced by this element. Integration of these data is not meaningful and is not reported. 
Depth, m

ثे $\dot{0}$ वे

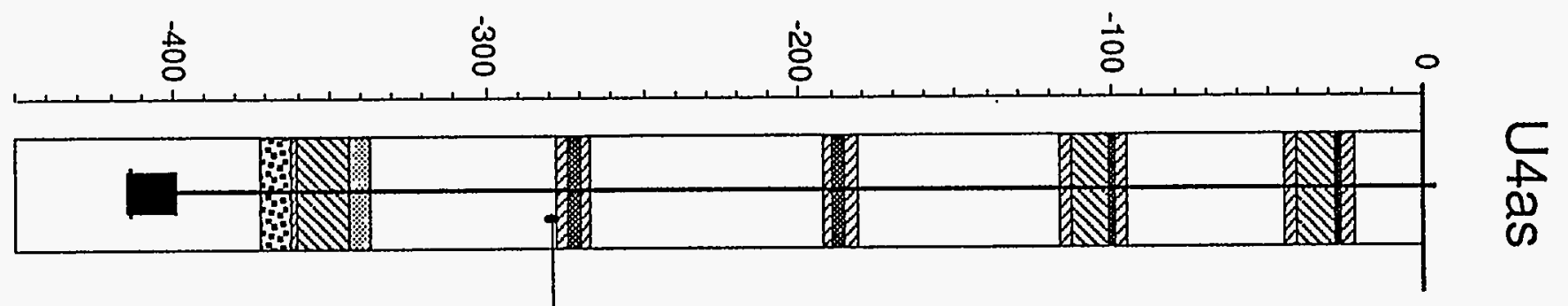

$\omega$
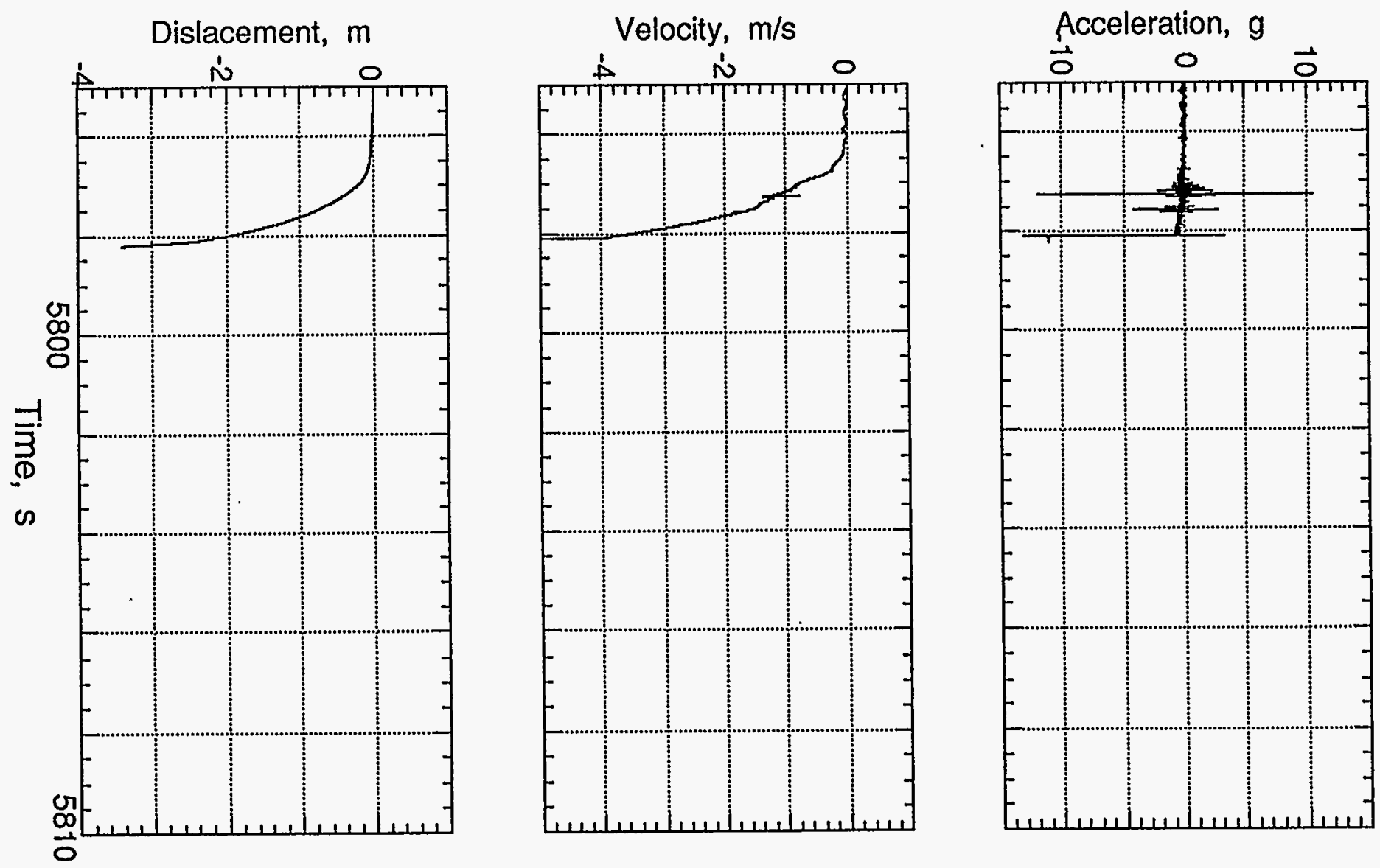


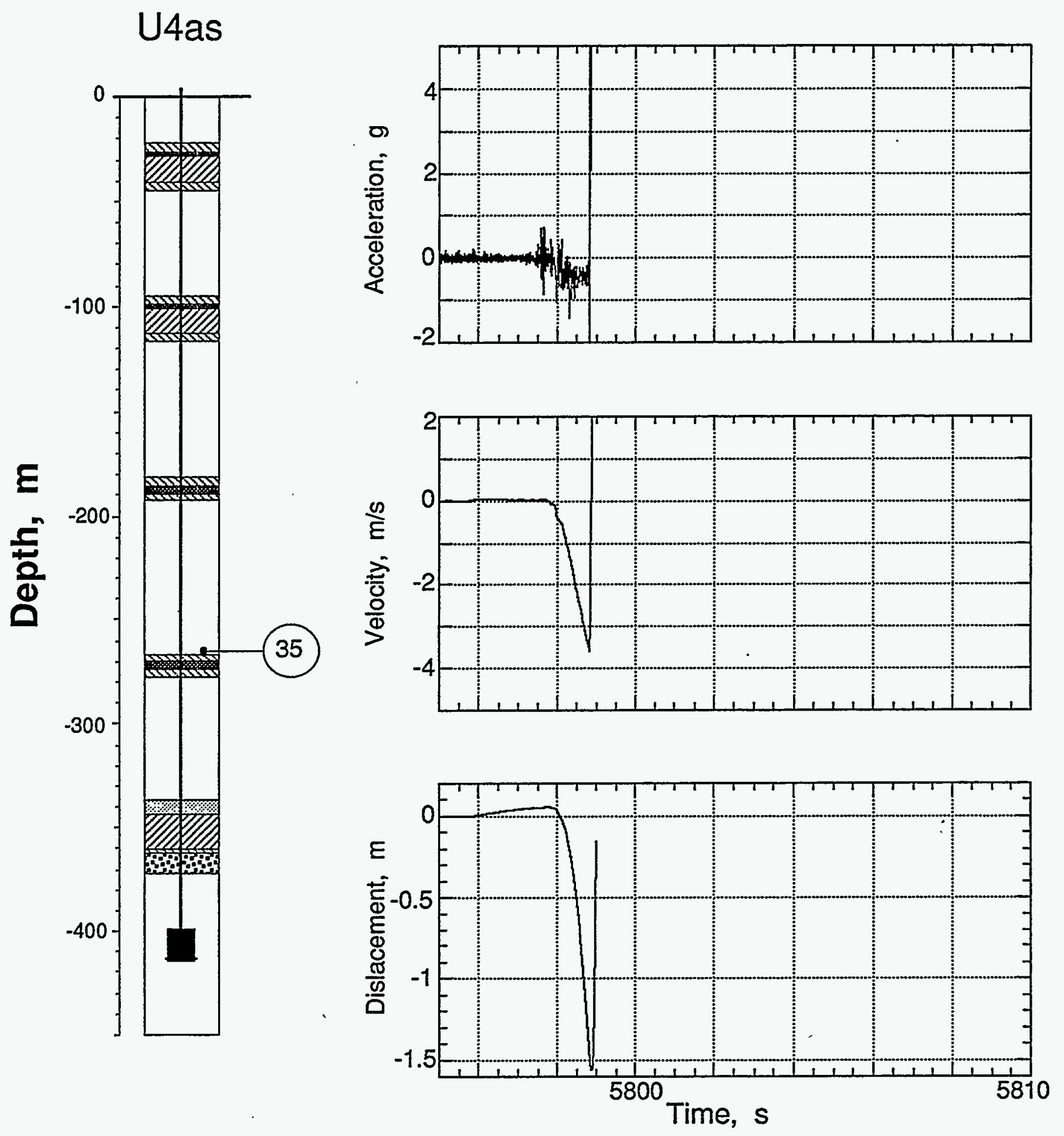

Figure 3.27 Collapse motion of the coarse stemming above CT/A plug 2 (Station 35 at 265.2 $m$ depth). 


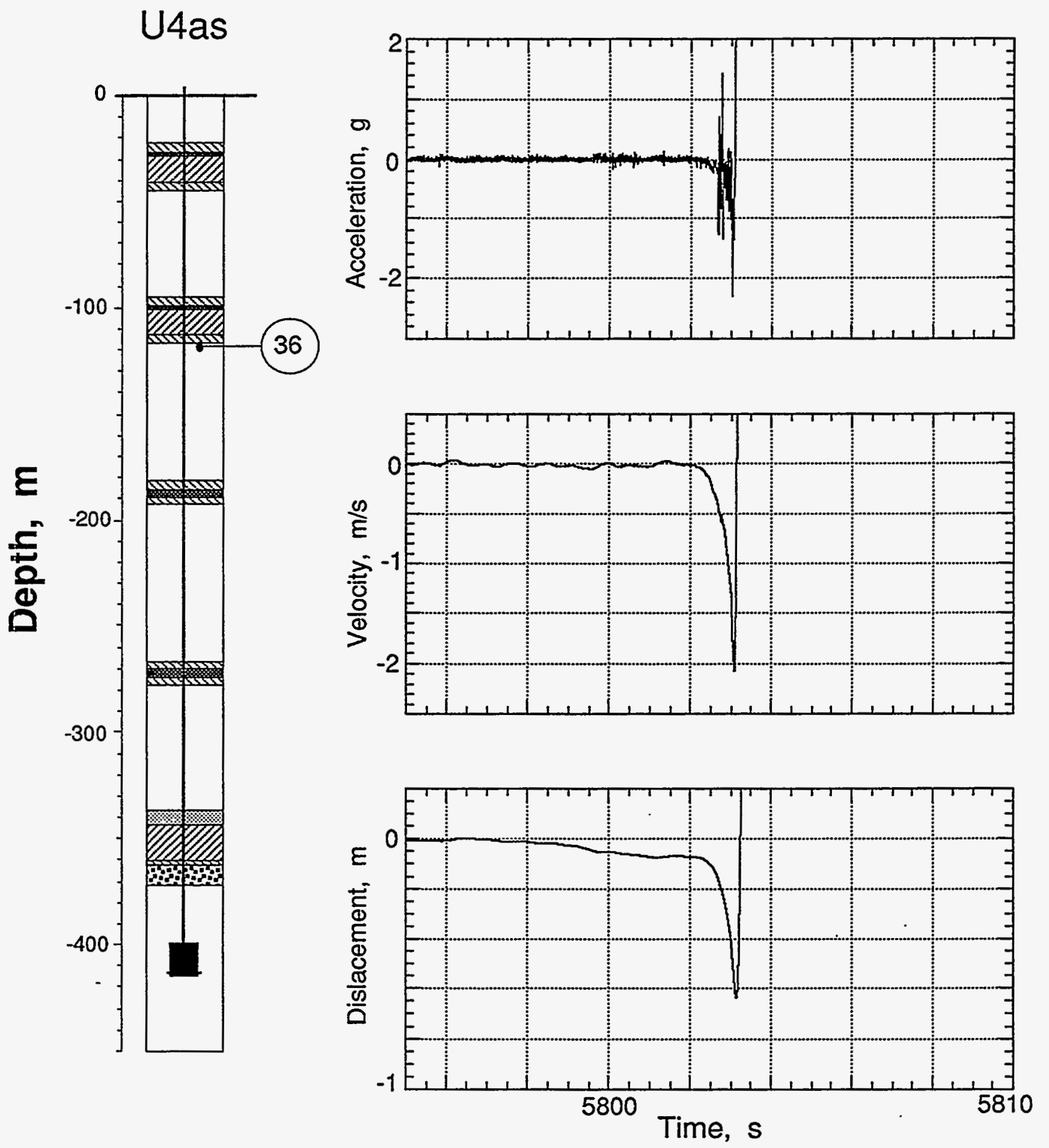

Figure 3.28 Collapse motion of the coarse stemming below GFA plug 4 (Station 36 at $117.4 \mathrm{~m}$ depth). 

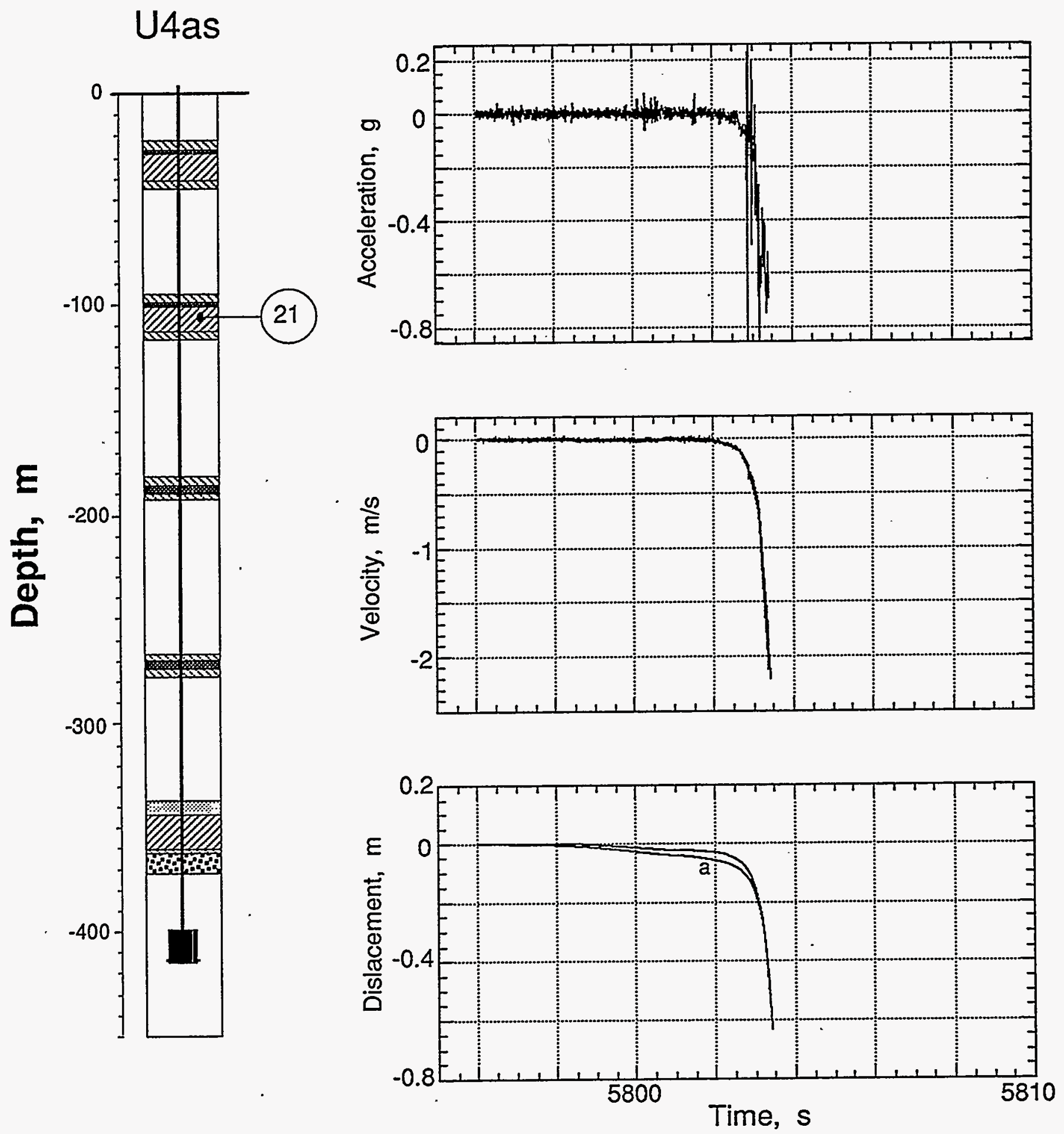

Figure 3.29 Collapse motion of GFA plug 4 (Station 21 at $106.7 \mathrm{~m}$ depth). Those traces annotated with " $a$ " are derived from the acceleration history. 

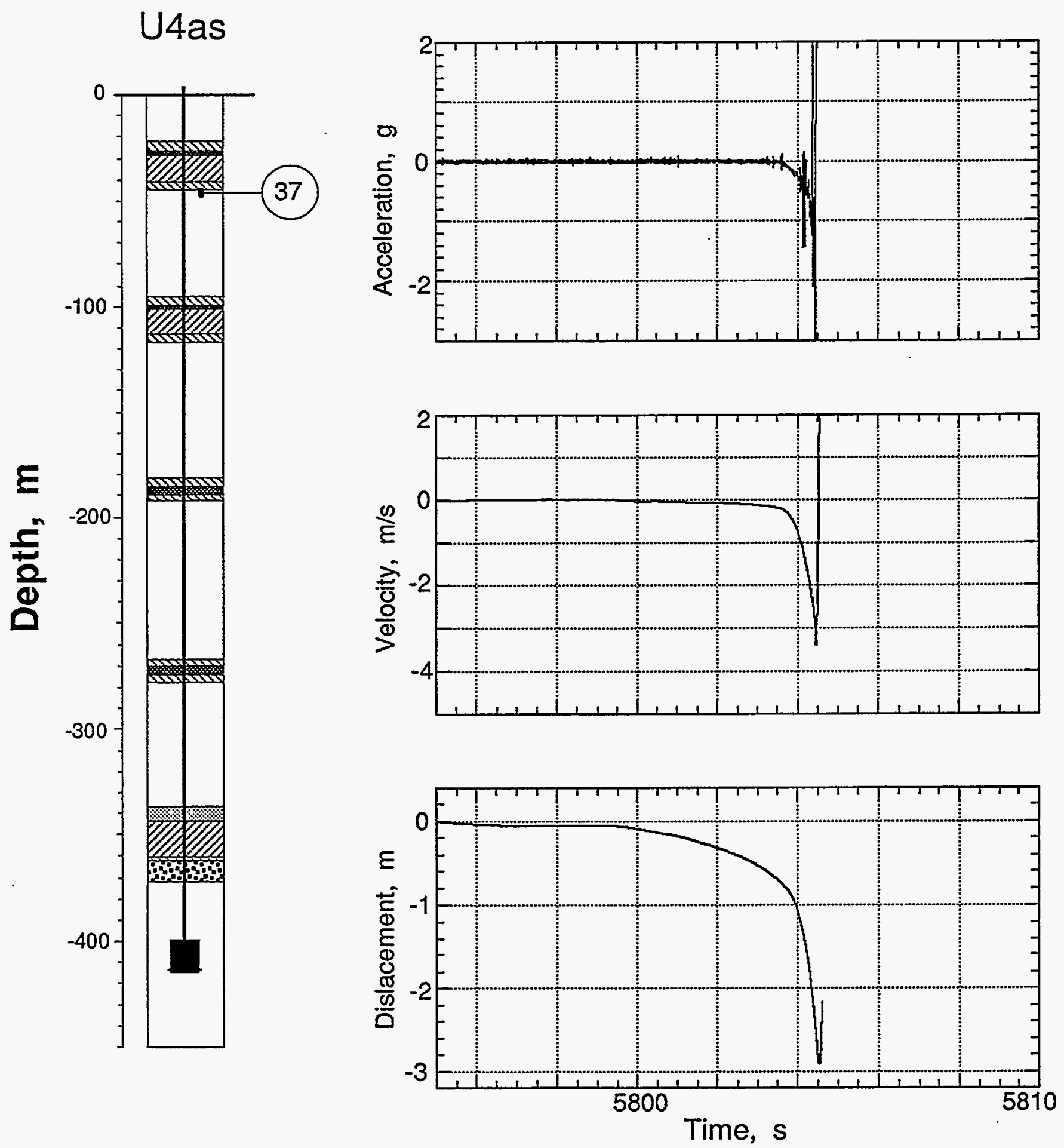

Figure 3.30 Collapse motion in the coarse stemming below GFA plug 5 (Station 37 at $46.3 \mathrm{~m}$ depth). 


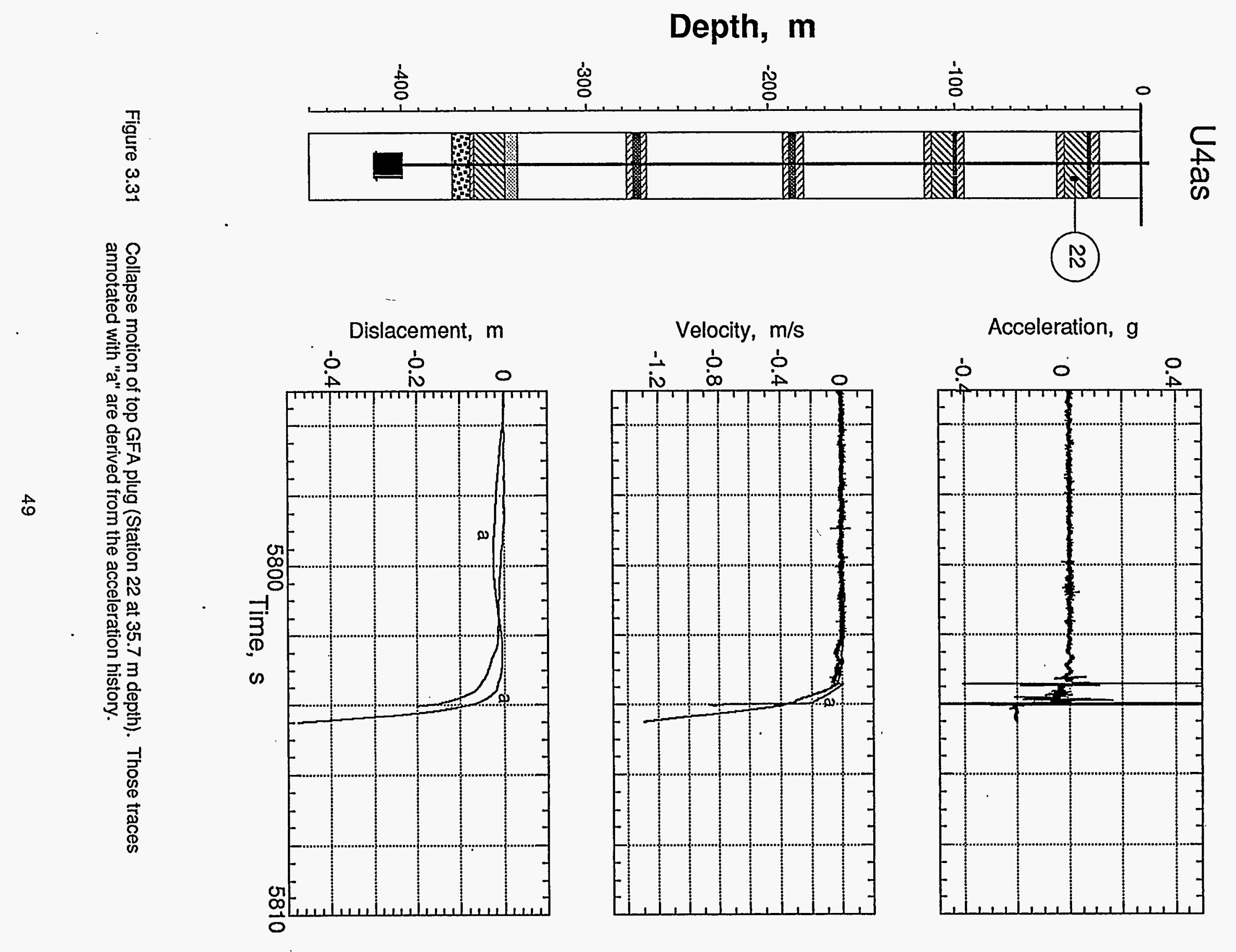



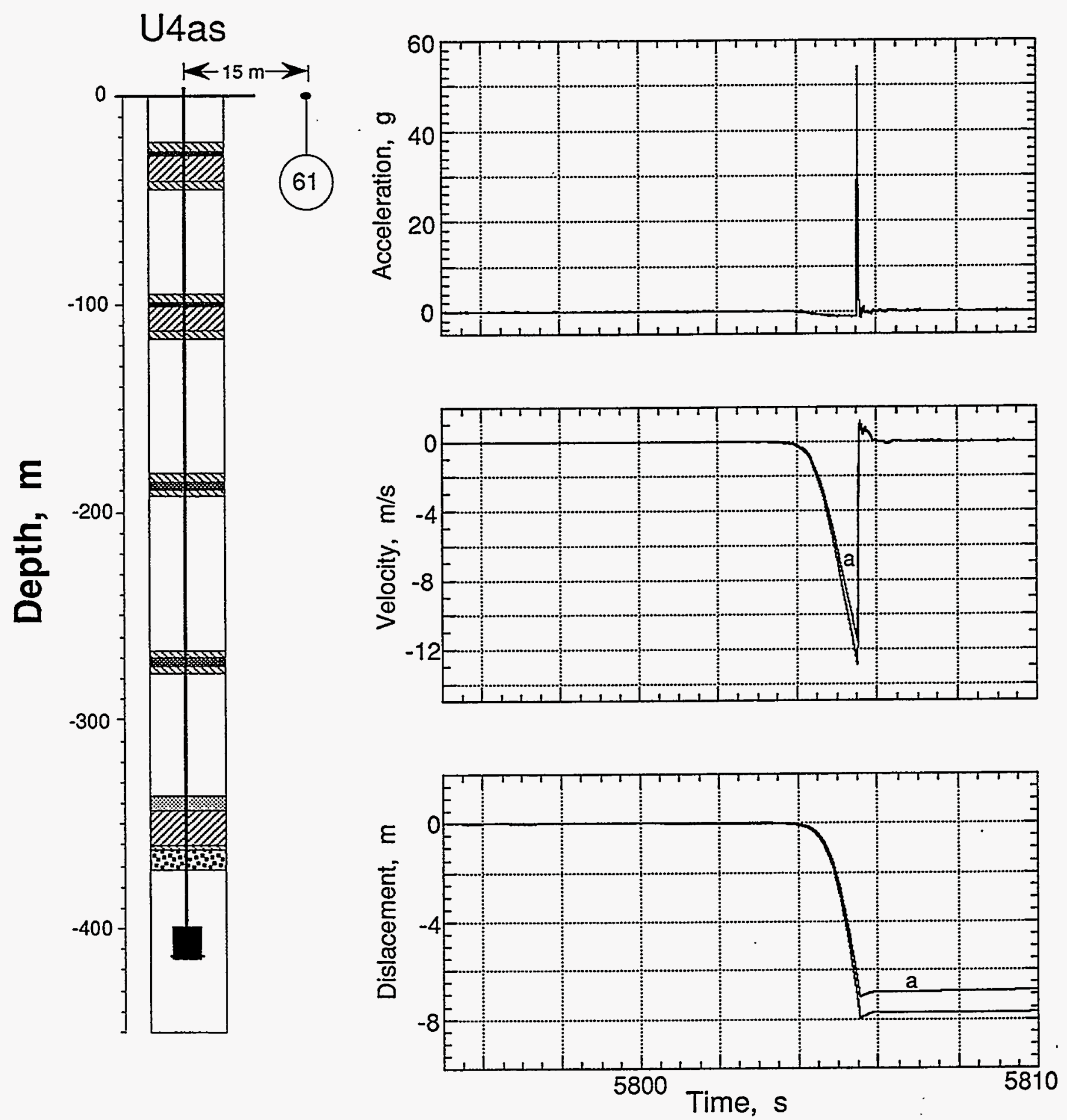

Figure 3.31 Collapse motion of the ground surface $15.24 \mathrm{~m}$ from Surface Ground Zero (Station 61, at a depth of $0.91 \mathrm{~m}$ ). Those traces annotated with "a" are derived from the acceleration history. 


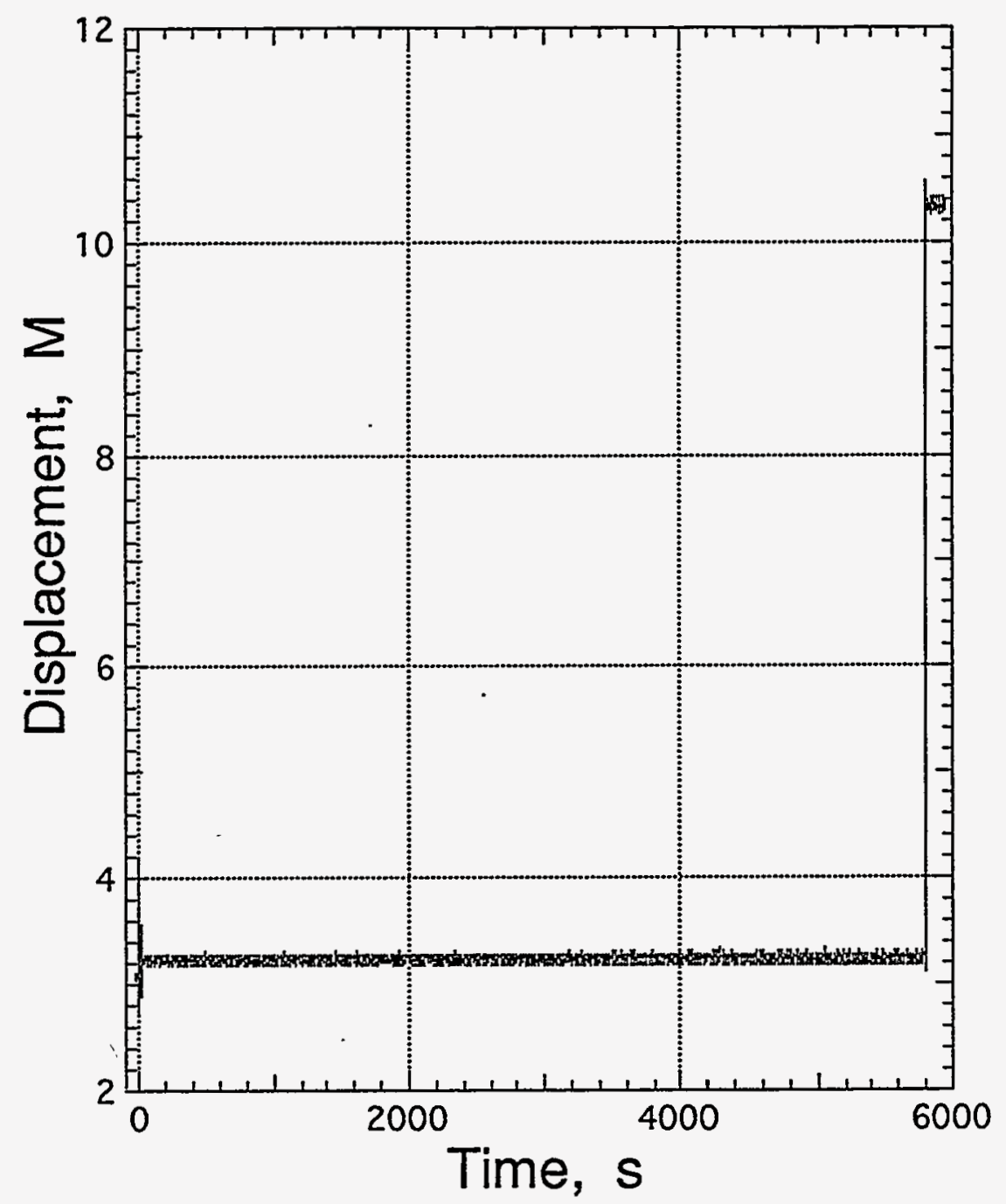

Figure 3.32 Displacement history monitored by a Genico "fishing reel" type transducer (Station 39) mounted between an anchor in the ground surface about $25 \mathrm{~m}$ from the emplacement hole and the full gas-sample hose in the emplacement hole. Initial extension was about 3. $\mathrm{m}$. 

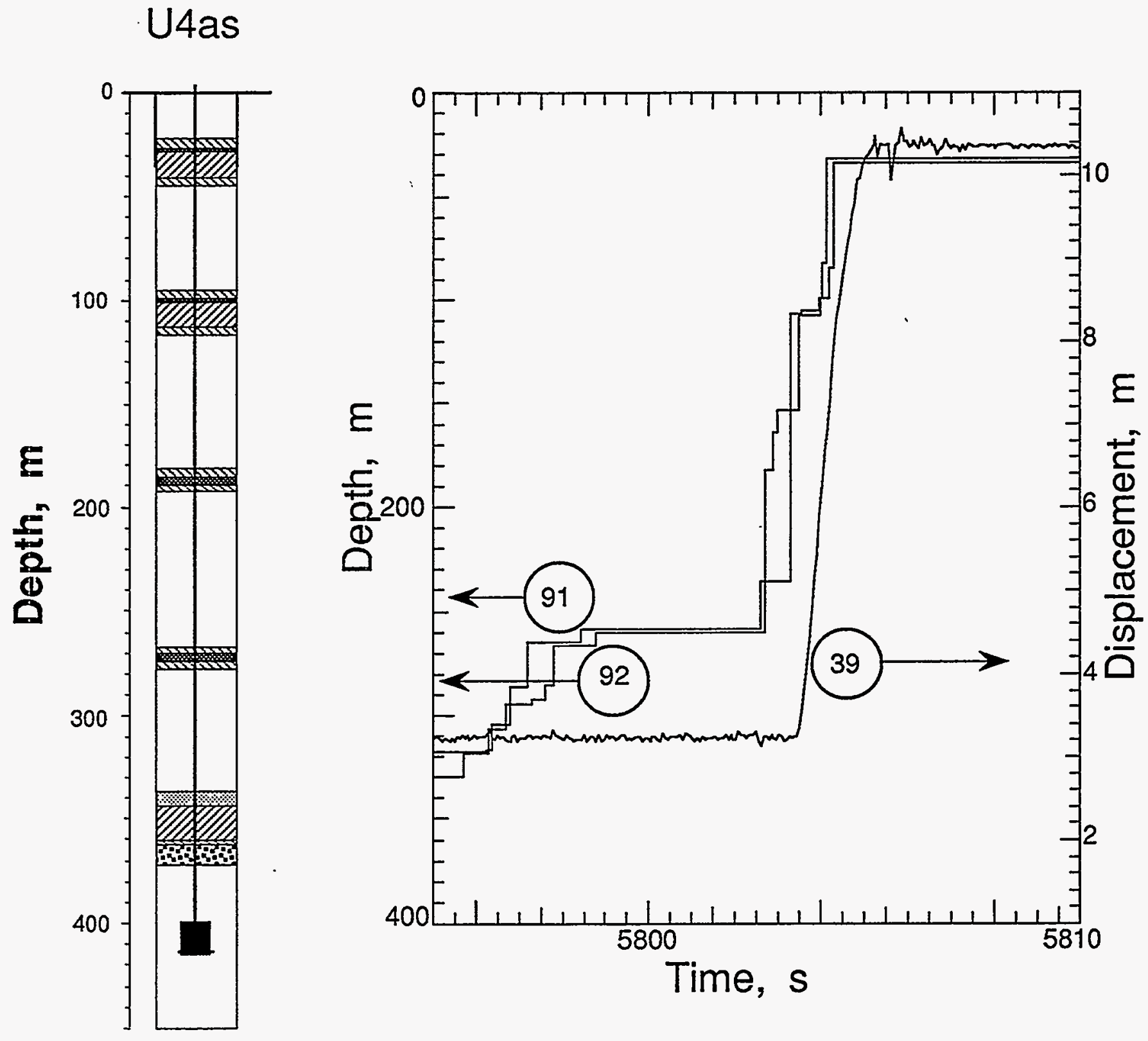

Figure 3.33 Composite plot of CLIPER and EXCOR records (Stations 91 and 92) and the Genisco transducer (Station 39). The beginning of the Station 39 excursion occurs when the data from the CLIPER and EXCOR indicate that the collapse has progressed to a depth of about $110 \mathrm{~m}$, in plug 4. 


\section{Qther Measurements}

\subsection{Surface motion}

Explosion-induced motion histories obtained from the ground surface and the recording trailer are shown in Figures 4.1-4.7. Arrivals and peaks of the motion are given in table 4.1 while characteristics of the motion transducers are given in tables 4.2 and 4.3. Stations 61 through 64 were located at a depth of $0.9 \mathrm{~m}$ in the ground surface on a line extending $44^{\circ}$ west of north at intervals of approximately $210 \mathrm{~m}$. Additionally, Station 61 is usualy considered to be part of the emplacement hole diagnostics and, as such, is also reported in section 3.2.

\subsection{Geophone history during and after detonation.}

The histories of the geophone and sensitive accelerometer (Station 69) are shown in Figure 4.8. This station was buried in the ground surface just outside of the recording trailer.

\subsection{Stress and strain in the bottom GFA plug.}

The stress and strain transducers fielded in the deepest GFA plug on ROQUEFORT consisted of flat-pack, interwoven Ytterbium and Constantan grids. Fluid coupling of the grids to the stress field was attempted to remove the effects of the mounting medium, the grids were interwoven to sense the same stress and strain, the Constantan was used to remove the strain effects from the $\mathrm{Yb}$, and the flat geometry was an attempt to assure that only one vector component was sensed. Radial and transverse transducers were fielded at each of two elevations in the plug.

Figures 4.9 and 4.10 show the output from the eight transducer grids. The EMP introduces an early time "ringing" in the electonics of the transducer, either from direct coupling to the grid, inadequate grounding, or both and invalidates the records for about the first $\mathbf{4 0} \mathrm{ms}$. Records are left in the form of percent resistance change since there is some ambiguity in the literature as to the corespondence of this measured quantity to the applied stress for $\mathrm{Yb}$ and these are the units in which the strain is removed from the $\mathrm{Yb}$ output. 


\section{Table 4.1 Summary of Motion}

\begin{tabular}{|c|c|c|c|c|c|c|}
\hline Gauge & $\begin{array}{c}\text { Slant Range } \\
\text { (m) }\end{array}$ & $\begin{array}{l}\text { Arrival Time } \\
\text { (ms) }\end{array}$ & $\begin{array}{c}\text { Acceleration } \\
\text { Peak (g) }\end{array}$ & $\begin{array}{l}\text { Velocity Peak } \\
(\mathrm{m} / \mathrm{s})\end{array}$ & $\begin{array}{l}\text { Displacement } \\
\text { Peak }(\mathrm{cm})\end{array}$ & $\begin{array}{l}\text { Displacement } \\
\text { Residual (cm) }\end{array}$ \\
\hline $61 a v$ & 413.8 & 235 & $3.5,7.3^{(a)}$ & 0.64 & 12.7 & 3 \\
\hline Giuv & & & - & 0.70 & 37 & 5.5 \\
\hline $62 a v$ & 476.0 & 277 & $1.64,2.12^{(a)}$ & $0.49,0.68$ & 14.3 & 5 \\
\hline $62 u v$ & & & - & $0.51,0.70$ & 14.8 & 3.5 \\
\hline $63 a v$ & 599.8 & 358 & $0.45,2.3^{(a)}$ & $0.22,0.30$ & $5.2,10^{(b)}$ & 5 \\
\hline $63 u v$ & & & - & $0.24,0.31$ & $5.2,9^{(b)}$ & 1.3 \\
\hline $64 a v$ & 765.2 & 450 & $0.28,0.43(a)$ & 0.13 & 1.7 & -0.5 (c) \\
\hline $64 u v$ & & & - & 0.13 & 1.7 & -0.3 \\
\hline $71 a v$ & $463^{(d)}$ & 275 & $2.6,5.7^{(a)}$ & 0.78 & 16 & 6 \\
\hline $71 u v$ & & & - & 0.80 & 16 & 4 \\
\hline $71 \mathrm{ar}$ & 463 (d) & 300 & 0.3 & 0.42 & 30 & 20 \\
\hline 71ur & & & - & 0.6 & 48 & 40 \\
\hline 71 at & $463(d)$ & 275 & 0.2 & 0.21 & 46 & 2 \\
\hline 71 ut & & & - & 0.21 & 46 & -4 \\
\hline
\end{tabular}
(a) Slap-down peak.
(b) Maximum value.
(c) Difficult to approximate.
(c) Range is approximate: station is in recording trailer. 
Table 4.2 Accelerometer Characteristics

\begin{tabular}{lcccc} 
Gauge & $\begin{array}{c}\text { Natural Frequency } \\
(\mathrm{Hz})\end{array}$ & Damping Ratio & $\begin{array}{c}\text { System Range } \\
\left(g^{\prime} \mathrm{s}\right)\end{array}$ \\
\cline { 2 - 4 } 61av & 600 & 0.62 & 30 \\
\cline { 4 - 4 } $62 \mathrm{av}$ & 540 & 0.62 & 30 \\
$63 \mathrm{av}$ & 600 & 0.68 & 30 \\
$64 \mathrm{av}$ & 530 & 0.65 & 30 \\
$71 \mathrm{av}$ & 325 & 0.65 & 20 \\
$71 \mathrm{ar}$ & 325 & 0.65 & 15 \\
71 at & 355 & 0.65 & 15
\end{tabular}

Table 4.3 Velocimeter Characteristics

\begin{tabular}{|c|c|c|c|c|c|}
\hline Gauge & $\begin{array}{c}\text { Natural } \\
\text { Frequency } \\
(\mathrm{Hz})\end{array}$ & $\begin{array}{l}\text { Time to } 0.5 \\
\text { Amplitude } \\
\text { (s) }\end{array}$ & $\begin{array}{c}\text { Calibration } \\
\text { Temperature } \\
\left({ }^{\circ} \mathrm{C}\right)\end{array}$ & $\begin{array}{c}\text { Operate } \\
\text { Temperature } \\
\left({ }^{\circ} \mathrm{C}\right)\end{array}$ & $\begin{array}{c}\text { System } \\
\text { Range } \\
(\mathrm{m} / \mathrm{s})\end{array}$ \\
\hline 61uv & 3.561 & 8.35 & 26.28 & 13.68 & 8 \\
\hline $62 a v$ & 3.672 & 8.24 & 26.3 & 15.86 & 8 \\
\hline 63uv & 3.670 & 8.76 & 24.15 & 16.83 & 8 \\
\hline 64uv & 3.578 & 9.28 & 24.59 & 16.54 & 8 \\
\hline 71uv & 2.999 & 23.50 & 24.34 & 16.57 & 7 \\
\hline 71ur & 4.711 & 11.11 & 24.42 & 16.57 & 5 \\
\hline 71ut. & 4.835 & 11.80 & 24.88 & 16.57 & 5 \\
\hline
\end{tabular}



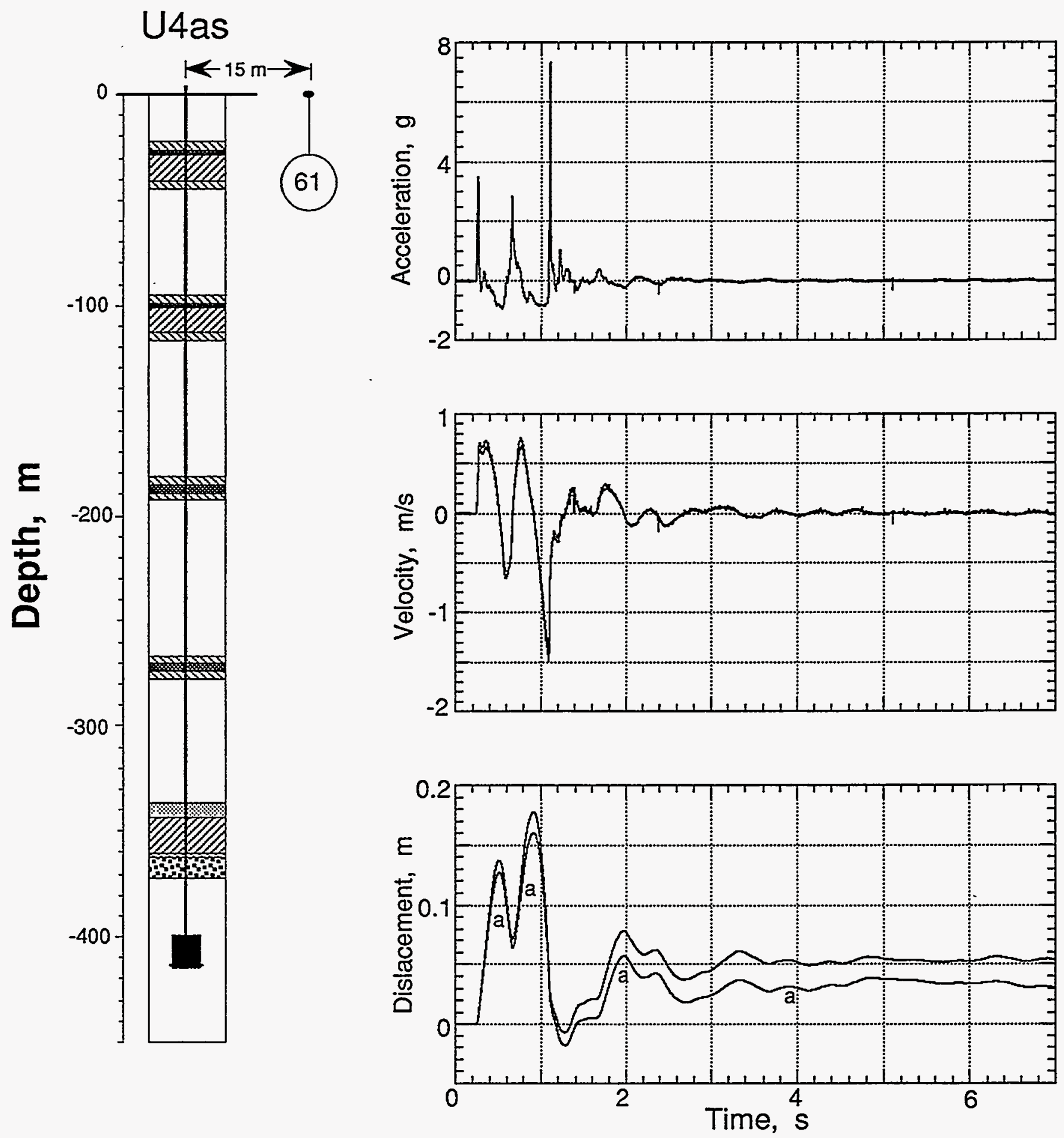

Figure 4.1 Explosion-induced vertical motion of ground surface at a depth of $0.91 \mathrm{~m}$ and horizontal range of $15.24 \mathrm{~m}$ from SGZ on a line extending $44^{\circ}$ west of north (Station 61). This station is considered as being part of the emplacement hole environment and, as such, is also shown in section 3 . Those traces annotated with "a" are derived from the acceleration history. 

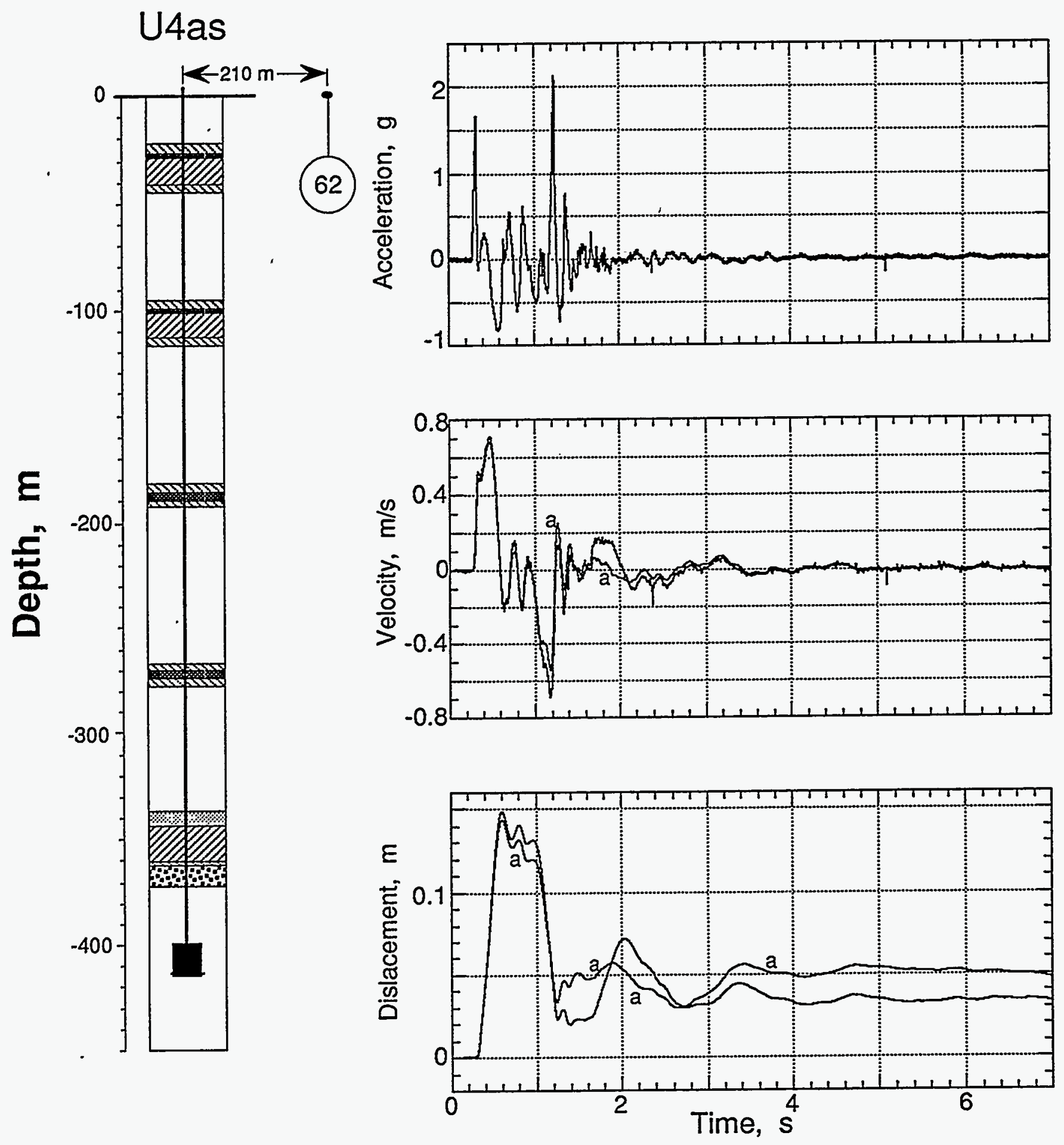

Figure 4.2 Explosion-induced vertical motion of ground surface at a depth of $0.91 \mathrm{~m}$ and horizontal range of $210 \mathrm{~m}$ from SGZ on a line extending $44^{\circ}$ west of north (Station 62). Those traces annotated with "a" are derived from the acceleration history. 


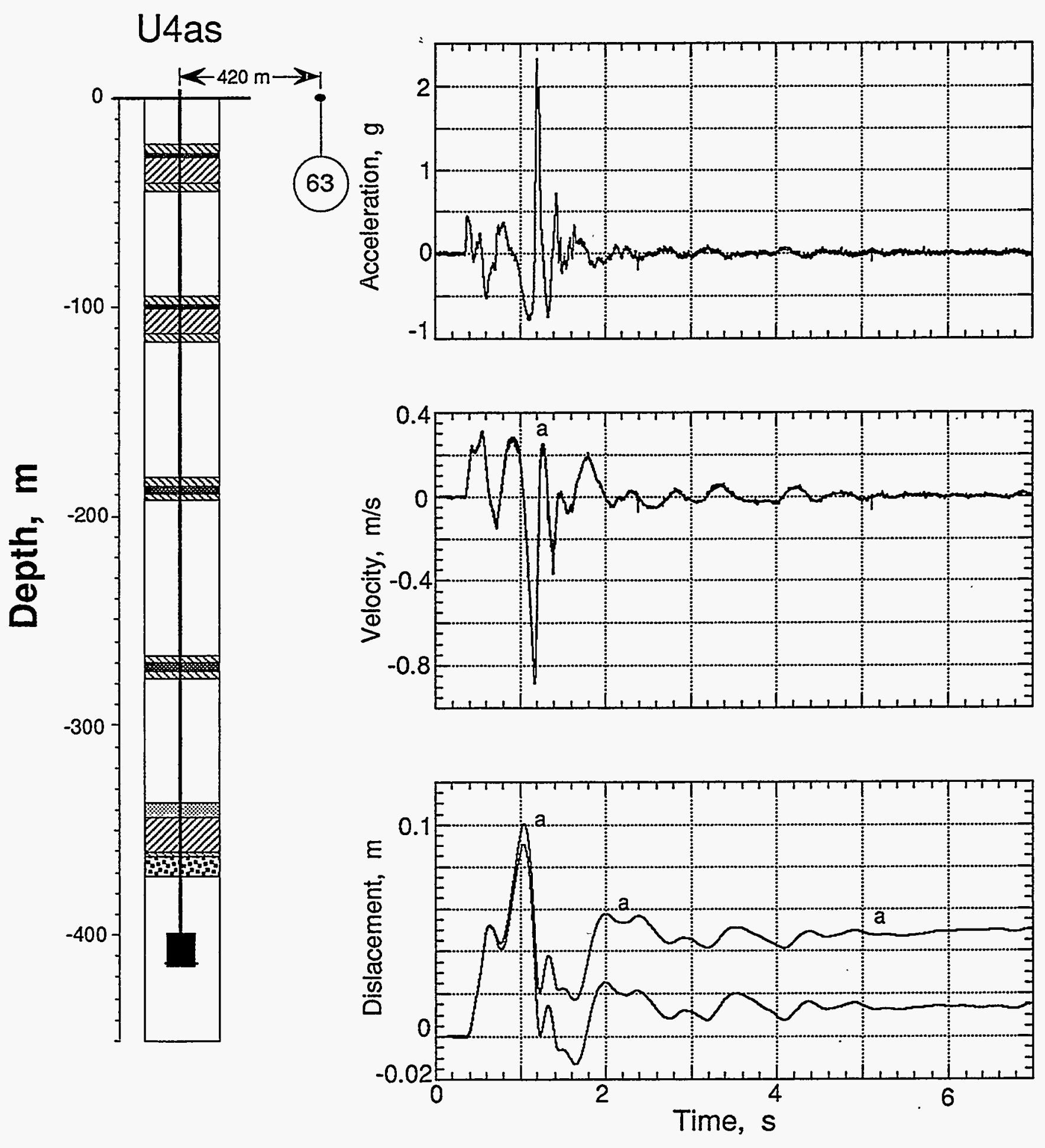

Figure 4.3 Explosion-induced vertical motion of ground surface at a depth of $0.91 \mathrm{~m}$ and horizontal range of $420 \mathrm{~m}$ from SGZ on a line extending $44^{\circ}$ west of north (Station $63)$. Those traces annotated with "a" are derived from the acceleration history. 

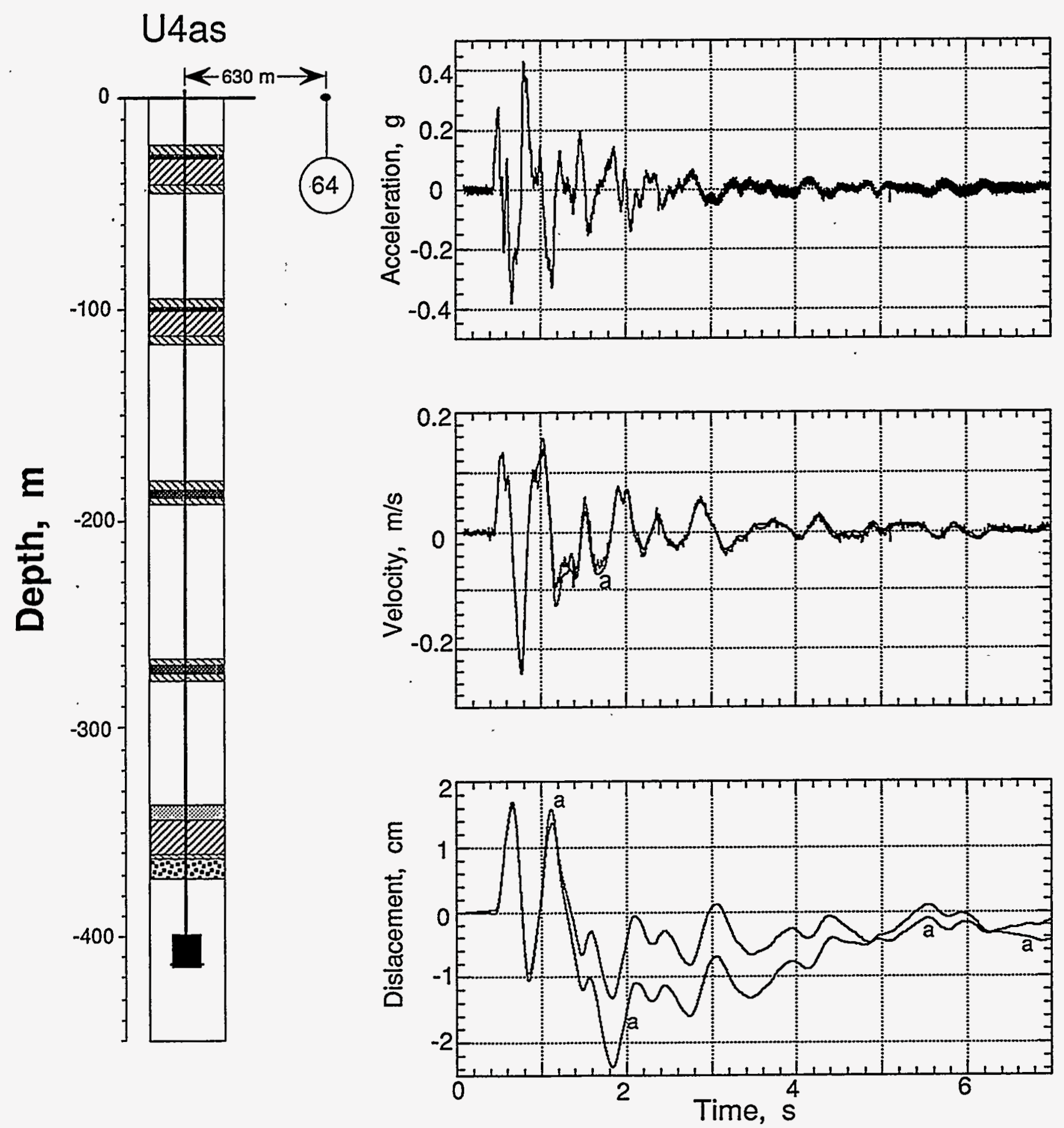

Figure 4.4 Explosion-induced vertical motion of ground surface at a depth of $0.91 \mathrm{~m}$ and horizontal range of $630 \mathrm{~m}$ from SGZ on a line extending $44^{\circ}$ west of north (Station 64). Those traces annotated with "a" are derived from the acceleration history. 

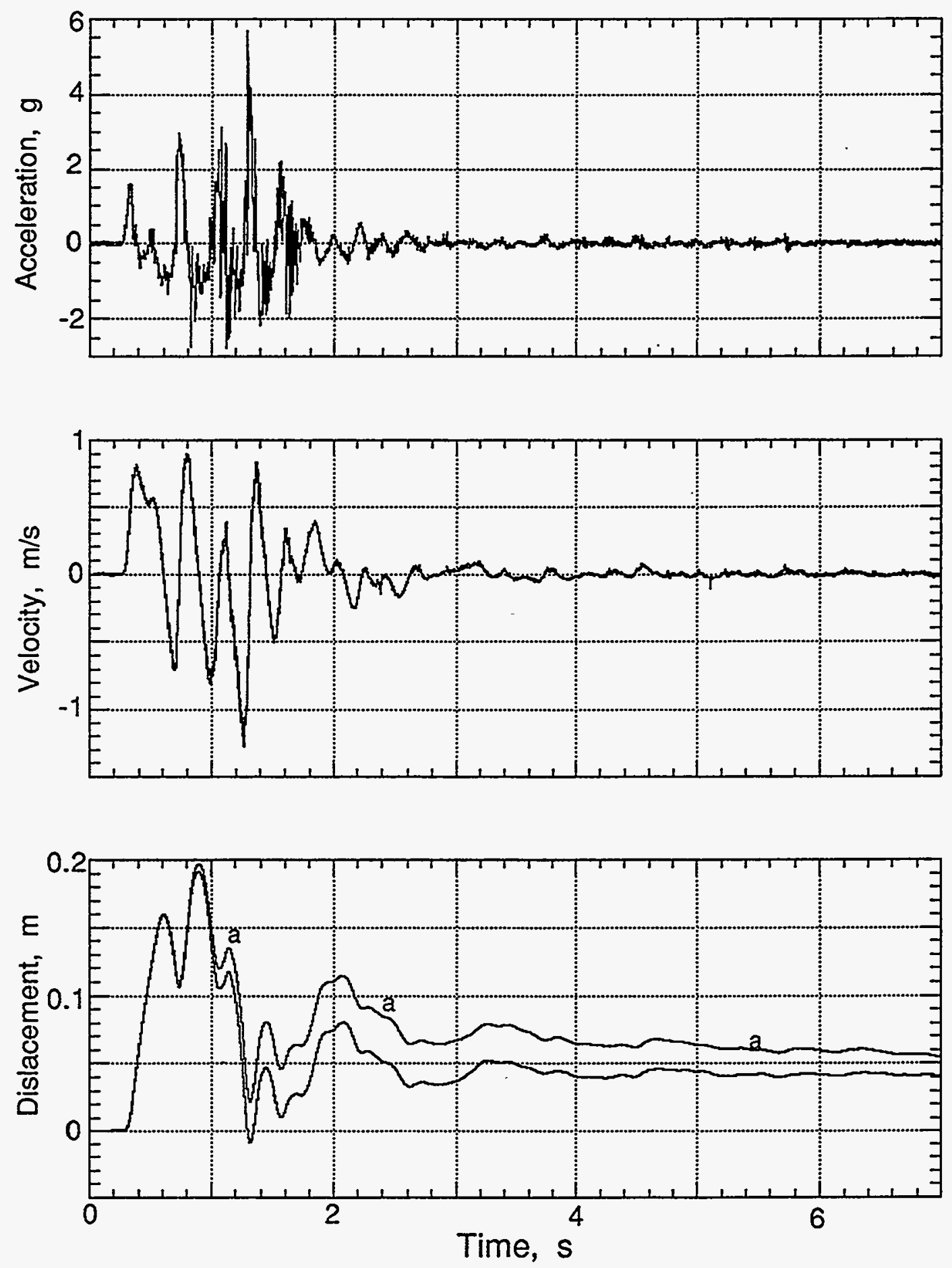

Figure 4.5 Explosion-induced vertical motion of recording trailer (Station 71). Horizontal range is approximately $464 \mathrm{~m}$. Those traces annotated with "a" are derived from the acceleration history. 

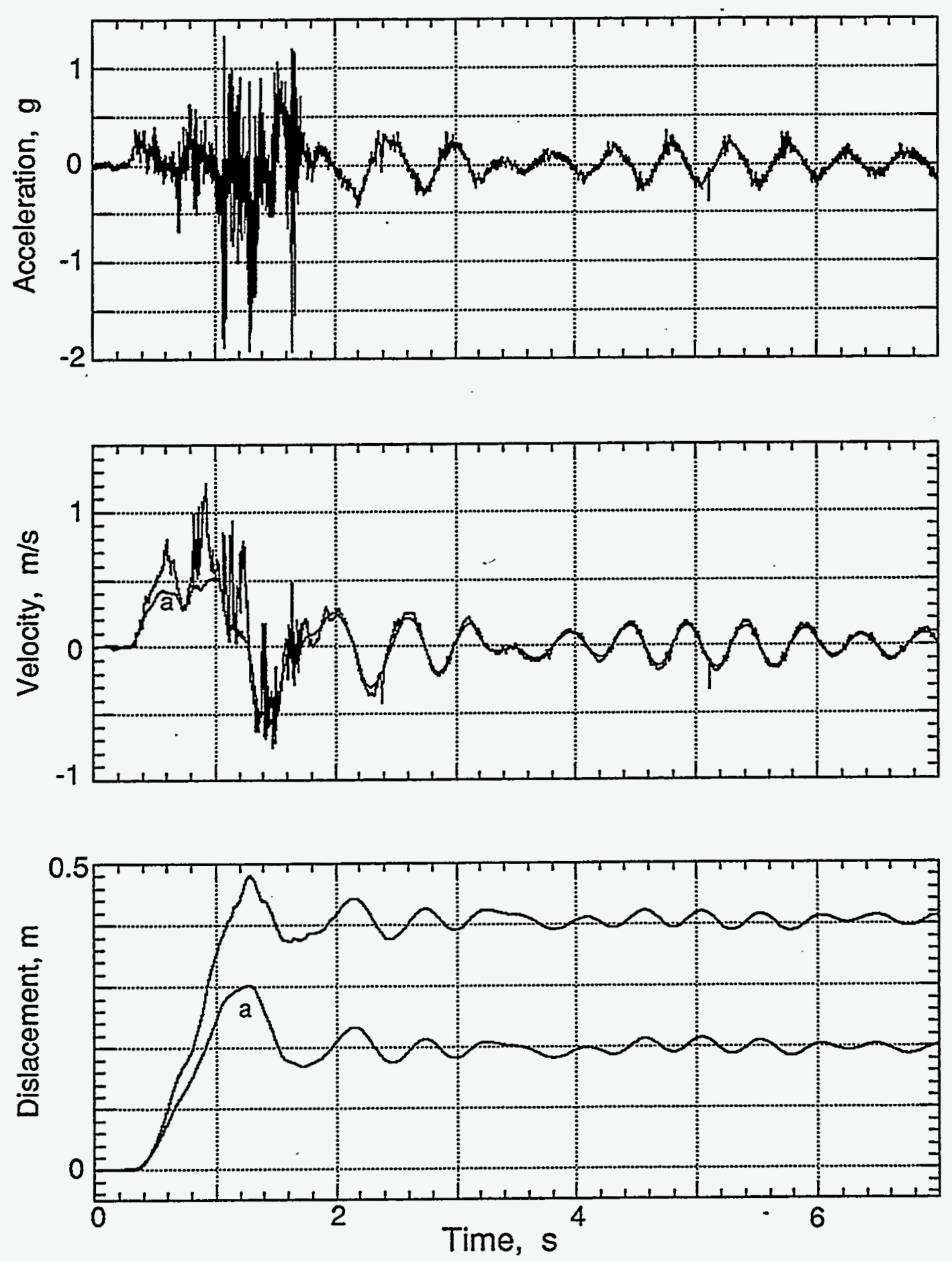

Figure 4.6 Explosion-induced horizontal-radial motion of recording trailer (Station 71). Horizontal range is approximately $464 \mathrm{~m}$. Those traces annotated with "a" are derived from the acceleration history. 

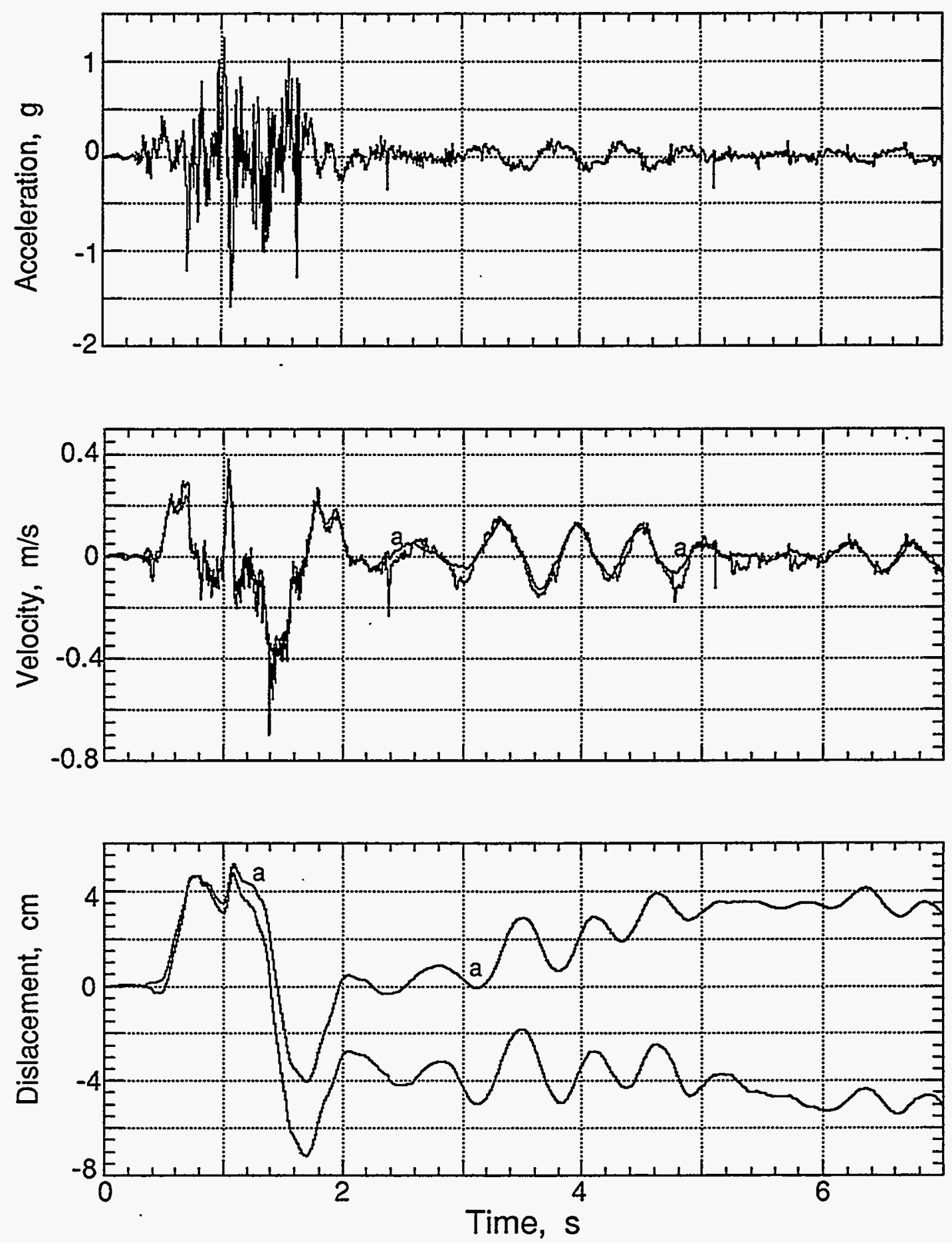

Figure 4.7 Explosion-induced horizontal-transverse motion of recording trailer (Station 71). Horizontal range is approximately $464 \mathrm{~m}$. Those traces annotated with "a" are derived from the acceleration history. 


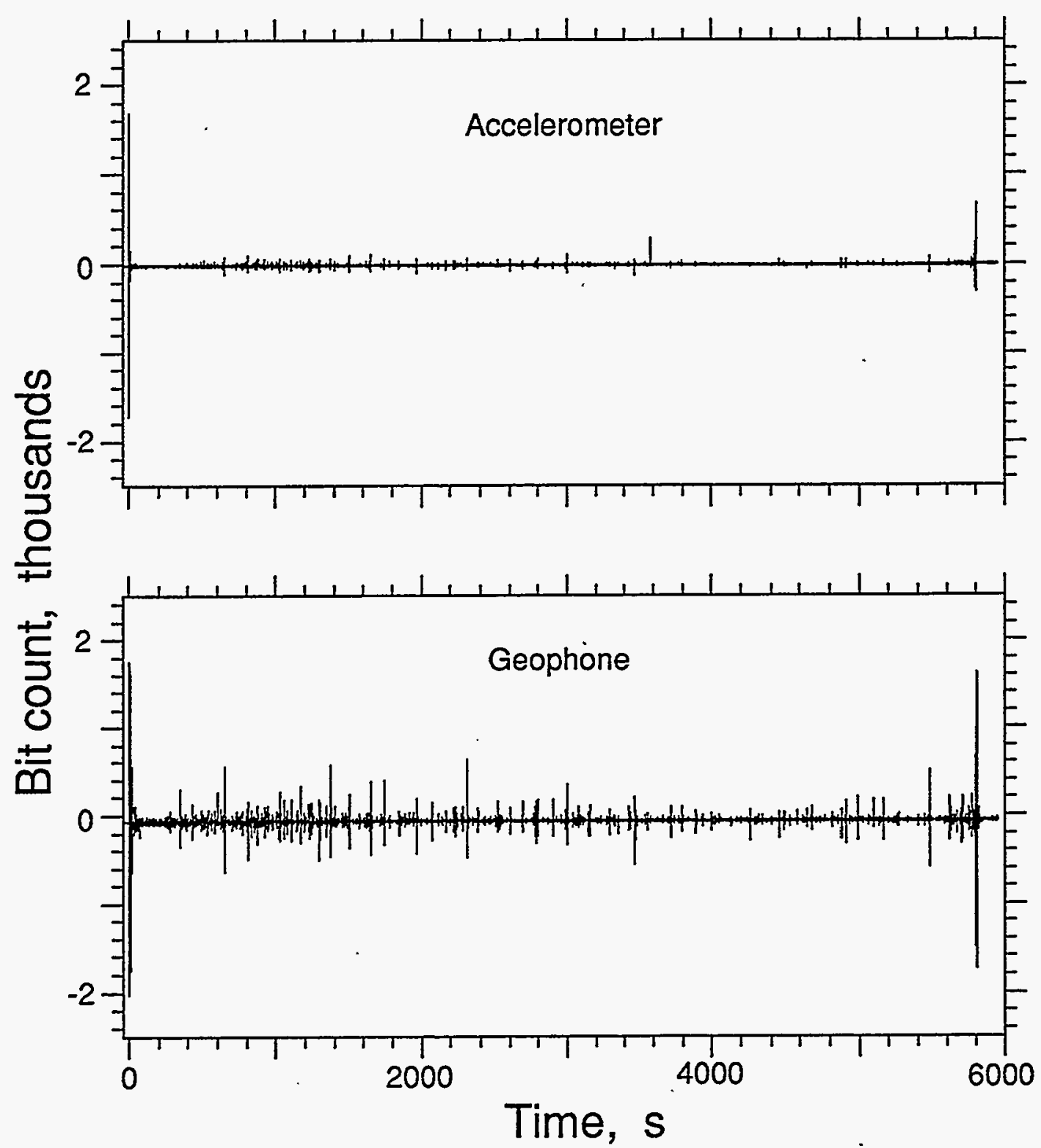

Figure 4.8 Geophone and sensitive accelerometer histories. These have not been converted to engineering units. 

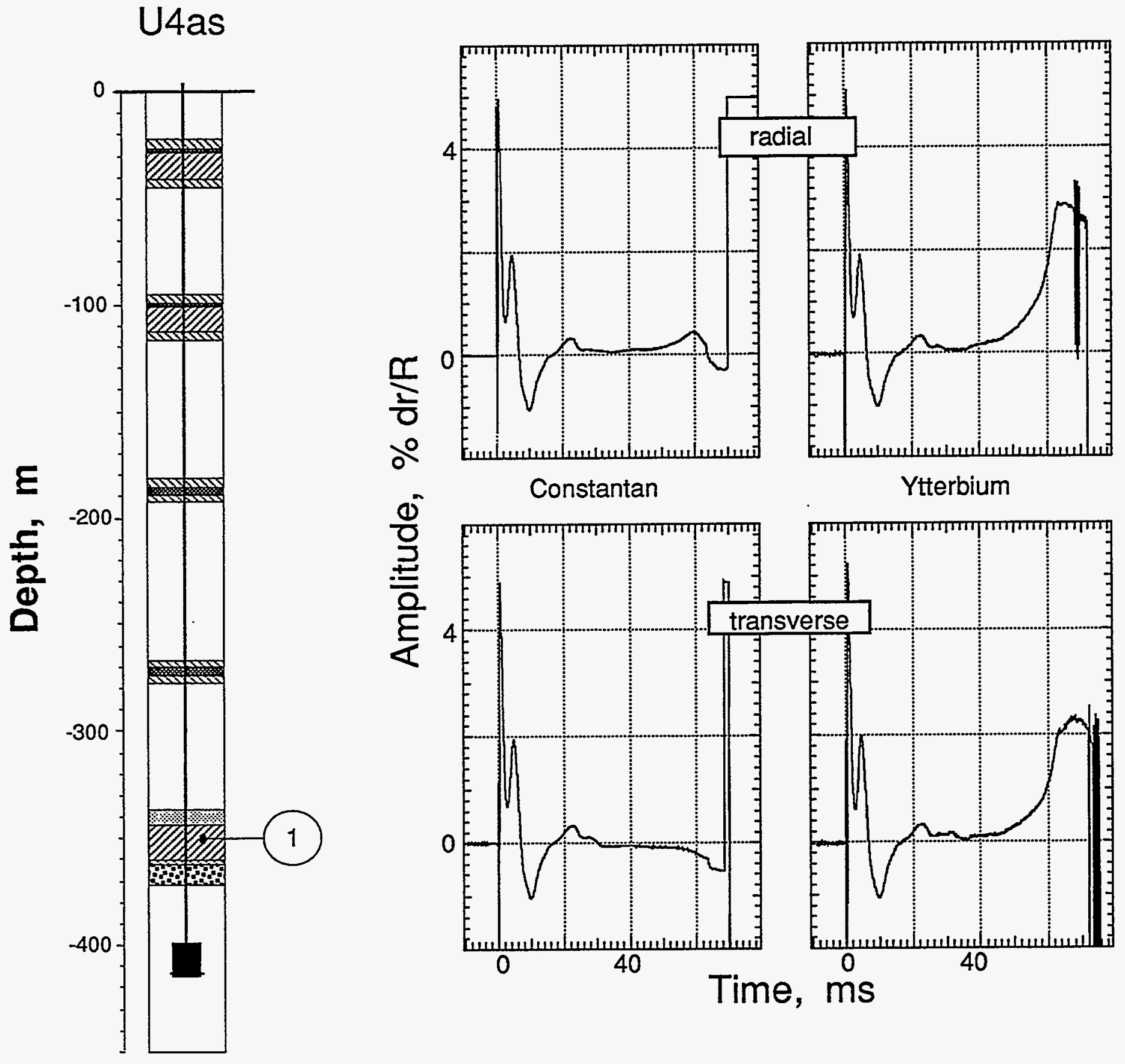

Figure 4.9 Stress and strain measured in the bottom GFA plug at a range of $53.92 \mathrm{~m}$ from the reference depth. Amplitudes are left in percent of resistance change. Initial resistance was about $350 \Omega$ for all transducers represented. 

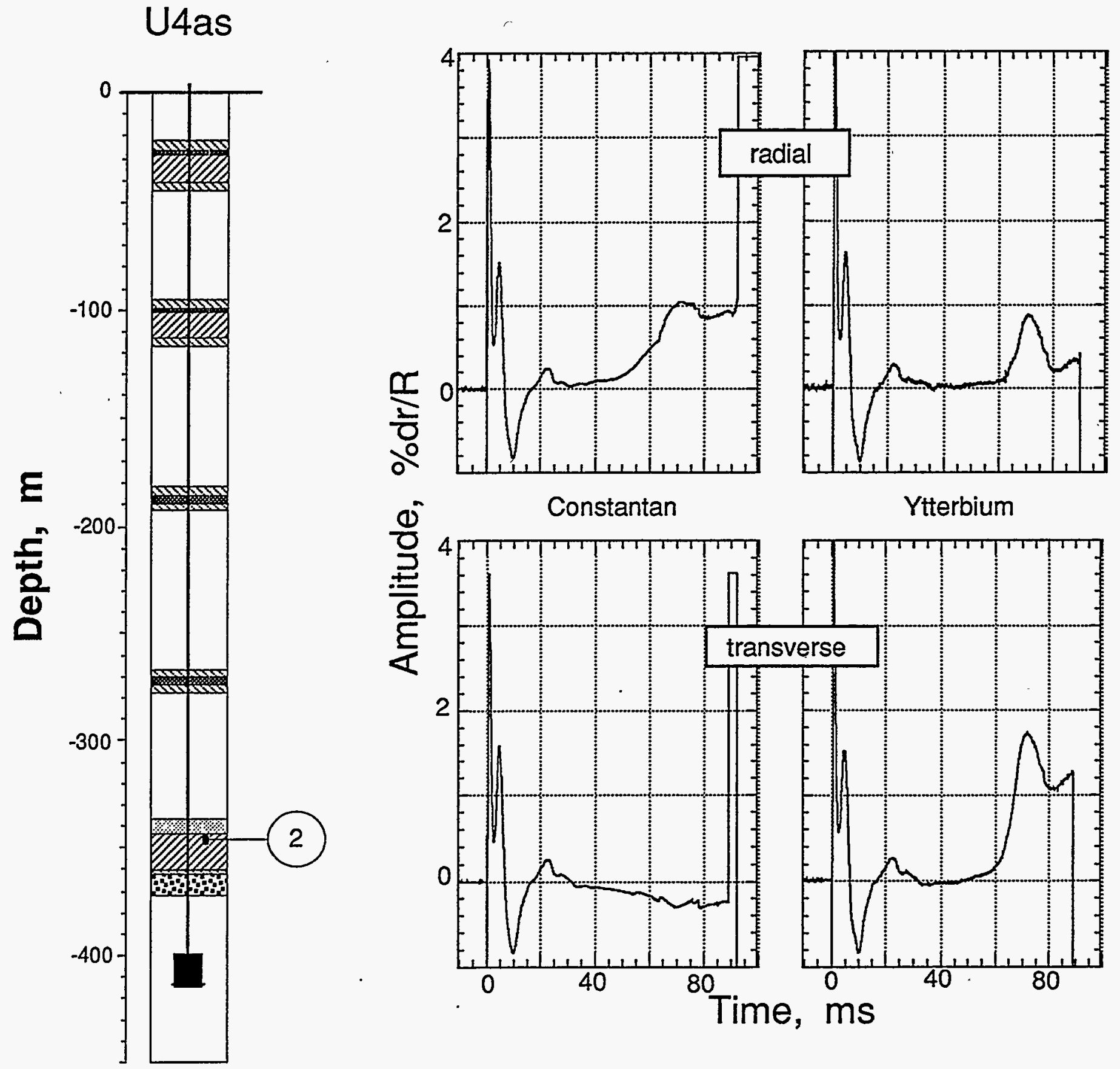

Figure 4.10 Stress and strain measured in the bottom GFA plug at a range of $66.97 \mathrm{~m}$ from the reference depth. Amplitudes are left in percent of resistance change. Initial resistance was about $350 \Omega$ for all transducers represented. 


\section{References}

1. Nancy W. Howard and Gayle A. Pawloski, "U4as Site Characteristics Report," CP 85-44, Lawrence Livermore National Laboratory, Livermore, CA, May 14, 1985.

2. R. Hutchinson for Alfred E. Burer, "Containment Report for U4as," Holmes \& Narver, NTS:A2:85-71, October 15, 1985.

3. LLNL contact for additional information: R. E. Heinle (CORRTEX and SLIFER data)

4. Troy L. Williams, "Special Measurements Physics/Instrumentation for ROQUEFORT, U4as", EG\&G, Energy Measurements, Las Vegas, NV, SM:85E-131-23, 23 August 1985. 
Distribution:

LLNL

TID (11)

Test Program Library

Containment Vault

Burkhard, N.

Cooper, W.

Denny, $M$.

Dong, R.

Goldwire, $H$.

Heinle, R. (5)

Mara, G.

Moran, M.T.

Moss, $W$.

Olsen, C.

Patton, $\mathrm{H}$,

Pawloski, G.

Rambo, J.

Roland, $\mathrm{K}$.

Roth, B.

Valk, $T$.

Younker, L.

LANL

App, F.

Brunish, W.

Kunkle, $T$.

Trent, B.

\section{Sandia}

Chabai, A.

Smith, Carl W.
EG\&G/AVO

Brown, $T$.

Gilmore, $L$.

Hatch, $M$.

Still, G.

Stubbs, $T$.

A-5

A-1

A-5

A-5

L-205

L-140

L-221

L-221

L-049

L-777

L-200

L-221

L-205

L-221

L-200

EG\&G/NVO

Bellow, B.

N 13-20

Davies, L.

Moeller, A.

Robinson, $R$.

N 13-20

N 13-20

Webb, W.

N 13-20

N 13-20
L-221

L-049

L-154

L-203

DNA

Ristvet, B.

S-Cubed

Peterson, E.

F-659

F-659

F-665

F-664

MS-1159

MS-1159
Eastman Cherrington Environment 1640 Old Pecos Trail, Suite H Santa Fe, NM 87504

Keller, C. 